Annals - Manufacturing Technology

Elsevier Editorial System(tm) for CIRP

Manuscript Draft

Manuscript Number: 2018-Keynote-FR1

Title: Flexibility in Metal Forming

Article Type: STC F

Keywords: Flexibility, Metal forming, Manufacturing

Corresponding Author: Professor Dong-Yol Yang, Ph.D.

Corresponding Author's Institution: GIST

First Author: Dong-Yol Yang, Ph.D.

Order of Authors: Dong-Yol Yang, Ph.D.

Abstract: Flexibility in metal forming is needed more than ever before due to rapidly changing customer demands. It paves the way for a better control of uncertainties in development and application of metal forming processes. Although flexibility has been pursued from various viewpoints in terms of machines, material, process, working environment and properties, etc., a thorough study of the concept was undertaken in order to with problems of manufacturing competiveness and tackle new challenges of manufacturing surroundings. Therefore, in this paper, flexibility in forming is reviewed from the viewpoints of process, material, manufacturing environment, new process combinations and machine-systemsoftware interactions. 


\title{
Flexibility in Metal Forming
}

\author{
D.Y. Yang(1) $)^{1,}{ }^{*}$, M. Bambach ${ }^{2}$, J. Cao(1) ${ }^{3}$, J. R. Duflou(1) ${ }^{4}$, P. Groche(1) ${ }^{5}$, T. Kuboki(2) ${ }^{6}$, A. Sterzing7 , A. E. \\ Tekkaya(1) ${ }^{8}$, C.W LEE ${ }^{9}$
}

1 Department of Mechanical Engineering, KAIST, Daejeon, South Korea

2 Lehrstuhl Konstruktion und Fertigung, Technische Universitaet Cottbus-Senftenberg, Germany

3 Department of Mechanical Engineering, Northwestern University, Evanston, IL, USA

4 Centre for Industrial Management, Department of Mechanical Engineering, KU Leuven, Belgium

5 Institute for Production Engineering and Forming Machines, Technische Universität Darmstadt, Darmstadt, Germany

6 Department of Mechanical Engineering and Intelligent Systems, The University of Electro-Communications, Tokyo, Japan

7 Fraunhofer Institute for Machine Tools and Forming Technology IWU, Reichenhainer Str. 88, 09126 Chemnitz, Germany

8 Institut fur Umformtechnik und Leichtbau, Technische Universität Dortmund, Dortmund, Germany

9 Department of Mechanical System Design Engineering, Seoul National University of Science and Technology, Seoul, South Korea

\section{ABSTRACT}

Flexibility in metal forming is needed more than ever before due to rapidly changing customer demands. It paves the way for a better control of uncertainties in development and application of metal forming processes. Although flexibility has been pursued from various viewpoints in terms of machines, material, process, working environment and properties, etc., a thorough study of the concept was undertaken in order to with problems of manufacturing competiveness and tackle new challenges of manufacturing surroundings. Therefore, in this paper, flexibility in forming is reviewed from the viewpoints of process, material, manufacturing environment, new process combinations and machine-system-software interactions.

Keywords: Flexibility, Metal forming, Manufacturing

\section{Introduction}

\subsection{Background and Motivation}

The manufacturing sector undergoes drastic changes in the global scale due to the advent of a new industrial revolution, the so-called fourth industrial revolution or Industry 4.0 [170]. A key feature of this revolution is the increasing interaction of human beings, production machines and products. As a consequence, conventional mass production is changing gradually towards manufacturing systems for mass customization, with higher flexibility and on-demand manufacturing, which brings about new technological challenges. Such a new industrial wave demands connectivity, automation and intelligent systems, in mass customization and on-demand manufacturing in addition to mass production as summarized in Fig. 1 [184].

The mentioned connectivity and intelligentization enable realization of automated manufacturing of products and related automated services. The pursuit of these three factors would finally lead to super-connection and super-intelligentization of human beings, things and space, and ultimately resulting in systemic innovation of industry and society.

While flexibility is inherent to manufacturing processes such as machining and welding, die-based manufacturing processes such as metal forming and casting are increasingly challenged to meet the demands on flexibility.

A working group study on mega-trends and the future of metal forming [127] in 2012 revealed the importance of flexibility. The results of the study were summarized as shown in Fig. 2. Various areas, including flexibilitization, intelligent processes, complexity of shape and integration of functions, all of which demand for flexibility of forming either directly or indirectly. 3D printing of metals was included as a separate category, though not having been included in traditional forming, but it becomes a very powerful means of highly flexible manufacturing for producing metallic parts and dies with reasonable productivity for some industrial manufacturing sectors.

Flexibility of metal forming has become an important issue in recent manufacturing demands and plays an essential role in customized mass and individualized production in the manufacturing industry. As flexible sheet metal forming, single point incremental forming has been widely employed and subject to extensive research $[61,73]$. The introduction of double point (sided) incremental forming had enhanced the formability and extended the range of shape complexity [125, 199]. The combination of incremental forming and conventional sheet forming processes further extended the capability of incremental forming with additional advantages including increased productivity [13]. Incremental bulk metal forming has a long history since the Bronze age. Since then, incremental bulk forming has been developed by employing various forming processes including forging typically and many incremental forming processes using rotating tools such as flow forming, rotary swaging, orbital forming, gear rolling, pierce rolling and ring rolling, etc. [52]. Various flexible forming processes for both sheet and bulk can be found in Japan and they are well summarized in reference [8].

Incremental forming is surely the key flexible forming process and has been diversified for manufacturing various metallic products. However, flexibility in forming has been pursued from diverse viewpoints in terms of complexity, material, process, working environment and machine, etc. In this work, flexibility is newly viewed and subjected to review from various angles of 
perspective in order to provide new prospects of flexibility in metal forming.

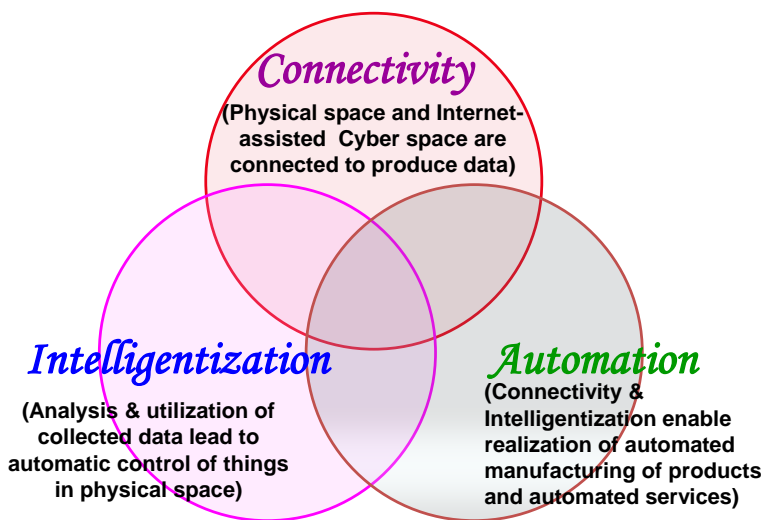

Fig. 1. Three key factors pursued in industry 4.0

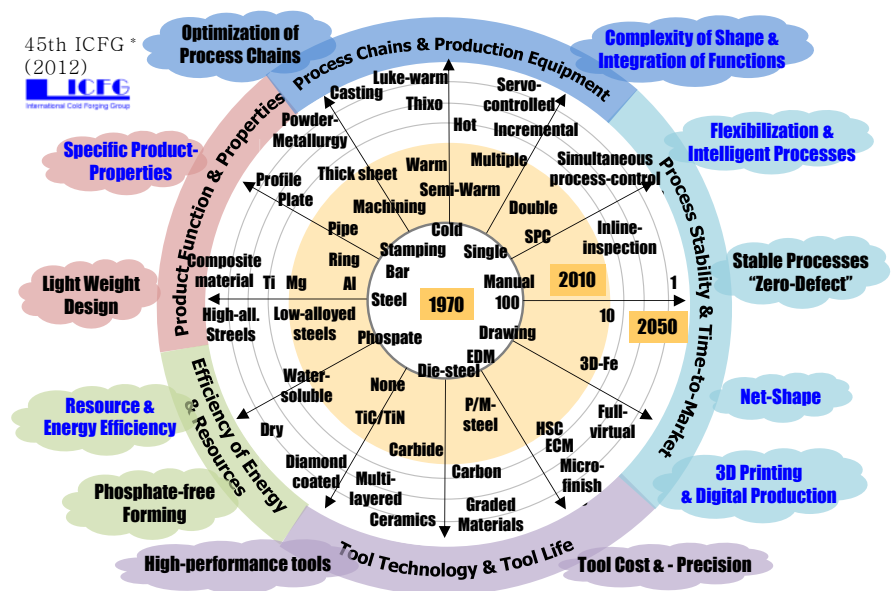

Fig. 2. Mega-trends and future of metal forming [127]

\subsection{Classification of flexibility in metal forming}

There are many ways to classify forming processes, as well summarized in the reference by Groche et al. [52]. In the reference, traditional classifications for conventional forming processes are discussed in detail. For incremental bulk forming, the authors introduced new simplified criteria: stress system and deformation sequence (i.e. intermittent, continuous). In addition to several conventional classifications, they also introduced the initial workpiece shape to distinguish between incremental bulk metal forming processes with rotational tool motion. That is: Billet (brick shape or plug shape), Long product (bars or rods) and Rings.

For general incremental forming processes covering both sheet and bulk forming processes, a more appropriate criterion is required.

Halevi and Weill [62] proposed an interesting systematic classification procedure for selecting an appropriate metal forming process according to technical feasibility and economic optimization considerations. The method can also be applied to general incremental forming processes. The proposed process selection procedure takes into account:

1) Lot size (product quantity)

2) Part shape (complexity)

3) Achievable accuracy

4) Material
In this process selection methodology four basic shape complexity levels are distinguished in an effort to discretize geometrical capabilities. These levels correspond to parts that can be specified by a characteristic cross section and length (mono), parts that can be made with a simple die set with monodirectional kinematics (open), parts with undercuts (complex) and other geometries, typically containing enclosed volumes (very complex).

The technical and economic feasibility of a process to support the manufacture of small lot sizes on the one hand and more complex shapes on the other, appears to be a useful categorization approach to distinguish the flexibility of forming processes. As in conventional classification methods, part shaping capability is still the most important criterion. Lot size is a criterion that is strongly related to the need for dedicated tooling and set-up costs for a specific part geometry, and reflects the process capability to use generic tooling and flexible set-up techniques: processes that are facilitated by tools which can accommodate a broad range of geometrical part specifications are thus requiring low direct investment costs and setup times between batches of diverse products. The achievable accuracy and material constraints are reject criteria reflecting technological process capability considerations.

Halevi and Weill [62] refined the preference rules for the full taxonomy of manufacturing processes, including forming processes, based on process capabilities to shape products as well as quantity considerations.

Fig. 3 shows the flexibility level with respect to geometric complexity and economically feasible batch size that can be derived from the approach described by Halevi and Weill [62].

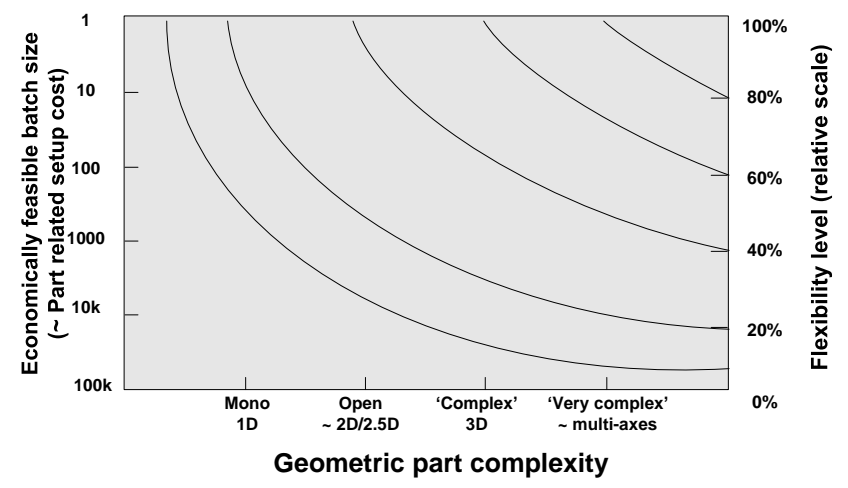

Fig. 3. Flexibility level with respect to Lot size and Shape complexity

Differently from the categorization for selecting general basic forming process(es), classification of flexibility in forming depends rather on the way in which the material is formed, how some physical parameters are varied and how processes are operated in terms of process, machine, system and operation software. In addition to shape complexity and lot size, therefore, degree of freedom and variation of physical parameters can be added as major factors to influence flexibility as summarized in Fig. 4. That is, major influencing factors on flexibility in forming are;

1) Lot size

2) Shape complexity

3) Degree of freedom in tool movement and machines

4) Physical variation of parameters 


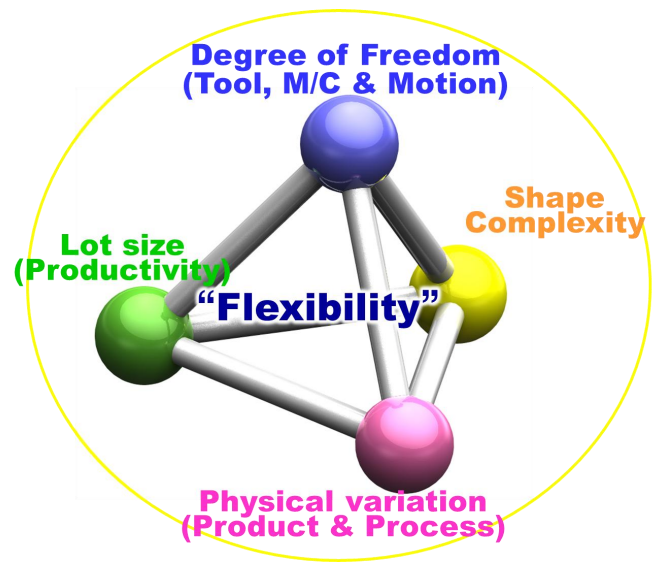

Fig. 4. Major factors influencing flexibility

Flexibility is accordingly defined as extension of possibilities to widen formable product categories to meet diverse demands in lot size, product shape complexity, and physical requirements of the product by enhancing the capabilities of forming processes, machines and forming system.

The flexibility level can then be increased by any of the following practical means as categorized by

1) Increasing the degree of freedom by using non-dedicated tools and by varying forming path.

2) Varying the physical parameters such as geometry, material, temperature, etc. in incremental forming.

3) Combining forming processes or combining a conventional forming process with a flexible forming process, or by combining a forming process with a non-forming process such as casting, etc.

4) Flexibilizing the operation of machine, structure, system and operation software, etc.

In Table 1 , the above means of flexibility increase are summarized with respect to four major influencing factors.

\begin{tabular}{|c|c|c|c|c|}
\hline $\begin{array}{l}\text { Means of } \\
\text { lexibility } \\
\text { level Increase }\end{array}$ & $\begin{array}{c}\text { Lot size } \\
\text { (Productivity) }\end{array}$ & Complexity & $\begin{array}{c}\text { DOF } \\
\text { (Tool, M/C, } \\
\text { Motion) }\end{array}$ & $\begin{array}{c}\text { Physical } \\
\text { parameters }\end{array}$ \\
\hline $\begin{array}{l}\text { DOF increase } \\
\text {-Incr. Sheet Forming } \\
\text {-Incr. Bulk Forming }\end{array}$ & $\begin{array}{c}\mathrm{L}, \mathrm{M} \\
\mathrm{L}\end{array}$ & $\begin{array}{l}\text { M, H } \\
\text { L, M }\end{array}$ & $\begin{array}{c}M, H \\
M\end{array}$ & - \\
\hline $\begin{array}{l}\text { Physical variation } \\
\text {-Geometric variation } \\
\text {-Material disposition } \\
\text {-Local(Incr.) heating }\end{array}$ & $\begin{array}{c}\mathbf{H} \\
\mathrm{L} \\
\mathrm{L}, \mathrm{M}, \mathrm{H}\end{array}$ & $\stackrel{\mathrm{L}}{\mathrm{H}}$ & $\begin{array}{l}\mathrm{L} \\
\mathrm{H} \\
\mathrm{L}\end{array}$ & $\begin{array}{l}\checkmark \\
\vee \\
\vee\end{array}$ \\
\hline $\begin{array}{l}\text { Process combination } \\
\text {-Convent. + Convent. } \\
\text {-Flexible + Convent. } \\
\text {-Forming + Non-form. }\end{array}$ & $\underset{H}{\mathrm{H}} \stackrel{\mathrm{M}}{\mathrm{H}}$ & $\begin{array}{l}\mathrm{M}, \mathrm{H} \\
\mathrm{M}, \mathrm{H} \\
\mathrm{M}, \mathrm{H}\end{array}$ & $\stackrel{\mathrm{L}, \mathrm{M}}{\mathrm{L}}$ & $\begin{array}{l}- \\
- \\
-\end{array}$ \\
\hline $\begin{array}{l}\text { Flexibilization of } \\
\text { M/c, System, } \\
\text { Software operation }\end{array}$ & H & $\mathrm{M}, \mathrm{H}$ & $\mathbf{H}$ & - \\
\hline
\end{tabular}

Table 1. Means of flexibility level increase in relation to four major influencing factors ( $\mathrm{H}=$ High, $\mathrm{M}=$ Medium, $\mathrm{L}=\mathrm{Low})$

2. Flexibility by increasing the degree of freedom without using devoted tools and by varying forming path

2.1 Incremental sheet and profile forming

\subsubsection{Incremental sheet forming by pointed tool(s) movement}

Incremental Sheet Forming (ISF) is an emerging sheet metal forming process which offers flexibility by eliminating the need for the geometric-specific forming dies $[36,46]$. The incremental forming processes can meet stringent demands in the sheet forming industry related to rapid and customized part realization coupled with rigorous requirements on geometric accuracy and material properties, etc., which made the traditional forming process expensive. In IF, one or multiple generic stylus-type tools move along a predefined tool path, incrementally deforming the sheet metal, as shown in Fig. 5.

The final geometry is formed by the accumulation of these sequential, localized plastic deformations. In industrial applications characterized by highly differentiated and small batch production, the avoidance of dedicated traditional stamping system reduces the forming time and cost $[73,124]$. In spite of the potential of the process for value-added manufacturing, there are challenges associated with manufactured part performance that significantly impede the adoption of IF for industrial applications [6], which are mainly geometric accuracy, formability prediction, fatigue behaviour [209], and forming time $[120,121,126]$.

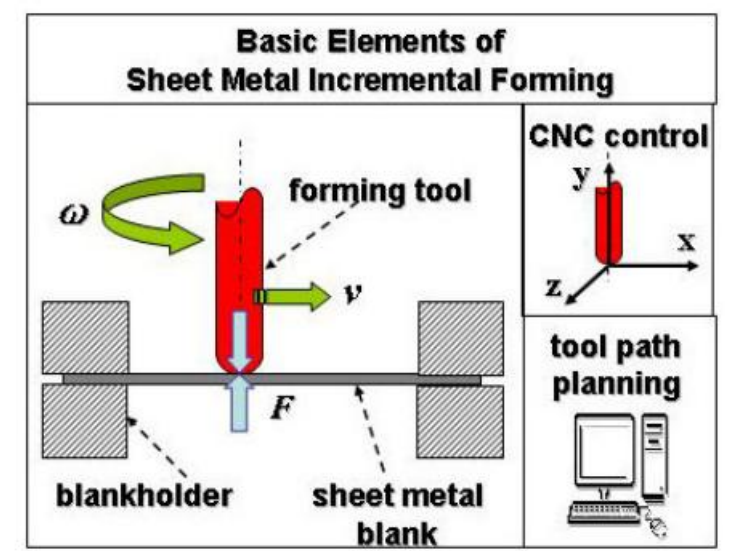

Fig. 5. Basic elements of sheet metal incremental forming [36]

The formability of the formed material also plays a key role in the part performance of IF $[19,38,114]$. For instance, unlike the typical sheet stamping process, the plastic deformation zone is usually localized around the forming tool in IF. The limited material flow causes non-uniform thickness distribution of the formed part or even the part failure due to the excessive thinning. To distribute the sheet thickness more uniformly and increase the maximum achievable wall angle, some intermediate passes are required before the final pass is imposed. For example, Skjødt et al. [185] and Duflou et al. [34, 35] utilized five passes to achieve a high wall angle as $90^{\circ}$. Malhotra et al. [32] further improved the multipass strategy by taking into account the possible rigid body motion to avoid the stepped feature as reported in $[33,185]$.

Despite of the achieved high wall angle, these open-loop multipass planning strategies usually require much longer forming time compared to the single pass ones, and they are also mostly empirical based which makes them hard to be generalized. Subsequently, the force signal was proposed as an indicator for possible fracture to achieve an online fracture monitoring and control in 2006 [39]. The change of the forming force is monitored during the forming process. It was noted the force behaviour after reaching the peak value is an effective index for the potential of excessive thinning. If the force slope is too steep, a fracture is likely to happen, and the process parameters need to be changed on line, like adapting a smaller incremental depth. 
However, since the force oscillation is often observed in the forming process, this proposed method requires an accurate numerical model for force prediction, especially for irregular shapes, and therefore, may limit the approach to axisymmetric part, like a cone, in practical applications.

Besides the tool path modification $[118,165]$, the IF process itself has been continuously improved. For example, the Two Point Incremental Forming (TPIF) was proposed in which a partial die is utilized to support the material and reduce the undesired global bending and geometric deviation [129]. Based on the TPIF, Double Sided Incremental Forming (DSIF) [145] was proposed to maintain the benefits of the local support while avoiding the overhead costs for the specific die by using a second tool on the opposite side of the metal sheet [128], as shown in Fig. 6. It has also been shown that DSIF alters the stress triaxiality by imposing additional pressure from the supporting tool, and thus improves the process formality [119] and fatigue behaviour [209] To better control the DSIF process, different control strategies were proposed for the supporting tool. For example, in Malhotra et al. [123], the supporting tool is displaced at a certain distance, i.e., tool gap, regarding the forming tool in the surface normal direction. The tool gap will be determined based on the local wall angle, in-plane curvature and also other experiment setups such as the tool diameters or sheet thickness. Correspondingly, the force control for the second tool is also implemented, and the effect of various supporting force imposed by the secondary tool was studied [119]. The second tool can also be offset in angle with respect to the first tool to create a different squeeze effect [119].
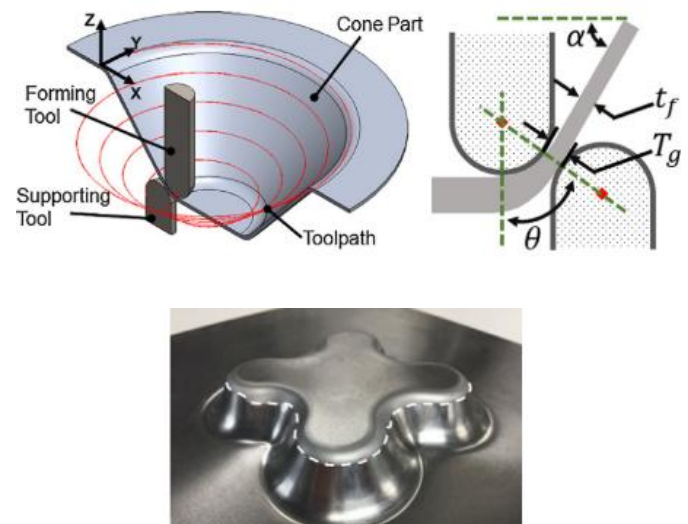

Fig. 6. Double sided incremental forming [145]

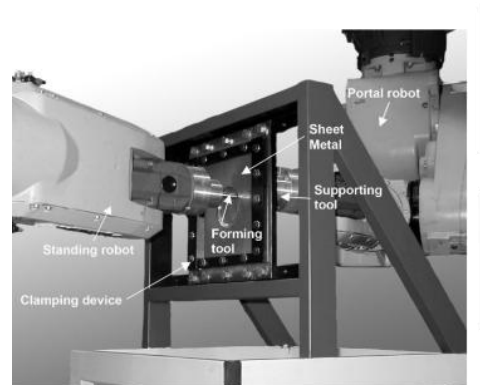

(a)

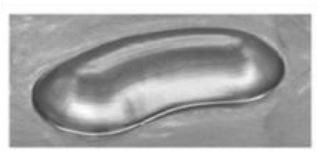

(b)

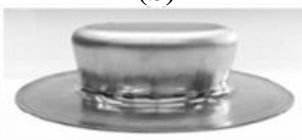

(c)
Fig. 7. Roboforming with two robots [129]

With the controllability and flexibility of CAM-process $[67,139]$ the formability and geometrical flexibility of the sheet incremental forming process can be maximized. Meier et al. [129] developed an incremental robot-based sheet forming process shown in Fig. 7. Roboforming is implemented by means of two industrial robots that are interconnected to a cooperation robot system [129]. The robot-based process can accurately fabricate more flexible-shaped products, as shown in Fig. 7(b) and (c).

There are many trials to decrease the process time in the sheet incremental forming process [196]. Kwiatkowski et al. [96, 197] introduced "Twin tool" concepts shown in Fig. 8(a) supplying an individual kinematics for each tool in the incremental sheet forming. Using "TwinTool" concept, it is possible to decrease the process time and costs. It presents an individual kinematics for each tool by introducing two additional linear axes. Each tool was inclined in order to allow two tools close to each other. Nowadays, they are working on multi-tool concepts shown in Fig. 8(b) consisting of a tool matrix. Each tool can be adjusted vertically.
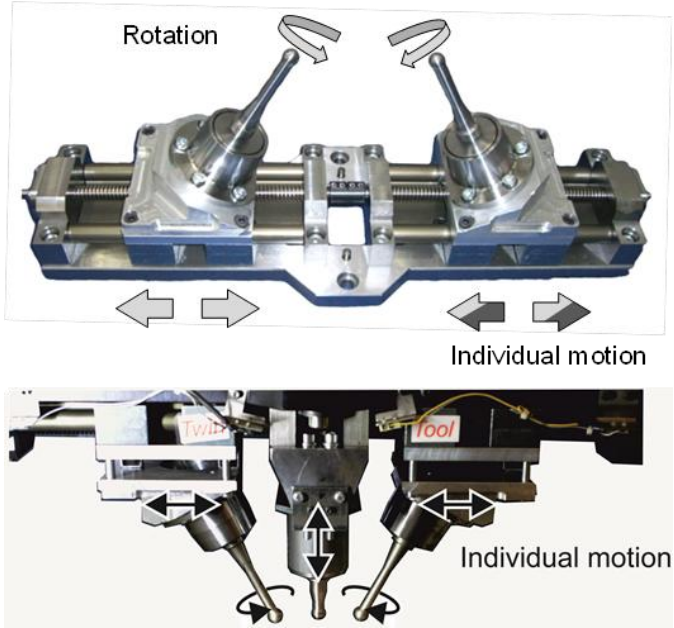

Fig. 8. Tools for flexible incremental forming (a) Twin tool (b) Multi-tool concept [96]

The major challenge in controlling the incremental forming processes is to increase the robustness of control methods for complex part geometry and various experimental setups while maintaining the overall process time or cost efficiency. To overcome the challenge, work has been conducted to address the requirement of an in-situ geometric measurement equipment in the on-line geometry accuracy control methods [63] and the accurate alignment of the scanned geometry with the target one. The optical measurement has an access problem. An efficient and cost effective in-situ geometric measurement at the presence of lubricant or a fast and accurate prediction method is desired.

Moreover, how to modify the tool path based on the measured error efficiently is still an unsolved problem, which depends on an accurate process modelling regarding the underlying mechanics of IF process and more advanced control methods for in-situ closed-loop process control. For example, the supporting force is usually follows in pre-set value in the current research [119] while the optimum tool gap in the displacement-controlled DSIF is purely empirically determined [145]. In this case, an analytical method to predict the optimum tool gap or supporting force regarding complex geometric features and various experimental setups is desired. Thus, a model-based force control loop can be implemented in the future, which will adjust the position of the tool(s) according to the model prediction and insitu sensing so that both over squeezing or loss of contact can be prevented.

\subsubsection{Incremental sheet forming by blank-rotation / Spinning}

Metal spinning is used to form shell components, but is constrained by two features: it can practically only produce axisymmetric shapes up to now; it requires a dedicated mandrel for each product. Examination of pressures between product and mandrel revealed that contact is limited to three well defined 
areas. Furthermore, if these rollers could be controlled, they could represent any symmetric or asymmetric mandrel. A sevenaxis machine was designed, manufactured, and used to spin trial parts. The machine design is described, and preliminary results give an indicator of process capability [148].

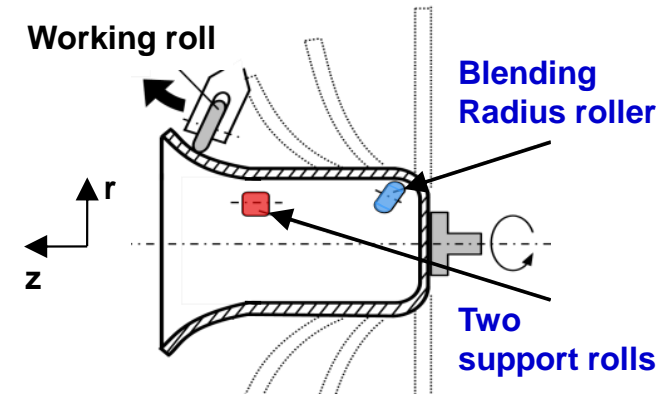

Fig. 9. Asymmetric spinning [148]

An opportunity to increase the economical relevance and flexibility of conventional metal spinning is the development of the process of "non-circular spinning" for producing rotationally non-symmetric components $[16,17]$. In principle, the production of rotationally non-symmetric, hollow components through spinning is possible with the application of force-controlled or motion-controlled roller tools shown in Fig. 9. Fig. 10 presents the products of the newly developed non-circular spinning process.
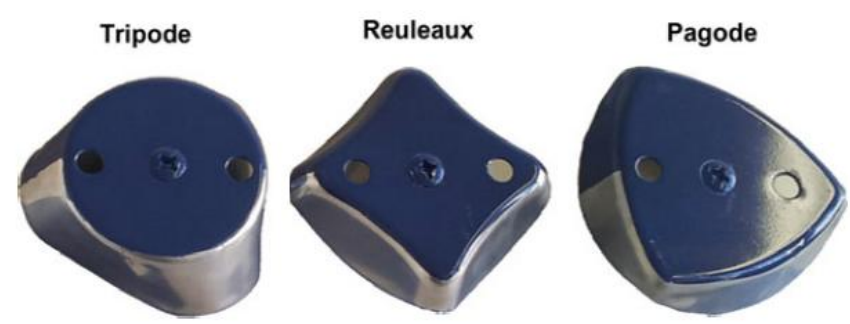

Fig. 10. Produced examples of non-circular spinning $[16,17]$

Another possibility for the manufacturing of rotationally nonsymmetric hollow parts through spinning is the exact feeding of the roller tool in the axial and radial directions. This ensures a constant gap between the spinning mandrel and the roller at all times during the spinning process. Arai et al. [191] developed a synchronous multipath metal-spinning method, which controls the roll position synchronously with the spinning rate. Rectangular box shapes were successfully formed by optimizing the tool trajectory, is shown in Fig. 11.

The material flow in the conventional spinning process follows the sine law $\left(t=t_{0} \sin \alpha\right)$. Tube and cup having a vertical wall cannot be manufactured from the conventional spinning process. Suzuki et al. [194] proposed a new spinning process using the elastomer shown in Fig. 12. The tool pushes a sheet metal locally and elastomer lifts up the sheet metal. Through the forming process, the tool concentrates the sheet metal to the center. Using the elastomer in the spinning process, the flexibility and the formability of the process was improved

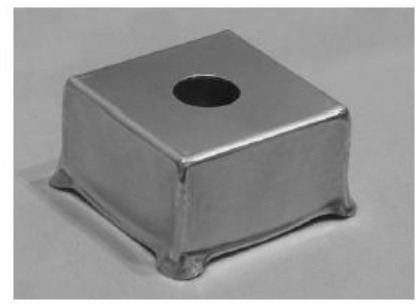

Fig. 11. Rectangular box shape through a synchronous multipath metalspinning method [191]

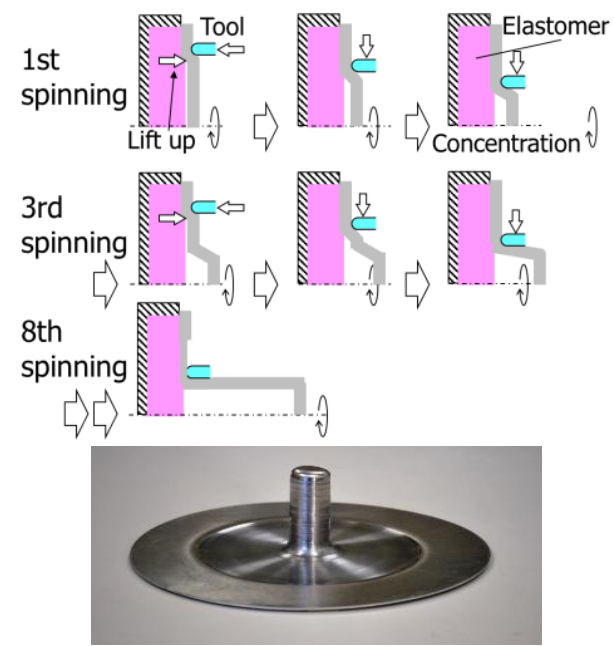

Fig. 12. Tube fabrication by spinning utilizing elastomer [194]

\subsubsection{Incremental profile forming by flexible roll movements}

Roll forming originally is a continuous bending process during which a profile with a desired cross section is formed in a steady state process. Flexibility in roll forming can be achieved by enabling variable cross-sections along the longitudinal direction through movable rolls. Groche et al. [55] developed a flexible roll forming stand shown in Fig. 13. The desired bending edge can be generated in a CAD-system and read by a control program to control the forming units. Constant flange heights can be achieved by using geometrically fitted metal sheets.

Lindgren [116] developed a 3D roll-forming process which allows for profiles with variable depth and width The concept shown in Fig. 14 consists of six forming stands which servo control axes two for translations and two rotations of the rolls. Products from this process are shown in Fig. 14.

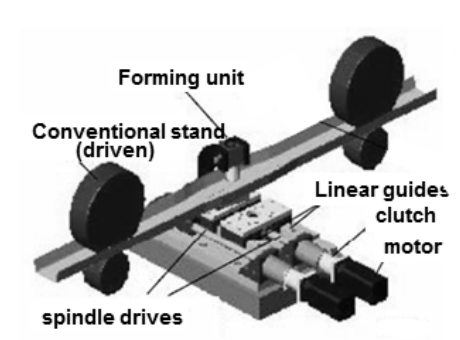

(a)

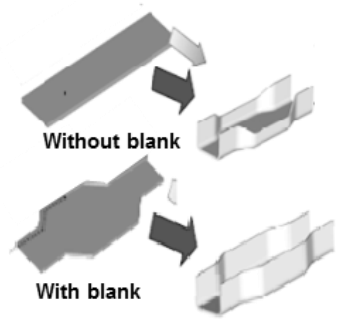

(b)
Fig. 13. Schematic of concept of flexible roll forming with additional forming unit (a) Apparatus (b) Design of blank [55]

Flange wrinkling and web warping are two major failure modes in flexible roll forming [77, 78]. They are caused by longitudinal compressive and tensile stresses in the inlet and outlet zones of the change in section [56] Larrañaga and Galdos [105] investigated the enhancement of the accuracy for the flexible roll forming. To reduce the shape error, a new process called incremental counter forming (ICF) shown in Fig. 15 was proposed by which the shape error can be reduced in incremental steps [158]. As a result, the precise geometry can be manufactured without shape errors. 


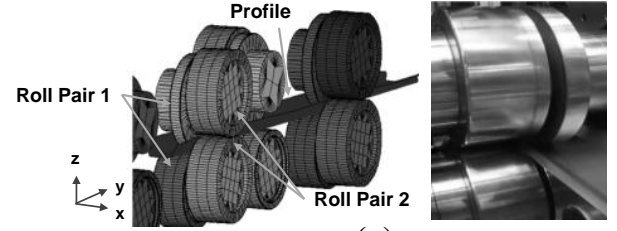

(a)

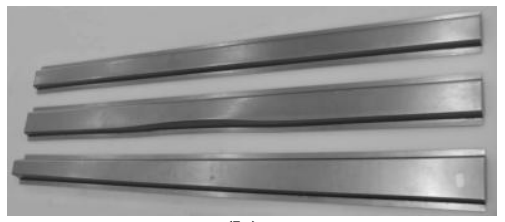

Straight

Middle Waist

Conical

(b)

Fig. 14. Schematic of 3D-roll forming (a) Apparatus (b) Product [116]
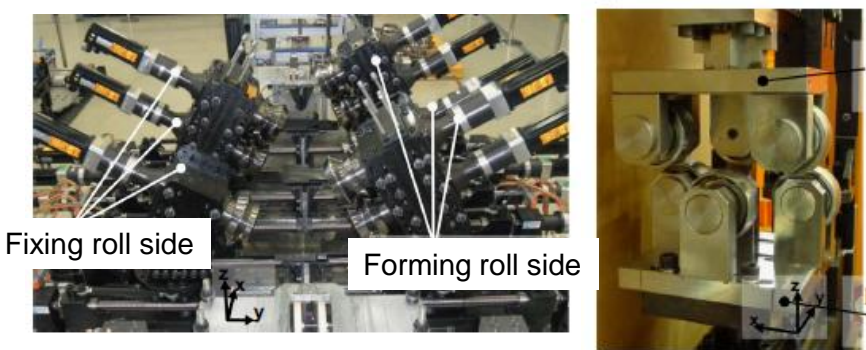

Fig. 15. Flexible roll forming using incremental counter forming [158]

Incremental Profile Forming transfers the principle of incremental sheet forming to tubes and profiles and allows the manufacture of tubular parts with a variable cross-section design along the centre line. Multiple forming tools with arbitrary shapes indent into the tube and move along predefined tool paths until the desired shape is realized. Based on the described concept Grzancic et al. [57] developed a flexible machine system with eight numerically controlled axes, given in Fig. 16, where up to six tools can be utilized and moved separately from each other at the same time.

\section{Forming unit}

Rotary disc

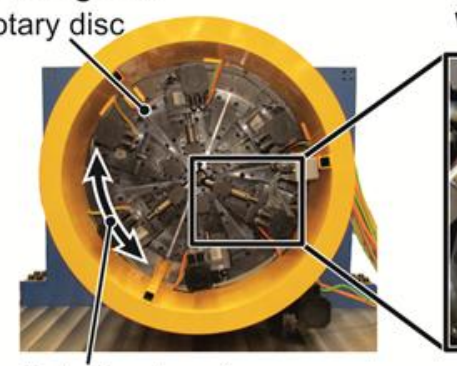

Rotational motion
Tool unit Workpiece Forming tool
Linear tool motion
Depending on the tool design and its combinations, a wide variety of part geometries can be generated. Some corresponding product examples are shown in Fig. 17 for the kinematic, formclosed and combined forming type, where, according to Grzancic et al. [58], the kinematic forming type shows the highest product variety due to the utilization of an universal tool design.

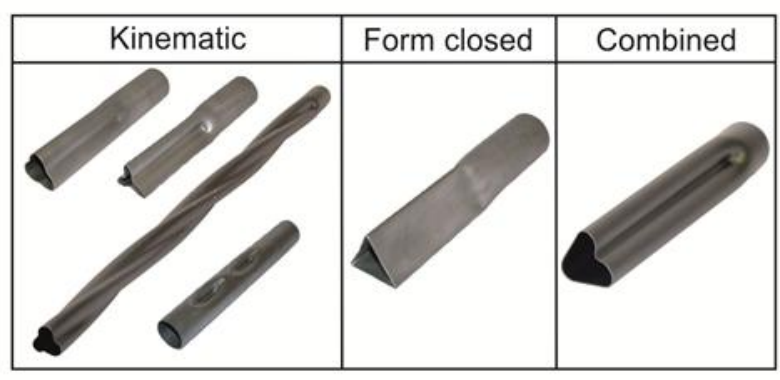

Fig. 17. Product examples of incremental profile forming [58]

Another category of flexible roll forming is forming of generally curved plates by employing multiple rolls in an incremental process. In a shipbuilding yard, hull forming is an important fabrication process in which flat plates are deformed into doubly curved plates. The manufacturing process of the doubly curved plate is usually carried out manually by skilled craftsmen by using gas torches. A multi-point forming process for producing a doubly curved plate was proposed [26, 214]. Reconfigurable multi point tools were employed to approximate the upper and lower solid dies. The line array roll set (LARS) was developed by Shim et al. [175-177]. Each roll set can be moved in vertical direction as shown in Fig. 18.
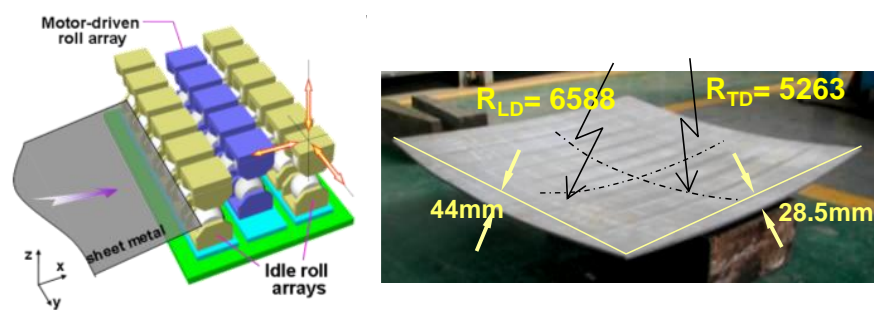

Fig. 18. Incremental rolling of doubly curved plates [177]

\subsubsection{Incremental profile forming by bending operation}

The demand for bent profiles as structural elements in transportation and in civil engineering has increased strongly [210]. Geiger and Sprenger [48] and Vollertsen et al. [201] mentioned that stretch bending is based on the principle of limited shape forming and is mainly used in the automotive industry for mass production [21].

Recently, 3D-bent profiles as incremental forming have provided engineers with higher flexibility and have allowed the construction of lighter and stiffer structures. It is also possible that three-dimensional flexibility in shaping profiles for lightweight construction will open up new possibilities [83].

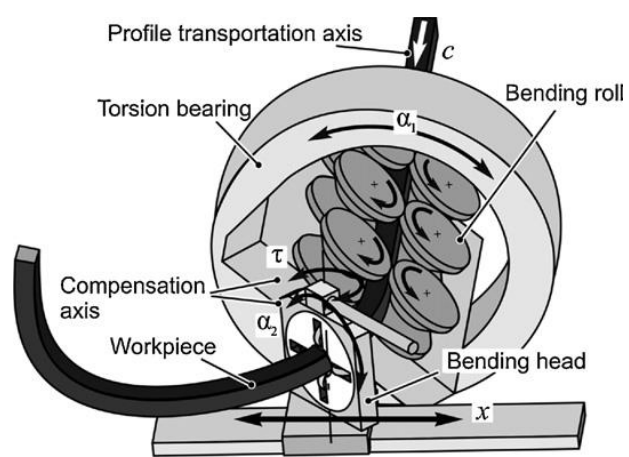

Fig. 19. Schematic of a machine setup-up of the TSS bending process [28]

Murata et al. [147], Kleiner et al. [84], Gantner et al. [45], Goodarzi et al. [49] and Hermes et al. [64] proposed bending processes for producing 3D-bent products. Chatti et al. [28] 
proposed the TSS (Torque Superposed Spatial) bending process that has been developed using methods of systematic engineering design shown in Fig. 19. The 3D bending contour of profiles was controlled by a superposed torque. The kinematic components of the machine were synchronized simultaneously to lead to higher flexibility.

Dieless U-bending methods had been introduced by Kuboki [92, 94]. Previously, bending of tubes was performed by the die bending process and three-roll bending process. The three-roll bending process is a flexible bending process. However, it cannot achieve precise geometry due to gravity and unstable portion at the beginning end and at the finishing end. Dieless U-bending method is a flexible bending process enabling various bending radii with flexibility [93]. This process eliminated the effects of gravity by clamp and feeding rolls. Various values of radius can be obtained by controlling arm radius and position of the bending roller. The schematic figure of the dieless U-bending process is shown in Fig. 20.

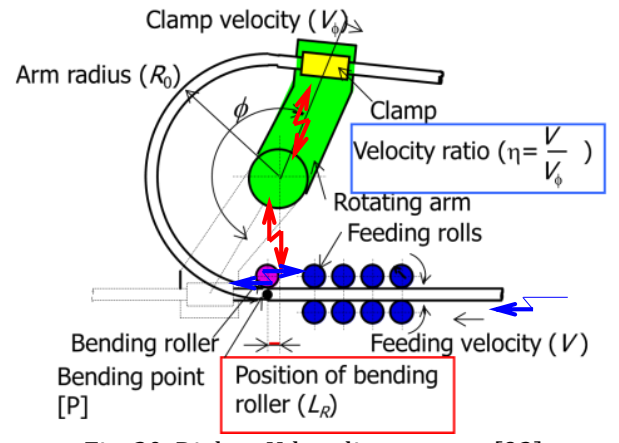

Fig. 20. Dieless U-bending process [93]

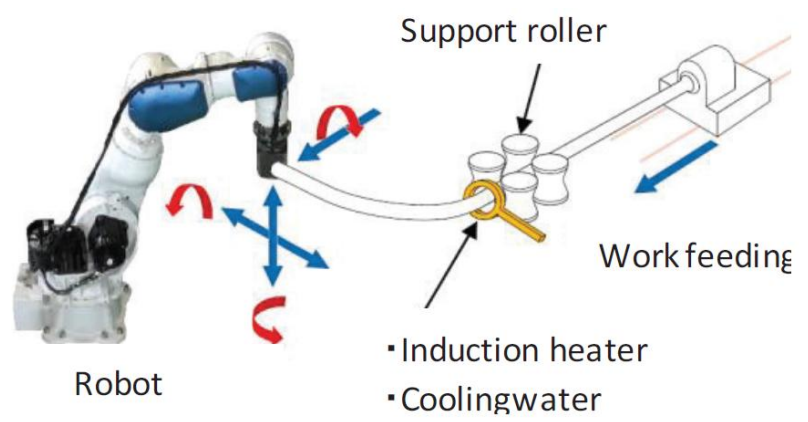

Fig. 21. Schematic figure of the three-dimensional hot nending and direct quench [178]

Shimada et al. developed "Three-Dimensional Hot Bending and Direct Quench (3DQ)" method. A tube is fed through a feeding system, at the exit of which the tube is locally heated. A robot arm holds the end of the tube, for generating bending moment at the heated point, and then the bent part is rapidly cooled as shown in Fig. 21 . As a result, the tube has a 3-dimentionally bent shape as well as high strength at the same time.

\subsection{Incremental bulk forming}

\subsubsection{Incremental bulk forming by discrete cogging operation}

Incremental bulk forming is the oldest known metal forming technology. At that time, man began to manufacture simple tools and ornaments from gold, silver and copper without devoted tools. Nowadays, incremental bulk forming is applied to manufacture large products with the usual name of "cogging" and incremental "upsetting". Various simple shapes could be manufactured flexibly with a small number of tools [52].

In bulk metal forming, which are often characterized by the final component geometry being largely represented by the tool geometry, specific approaches exist for making component production more flexible.
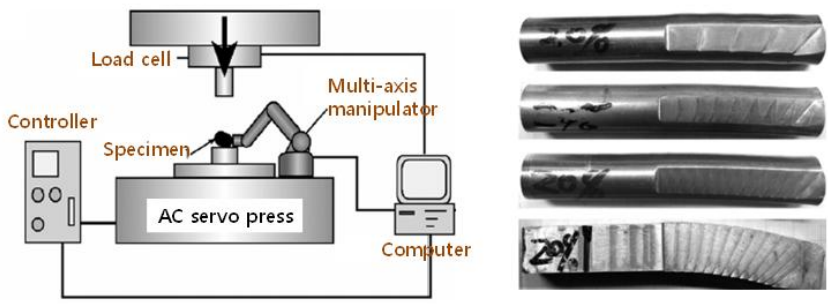

Fig. 22. Incremental forging with a robot and formed products with various shape [203]

The forging process, in comparison with the machining process has advantages such as the improvement of mechanical properties for the component, mass production capability and saving of raw material. The closed-die forging process needs a devoted die set for each product. However free forging process has been applied to incremental bulk forming, because the specific die-set is not required and various shapes could be flexibly formed with a small number of tools [52]. In incremental bulk forging, deformation of materials is not restricted by the tool shape [155]. Therefore, the bulk incremental forming process, which utilizes rather small equipment and more universal tools instead of a special die, has been carried out in many applications.

In bulk incremental forging, an integrated manufacturing system of free forging was developed, as shown in Fig. 22. Wang et al. [203] investigated the free forging process with a 6-axis degree of freedom robot and servo-press which is very economical in forming of complex shape parts due to high process flexibility and simple die-setting. The basic experimental results were shown in Fig. 22.

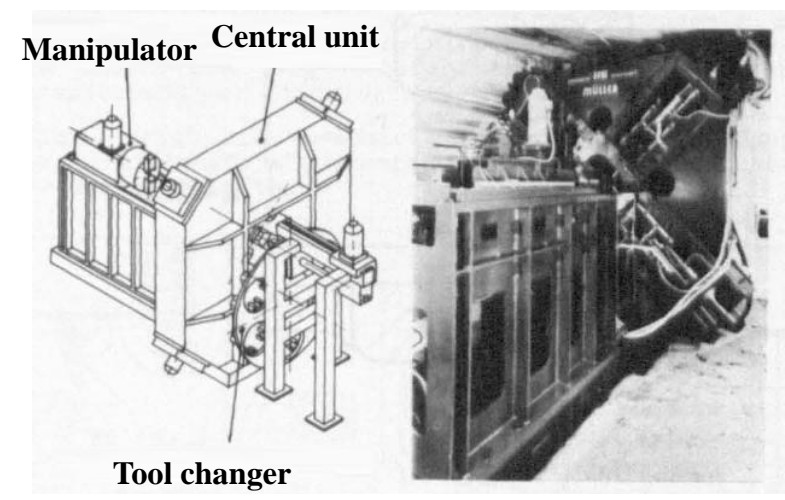

Fig. 23. Radial forming machine RUMX $2000[103,159]$

Rotary swaging is a metal forming process for changing diameter of a tubular or solid bar. Most applications involve the reduction [65]. Axial-Radial-Forming was developed in order to manufacture additional shapes like shaft collar in gear shafts which requires a local increase of diameter. The shaft collar was formed by engraved die segments [164]. Jin et al. [74] developed a rotary forming process to thicken the rim of a disc-like part. As the ring roller moves around the workpieces, the rim of stationary workpieces is rolled and thickened with desired shape. 


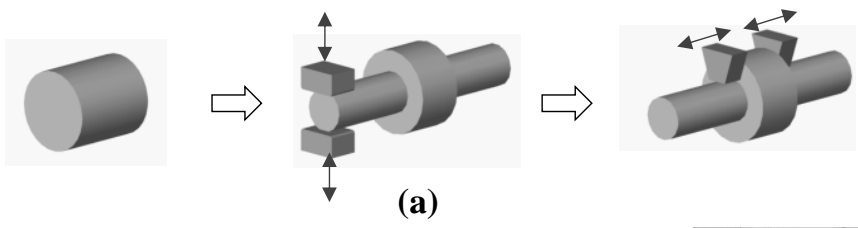

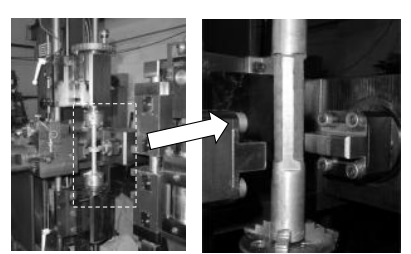

(b)

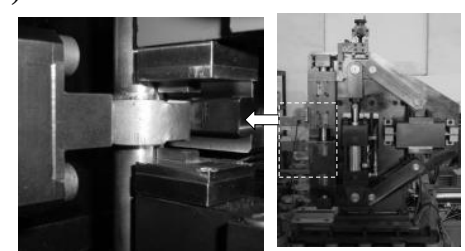

(c)
Fig. 24. Schematic of incremental radial-axial forging of flanged shaft parts (a) Concept of the incremental radial-axial forging (b) Radial forging (c) Axial forging [109]

For flexible and CNC controllable radial forming machine was developed by Lange [159]. The radial forming machine RUMX 2000 (Fig. 23) [103, 159] contained all necessary systems for automatic manufacturing. Stepped shafts with longitudinal axis and more complex shapes such as T-sections and X-sections can be fabricated. As shown in Fig. 24, Lee et al. [108] developed an innovative radial-axial forging process employing incremental forming in order to produce shaft parts with complex-shaped flanges. Three-dimensional parts can be fabricated from a raw material having smaller outer dimensions than those of final product by repeating the radial-axial incremental forging process. Fig. 24(b) shows apparatus for radial forging, and Fig. 24(c) shows apparatus for axial forging.

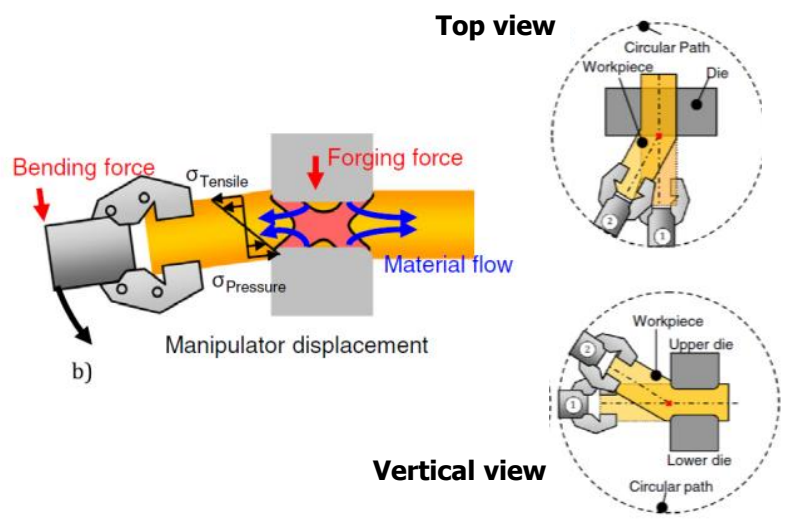

Fig. 25. Open die forging for curved workpieces [206]

A new approach for the integrated open-die forging of curved workpieces is presented, by Wolfgarten and Hirt [206]. In this incremental forging process, the material flow is controlled by superimposed manipulator displacements. Superimposed manipulator displacement gives bending deformation to workpieces. The deformation in the top view and vertical view are presented in Fig. 25. Through this forming process, a generally curved workpiece can be manufactured within one forging pass with flexibility.

2.2.2 Incremental forming by ring blank rotation / flexible ring rolling

Ring rolling is one of the incremental bulk forming process and used to manufacture products of ring shapes for engine parts and aerospace parts. The shape of products made by conventional ring-rolling is limited to constant cross-sections and flat rings. To extend the process for industrial applicability and flexibility of the ring rolling process, new approaches for ring rolling of various shapes of cross-sections had been suggested.

Allwood et al. [7] and Stanistreet et al. [187] developed a novel type of flexible ring rolling machine (Fig. 26). By increasing the number of elemental modules, the machine provides the possibility of increasing the flexibility of the process and increasing its production capability. In addition to flexible ringrolling, Lee et al. [110] fabricated a tilted ring by changing mandrels during the process. Christoper et al. [29] studied the ring rolling process for the non-axisymmetric components having variable wall thickness. By controlling roll gaps and speeds online, products with variable thickness could be made without loss of circularity. Flexible ring rolling shows the potential to extend the complexity of the ring cross-section.

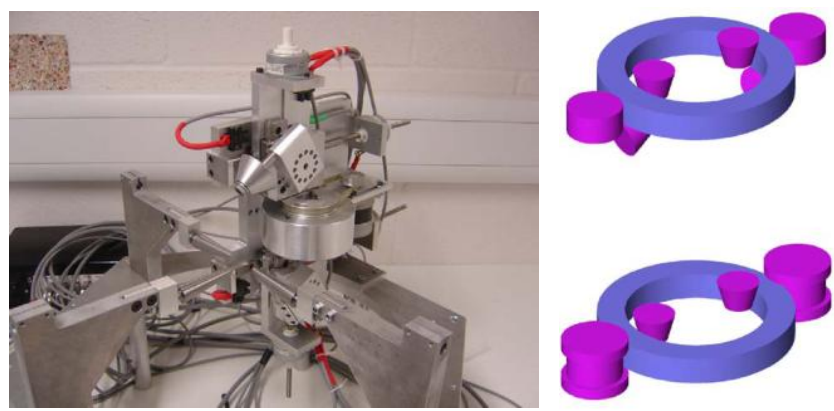

Fig. 26. Flexible ring rolling machine and the module of the experimenta ring rolling machine [187]

2.2.3 Other incremental forming by flexible tool movement(s) transverse rolling

Orbital forming as an incremental bulk forming process can be applied on a metal plate to create a defined circular plate thickness characteristic [179]. From the orbital forming process, flanged automotive parts and impeller shafts can be manufactured.

In orbital forging, deformation occurs in a small segment of material. As a result, orbital forging presents smaller forming loads, small stresses in dies, longer die life and reduced noise and vibrations. As shown in Fig. 27, the orbital forging process can increase the formability of materials. In addition to formability, Orbital forging has advantages in product shapes and does not require a specific die-set [160]. These indicate that orbital forging is economical in medium and small-batch production. In addition to economic points, orbital forging provides flexibility in production shapes [154].

Functionally integrated sheet metal components can be manufactured flexibly with less yield loss, better mechanical properties and shorter process chains by combining sheet forming with incremental bulk forming. Process adapted semifinished products like tailored blanks with a defined sheet thickness distribution are necessary for some processes of this class to achieve the desired geometrical dimensions. These tailored preforms can be manufactured with a sheet-bulk metal forming operation itself. Since high process forces are required due to spatial material flow and large contact areas, incremental forming technologies like orbital forming are well suited for this task [136]. The thickness distribution and the orbital forging process are presented in Fig. 27. Various types of tools can be utilized in the sheet-bulk metal forming process as shown in Fig. 27 [183]. Through the continuous and discontinuous forming process, flexible geometries can be manufactured. 

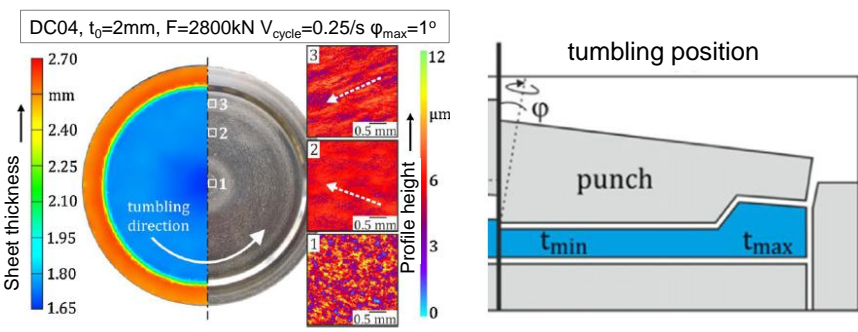

Fig. 27. Tailored blank by orbital forging [136]

Another approach of the sheet-bulk metal forming technology deals with an incremental procedure (iSBMF) shown in Fig. 28. Within the trend of individualization, a flexibility of manufacturing processes is necessary for a high product variety by kinematic strategies of simple forming tools. A characteristic feature is the small forming zone in comparison to the workpiece volume, and thus, lower forming forces occur. With the localized iSBMF forming operations are applied to sheet metals and enable an intended three-dimensional material flow. The key innovation is the defined control of the 3D material flow in a sequence of forming operations. The local setting of the workpiece contour, the sheet thickness and the hardening based on individual requirements are the most important advantages provided by this approach. For this purpose a special forming press with five axes of motion was realized and allows for a wide variety of different forming operations.
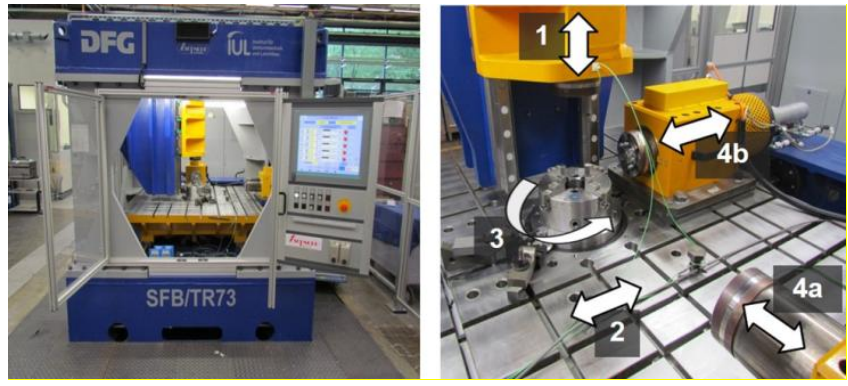

Fig. 28. Five-axis forming press for the incremental sheet-bulk metal forming [180]

The forming operations can generally be separated into continuous and discrete sequences. The continuous processes represent forming steps with a permanent tool engagement and discrete processes have a temporally limited, interrupted tool contact. A further distinction occurs due to the position of the processing. Characteristic cases are the processing of the sheet plane (Fig. 29a) and of the sheet edge (Fig. 29b). By processing the sheet edge, form-elements are aspired, such as gears [182]. With the forming operations on the sheet plane a locally defined material pile-up is formed which can be used as additional volume for fastening elements or as secondary design elements [205]. Both process variants require adequate tooling systems, particularly chambering elements, in order to control the material flow. These necessary elements also represent a restriction for the tool dimensioning.

For the fundamental process understanding of the innovative iSBMF processes, analytical frameworks were developed to offer a physical insight at the deformation mechanics and to estimate the influence of the main process parameters on the force requirements [182, 205]. Challenges during the incremental gear forming regarding a high tool wear and an insufficient form filling of the first gear element formed were faced and solved [205].

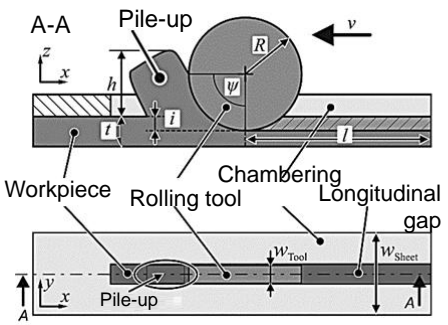

(a)

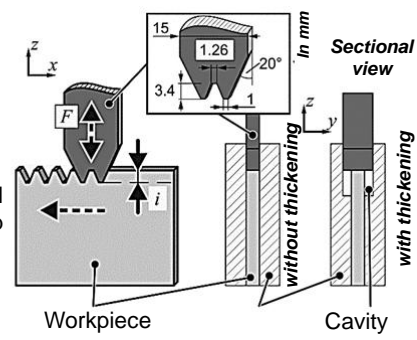

(b)
Fig. 29. Schematic presentation of the processing of a) the sheet plane and b) the sheet edge. [181]

As in the case of incremental sheet metal forming, the realization of component geometry based on a suitable tool kinematics also represents an approach in the field of bulk metal forming, which increases flexibility. In this context an innovative solution is represented by the so-called axial feed cross rolling $[100,102]$. A large variety of part geometries can be manufactured without specific forming tools. The forming process is based on the relative motion between the workpiece and two rolling tools rotating simultaneously. These rolling tools groove the workpiece due to a corresponding infeed motion. Additionally, the workpiece, which is rotating freely, is moved axially i.e. it is pulled through the rolls. The infeed motions of the rolls and the feed motion of the workpiece may be varied in the process sequence.

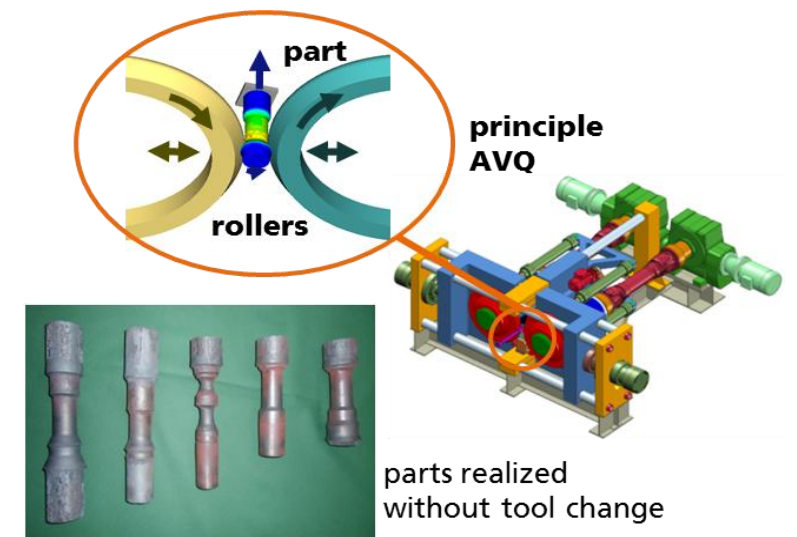

Fig. 30. Schematic figure of the axial feed cross rolling process and products [100]

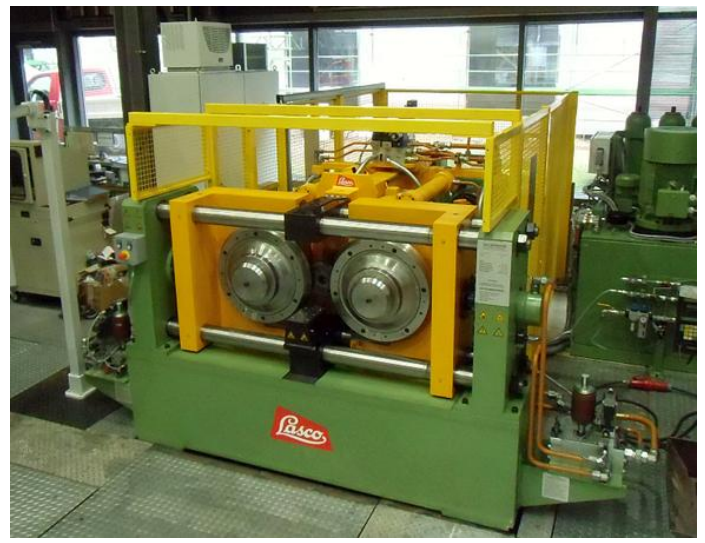

Fig. 31. Prototype machine for axial feed cross rolling [190]

The schematic figure of the axial feed cross rolling process and products are presented in Fig. 30. Moreover, it is possible to realize several grooves and repeated rolling in one clamping, which allows for the diameter of the workpiece to be reduced by 
more than $80 \%$. The overall estimate establishes that axial feed cross-rolling is one of few processes of bulk metal forming that enable economic manufacturing of complex component geometries for a range of small or medium-sized number of pieces. In addition to flexibilization of the component production, significant effects can be achieved regarding efficiency of materials and resources. Fig. 31. presents a prototype machine developed by a joint collaboration between Lasco Umformtechnik $\mathrm{GmbH}$ and Fraunhofer IWU [190].

\section{Flexibility by physical parameter variation}

\subsection{Flexibility of Strength distribution by geometric variation}

3.1.1 Flexible geometric variation by continuous operation (Flexible rolling)

The efficient production of weight optimized components often requires new, more flexible forming processes. novel hot rolling process was presented for forming I-beams with variable crosssection [27], which are lighter than prismatic alternatives. Additionally, demands on mechanical performances by optimization of local properties and optimized sheet thickness for structures are increasing [71, 91]. The process is capable of generating variable cross-section beams with variation in web depth of $30-50 \%$. Some examples of variable cross-sectional beams and manufacturing process are shown in Fig. 32.

A new rolling process is being developed for producing cold rolled strips with a defined cross section $[53,68]$. These strips feature differences in thickness up to $50 \%$ perpendicular to the rolling direction. A special roll system is used to achieve a material flow exclusively in the direction of the strip width. As a consequence, the strip width is increased significantly. In this way a wide variety of different cross sections can be produced. The application of sheet with variable cross-section covers novel loadadapted and load-optimized structures with different thicknesses, e.g. special profiles and special section tubes.

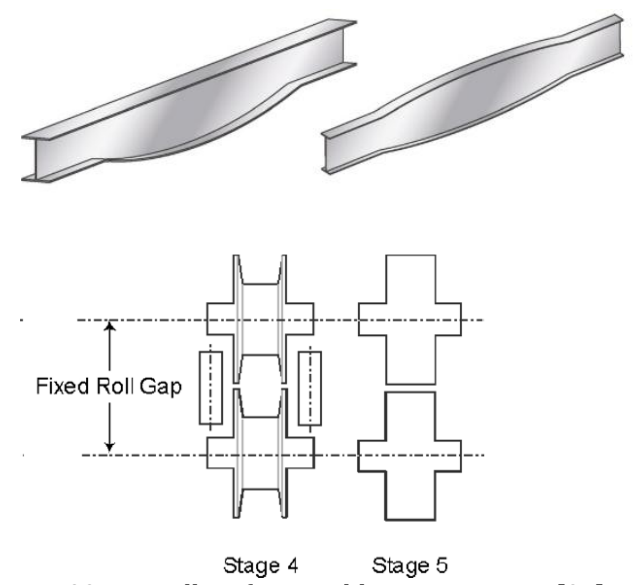

Fig. 32. Hot rolling for variable cross-section [27]

Ryabkov et al. [166] proposed a new tailored rolling blank (TRB) through 3D-strip profile rolling. By combining flexible rolling (FR) and strip profile rolling (SPR) into one production chain [88]. It was possible to produce blanks with both longitudinal and latitudinal transitions. A schematic figure of a 3d-profiled blank is shown in Fig. 33.

As shown in Fig. 34, the tailored rolling blank (TRB) regions that have been reduced maximally in thickness have a higher yield stress in comparison with the regions that have been minimally reduced due to strain hardening. The rolls can be arranged as shown in Fig. 34. Also, some examples are presented in Fig. 34.

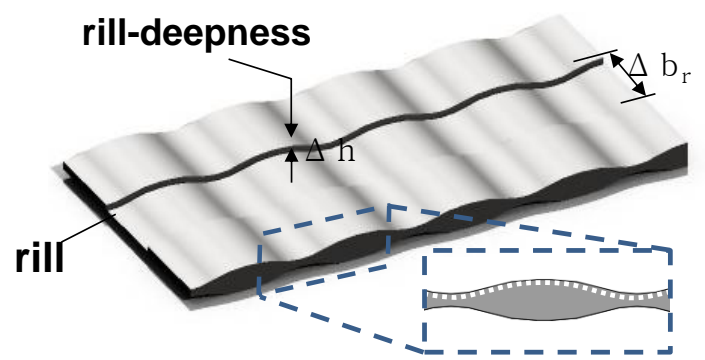

Fig. 33. 3D-profiled blank $\overline{16} \overline{6}]$

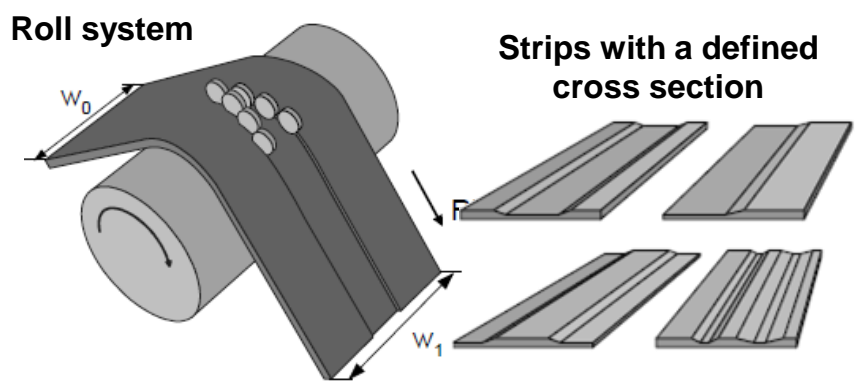

Fig. 34. Flexible rolling for defined cross section [88]

3.1.2 Flexible geometric variation by discrete operation (Flexible plate forging)

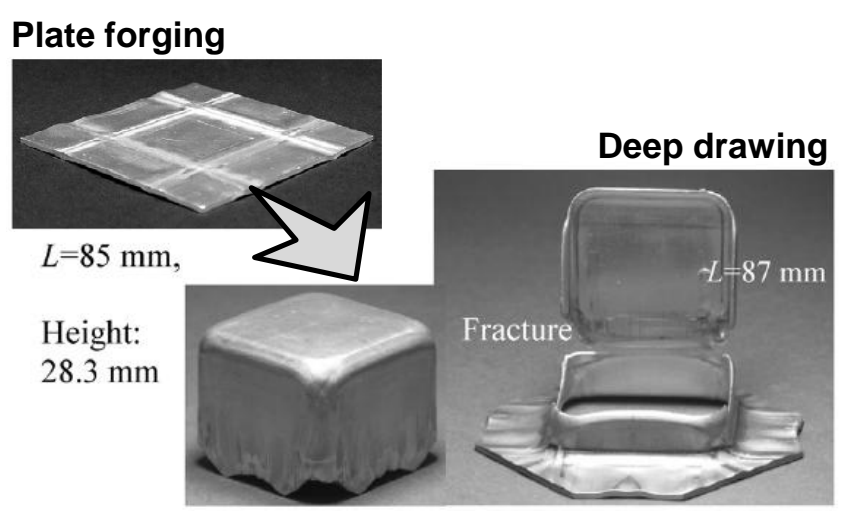

Fig. 35. Plate forming of tailored blanks [141]

A plate forging process of tailored blanks having local thickening for the deep drawing of square cups was developed to improve the drawability [141]. A sheet having uniform thickness was bent into a hat shape of two inclined portions, and then was compressed with a flat die under restraint of both edges to thicken the two inclined portions. The bending and compression were repeated after a right-angled rotation of the sheet for thickening in the perpendicular direction. A plate forged sheet and results of the deep drawing are shown in Fig. 35. The thickness of the rectangular ring portion equivalent to the bottom corner of the square cup was increased, particularly the thickening at the four corners of the rectangular ring undergoing large decrease in wall thickness in the deep drawing of square cups became double. Merklein and Opel [135] investigated the sheet-bulk metal forming process [130] to manufacture tailored blanks with a defined sheet thickness. Manufactured sheets with different thickness were employed in the deep-drawing process and forming process to obtain flexibility in geometric variation of sheet products. 
3.2 Flexibility of material disposition by introducing different materials

\subsubsection{Flexible material disposition using by patchwork blanks}

A promising approach to reduce manufacturing costs, decrease vehicle weight, and improve the quality of automotive body components is through the use of tailor-welded blanks [81]. This term refers to blanks where multiple sheets of material are welded together to create a single blank prior to the forming process $[2,138]$. The key idea of patchwork blanks is to partially reinforce a mainsheet by one or more blanks (patch) as shown in Fig. 36 [99] and Fig. 37 [132]. In most cases the patched blank is smaller than the main sheet. The difference to conventional reinforcement methods used in the automotive industry is that the blank and the reinforcing patch are joined prior to the forming process. The blanks are connected with an overlap joint. Another advantage of patch-work blanks in contrast to conventional reinforcing is the higher fitting accuracy between the two sheets as a consequence of the joint. Moreover, even very small areas of the blank can be reinforced.

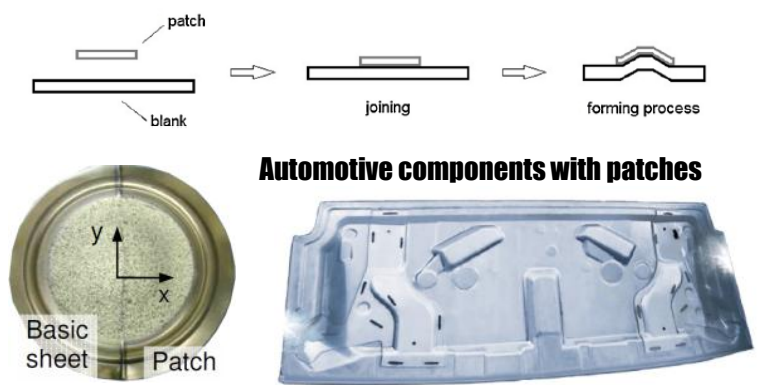

Fig. 36. Automotive components with patches [99]

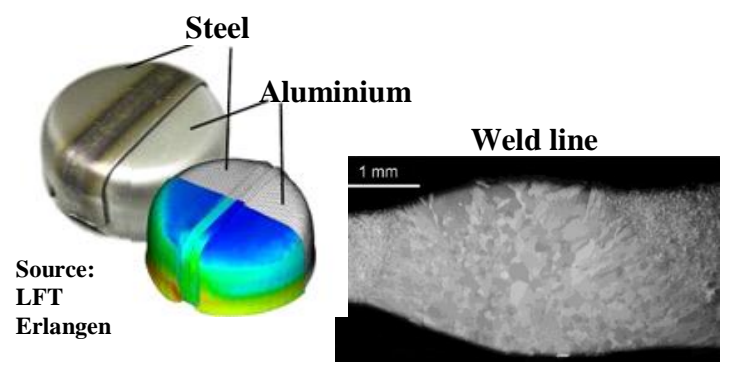

\section{Five-piece body side (TWB)}

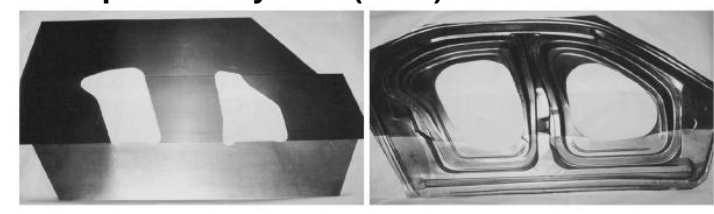

Fig. 37. Examples of the tailor welded blanks [132]

3.2.2 Flexible material disposition using by metallic sandwich plate(s)

A sandwich structure is a common practice in lightweight structures in nature such as branches, bones, etc. These structures are featured by structural optimization and minimum weight for maximum performance, such as high specific strength and high energy absorption value. As inner structures between skin sheets, tetrahedrons, pyramids, 3D kagomes, diamond weaves, hollow trusses and honeycomb structures can be used for the inner structure [195, 202] have been used.

Various methods such as perforated sheet folding, wire assembly and investment casting have been applied to the manufacture of a light-weight metallic sandwich plate. Such manufactured sandwich plates are not amenable to forming with very low formability due to their extremely high bending strength and stiffness, which hinders practical application.

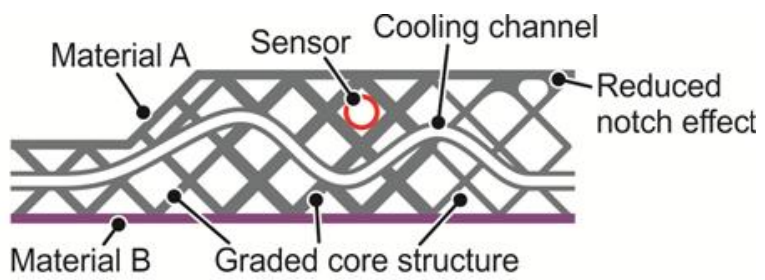

Fig. 38. Schematic composition of multi-material additively manufactured sandwich sheets with integrated functions

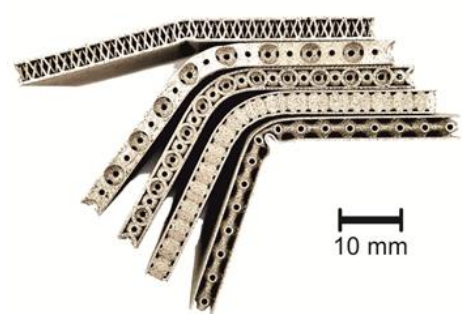

Fig. 39. Metallic sandwich sheets manufactured by selective laser melting with different core structures after bending to the same bending angle showing different spring-back.

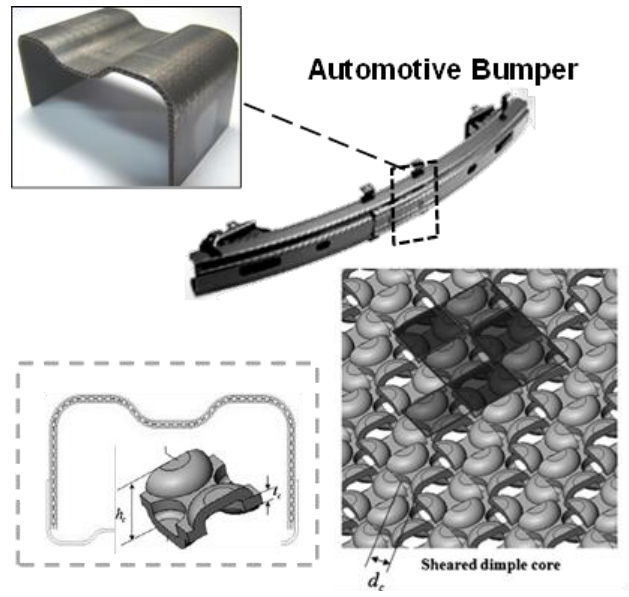

Fig. 40. Application of the bendable metallic sandwich plate $[171,172]$

A new approach is the forming of additively manufactured sandwich sheets by selective laser melting (SLM). Sandwich sheets with optimized core structures and high ductility are developed with respect to high formability. Fig. 38 shows the possibilities of additive manufacturing (AM). Multi-material applications, functional integration, such as complex cooling channels or integrated sensors, as well as load-adjusted graded core structures are developed and produced. With AM it is possible to combine the benefits of both processes - the flexibility and free complexity of AM plus the efficiency and productivity of forming technologies. The sandwich sheets are completely produced with SLM and show promising results in the threepoint-bending test (Fig. 39). Another upside of the aforementioned process combination, is the substantial time saving of up to $50 \%$ compared to the manufacturing of the final contour. 
Seong et al. [171, 172] developed bendable sandwich plates with sheared dimple inner cores to increase bendability. The sheared dimple cores prevent face buckling and core shear failure because the shear strength of the sheared dimple cores is higher than that of other sandwich cores with the same relative density. Such a bendable sandwich structures provides the flexibility in design and manufacture of sandwich plate. The car bumper shown in Fig. 40 is made from the sandwich plates with sheared dimple cores.

\subsubsection{D printing of metals and Smart material utilization}

The evolution of 3D printing (3DP) or additive manufacturing over the past three decades has been nothing less than extraordinary [198]. The evolution of 3DP has been made by improvements in 3DP materials and technologies. Additive manufacturing processes produce physical objects from digital information point-by-point, line-by-line, surface-by-surface, or layer-by-layer $[41,168,173]$. Today, 3DP products and services support a wide range of activities including manufacturing, energy, transportation, art, architecture, education and the military $[59,66,70,111]$.

Recently, researchers related to the development of eco-friendly molding and forming tools have refocused their efforts on the laser assisted metal rapid tooling process to cope with the global warming issue and the resource depletions [42, 207]. The advantageous inherent features of the laser assisted metal rapid tooling process include an readily additive characteristics, switchable supply of materials and material deposition along an arbitrary trajectory. These features provide the tool designer and manufacturer with an opportunities to overcome the limitations of the conventional molding and forming tools from the viewpoints of energy consumption, environmental impact and material usage [3] as shown in Fig. 41.

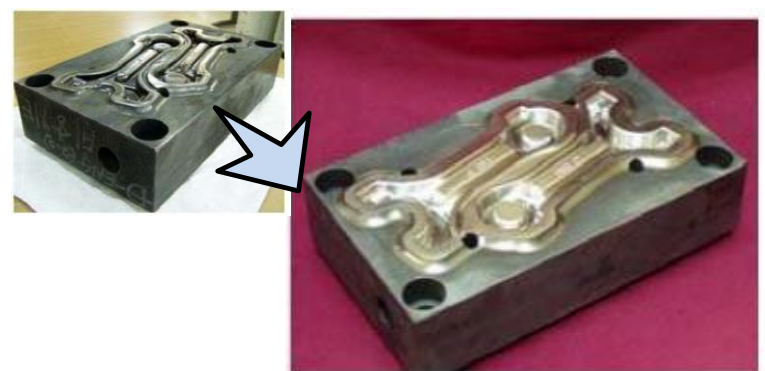

Fig. 41. Restoration of hot forging tools using laser assisted material deposition [3]

The forming load of the bulk metal forming process, including forging, extrusion, rolling, etc., is greater than that of the sheet metal forming process. The laser assisted metal rapid tooling process has been hardly applied to the manufacture of the tools for the bulk metal forming process. Recently, several researchers have tried to utilize cladding and melting types of laser assisted metal rapid tooling process for the improvement of the wear resistance of warm and hot forming tools.

Since the laser assisted metal rapid tooling process was introduced into manufacturing industries, restoration of molding and forming tools has been considered as a competitive application field. The cladding type of laser assisted metal rapid tooling process along with coaxial nozzles for powder feeding, as in many commercial processes, can deposit the desired material on the damaged tool surfaces. In addition, the porosity and the heat affected zone are hardly formed in the deposited region. InssTek Inc. is researching into five-axis controlled flexible deposition system. The flexible deposition system makes possible to near net shape repairing of the tools. InssTek Inc. has carried out the restoration of hot forging tools. [3]. The company has reported that the life of the restored hot forging tool for the case of the connecting rod is increased nearly 2.5 times or more.

\subsection{Flexibility of strength control by local or incremental heating}

\subsubsection{Flexible local heating for tailor-tempered sheets}

Tailor welded, tailor rolled and patchwork blanks [156, 163] are mainly produced to improve the properties of the parts for its final application. In many cases, the forming process of tailored blanks is even more difficult compared to conventional blanks because of the inhomogeneous thicknesses or strength distribution [95].

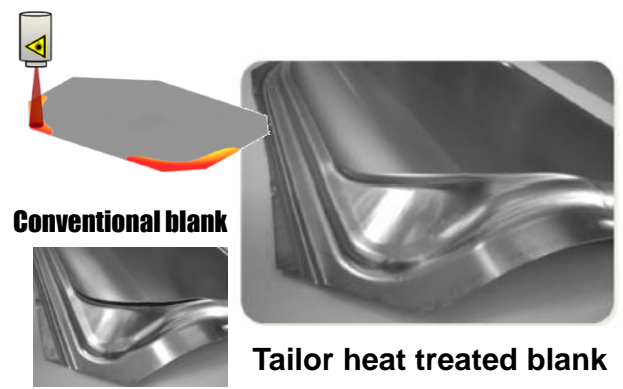

Fig. 42. Tailored heat treated blank (THTB) [132]

In contrast, the aim of tailored heat treat blanks (THTB) [132] is to improve the formability of the products. Blanks produced with the THTB technology have locally different property distribution along the sheet plane [47, 131]. The partial mechanical properties are tailored to improve the subsequent forming operation. The technologies' key idea is that the gradation of the mechanical properties is obtained by local heat treatment performed before the actual forming process. Consequently, the forming process is realized in cold conditions. This has many advantages in comparison to conventional warm or hot forming operations: no special and expensive components, like hot forming tools or heat-resistant handling systems, are necessary and the heat treatment operation can be locally and temporally separated from the forming process. Fig. 42 shows an example of the tailored heat treated blanks. After heat treatment, the formability of the material increases and the product can be formed without problems.
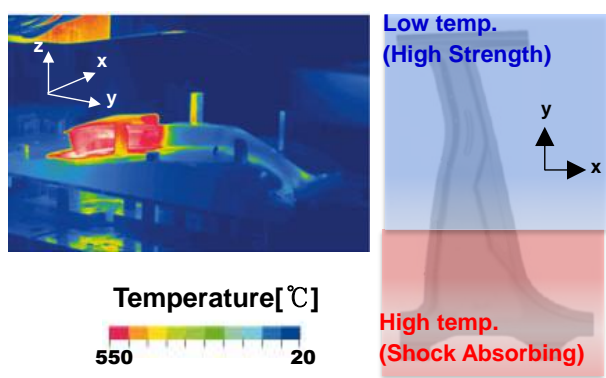

Fig. 43. Tailored tempering [76]

Recently, a new process of the tailored tempering system, has been developed in the industry. In a continuous cooling process of the tailored tempering system, the cooling rate and hardness are the relevant parameters. This method uses cooling gradients, calculated in the hot forming simulation, to determine the value of hardness and other mechanical characteristics of the part. The mechanical properties depend on the thermal and forming 
history of the part. For instance, Fig. 43 shows a B-pillar product with excellent intrusion control in the upper section and high energy absorption in the lower section.

Studies on changing the properties of products by controlling the cooling rate and heating region locally have been carried out to simplify the process and reduce the cost. The manufacturing of a single part with tailored properties with flexiblity can be carried out using different process control strategies such as tool temperature, thermal conductivity, and contact surfaces as stated by Karbasian and Tekkaya [76]. Mori and Okuda [144], Mori et al. [142] quenched only local portions requiring high strength using tailored die quenching in hot stamping. They produced formed parts of ultra-high strength steel with good strength distribution.

The heat assisted sheet metal forming in progressive or transfer tools by local induction heating is another approach for the flexible setting of geometrical and mechanical properties in large-scale production. Compared to conventional hot stamping, only critical zones are heat treated so that required product properties are fulfilled either by the initial condition or by the rapid heat treatment $[97,98]$

\subsubsection{Flexible local heating for formability improvement}

The formability of hard-to-form materials can be increased by increasing forming temperatures [12, 80, 200, 212, 213]. To increase formability and flexibility, the external heat sources can be applied to the hard-to-form materials where plastic deformation occurs [69]. Local heating of the materials eases processing of materials due to the dependence of the yield strength on temperature. Heat transfer by thermal radiation, conduction, convection, induction heating and microwave heating can be applied to the selective heating of the materials.

Using external heat sources such as heated forming tools and gas burners have technical disadvantages such as process control, guarantee of required quality, thermal loading on the machine tool and safety in the workplace as stated by Neugebauer et al. [150] in their review paper. It becomes clear that there is a need for a heating strategy which enables targeted, simultaneous heating of the forming zone during metal forming processes. Selective laser heating offers a possibility to heat only the areas of the work piece where strongest deformations are required. The laser beam is applied to conventional forming process such as the bending, roll forming, deep drawing, the sheet incremental forming process and the spinning process to increase the formability of the materials.

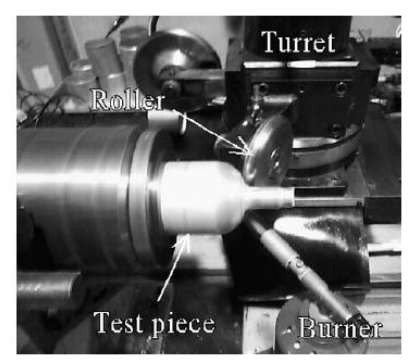

(a)

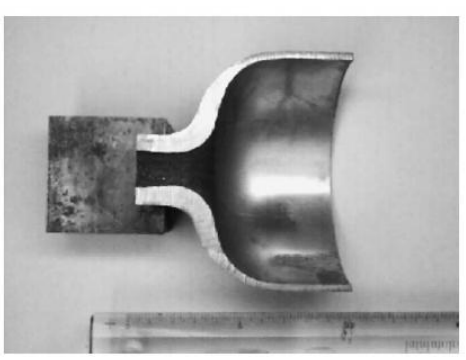

(b)
Fig. 44. Spinning process using gas burners (a) Photograph of experimental equipment in spinning (b) Geometry of the cross-section in formed magnesium alloy pipe

Spinning is widely applied to tube forming with the increasing usage of tubular parts. For hard-to-form materials, the conventional spinning process is difficult to be applied due to their low formability. Yoshihara et al. [211] investigated the spinning process of magnesium alloy tubes using gas burners and $\mathrm{NC}$ control. The feasibility of the spin forming of a magnesium alloy tube was proved by experiments as shown in Fig. 44. Murata et al. [146] developed a new CNC spinning machine having roller tools with heaters. The heated tools heat and form the magnesium tubes into various shapes by the spinning process. Laser assisted spinning process [86] was also introduced to make spinning more flexible by more focused local heating.

In roll forming, Lindgren et al. [117] developed a new method using partial heating to increase the formability of the sheet metals. It is shown that partial heating make it possible to roll form large bend angles. For bending of high strength steels, complex phase steels and martensite phase steels, Merklein and Geiger [131] developed the laser assisted bending process in order to enhance the formability of the materials to reduce springback and to realize smaller bending radii and increased bending angles.

In sheet incremental forming process, recent advances have enabled localized deformation to be accurately controlled. Sheet incremental forming process has the potential to innovate sheet metal forming, making it accessible to all levels of manufacturing as stated by Jeswiet [73] in his review paper about the asymmetric sheet incremental forming.

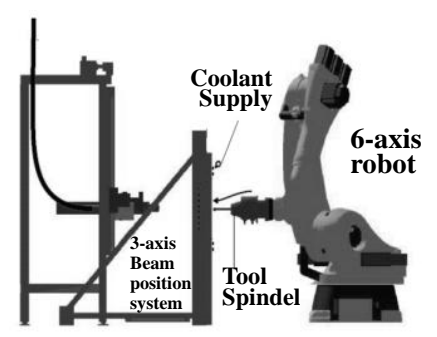

(a)

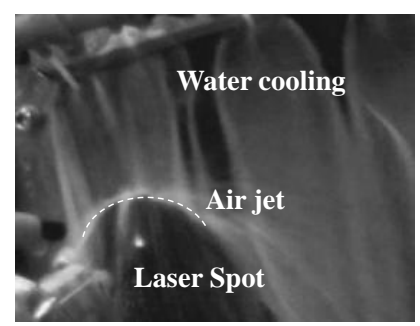

(b)
Fig. 45. Sheet incremental forming process using dynamic local heating (a) Experimental setup (b) Clamped workpiece and tool stylus with cooling flow locally re-moved by means of an air jet, and visible, dynamically moving heated spot [34]

Fig. 45 presents the sheet incremental forming process using laser. The sheet incremental forming process of the hard-to-form materials at room temperature is limited due to its formability. In order to increase formability, the external heat sources such as laser [34, 35], resistance heating [11, 37], friction heating [157, 208] and induction heating [5] were applied to the sheet incremental forming process.
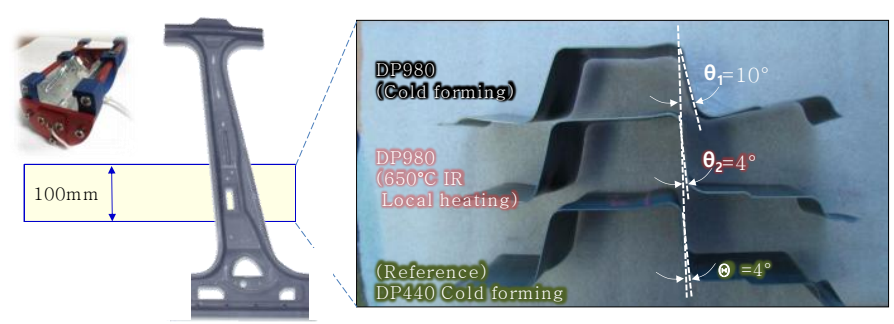

Fig. 46. B-pillar forming test using near infrared sources [107]

A forming process by local heating using near-infrared rays (NIRs) is proposed to reduce springback of non-quenchable advanced high-strength steels [107], such as dual-phase steels, that are not suitable materials for hot stamping. NIR lamps show outstanding cost performance, and the width of the heating area can be controlled by designed reflectors. V-bending and 2D-draw bending were conducted with heated DP980 sheets. Results (Fig. 46) showed that NIR local heating has advantages over furnace heating in both shape accuracy and hardness [107]. 
Dieless drawing is heat-assisted forming to reduce the cross sectional area of a tube or wire [193]. The main prerequisites of dieless drawing are localized heating and uniaxial tension. Localized reduction in an area is caused in the tension state by low flow stress at the locally heated part [44]. Dieless tube drawing offers flexibility to reduce the cross-sectional area of a tube only by adopting a drawing speed higher than the feeding speed without requiring dies or a mandrel.

Metal bellows have wide applications in piping systems, automotive industries, aerospace, automatic control and measuring instruments, transportation, nuclear energy industry and micro-electro mechanical systems. A novel manufacture method without any dies and tools for producing the metal bellows with various shapes (Fig. 47) was proposed [216].

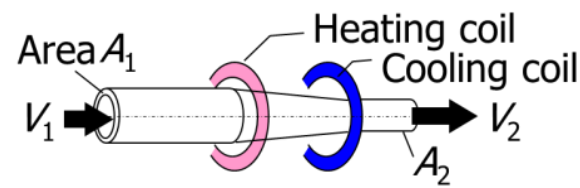

\section{$V_{1}>V_{2}->$ axial compression}

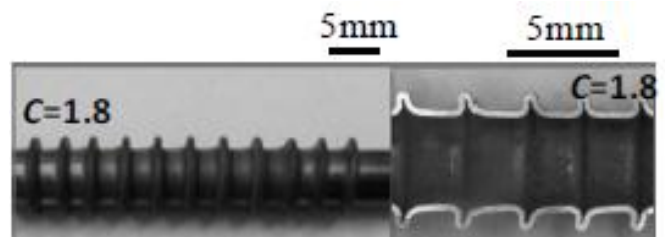

Fig. 47. Bellows forming and diametral expansion by local heating [216]

\section{Flexibility by process combination}

\subsection{Combination of conventional forming processes}

A motivation for combination of forming processes is the synergistic effect, meaning that the advantages of single processes can be combined [106, 169]. In addition to improving the formability, the increase in flexibility is an important aspect [217].

One interesting approach is represented by combination of conventional processes (e. g. deep drawing) with forming operations using active media or energies (e.g. elastomers, fluids, gases, electromagnetic fields) which offers advantages in terms of

- achievement of high levels of deformation,

- guaranteeing a high accuracy (e. g. reduction of spring-back behaviour) and

- integration of additional forming, cutting and joining operations.

One example is a kind of partial "explosive forming" process based on gas generators following a deep drawing operation for the realization of a uniform pre-form. Gas generators, normally responsible for triggering airbags, offer the potential to generate corresponding volumes of gas within very short time units. In order to follow up on this basic idea, investigations were performed at the IWU in Chemnitz to establish whether this technology can be used both for cutting and for forming processes. Fig. 48 shows realized derivatives of an engine hood based on a process combination of deep drawing and "explosive forming".

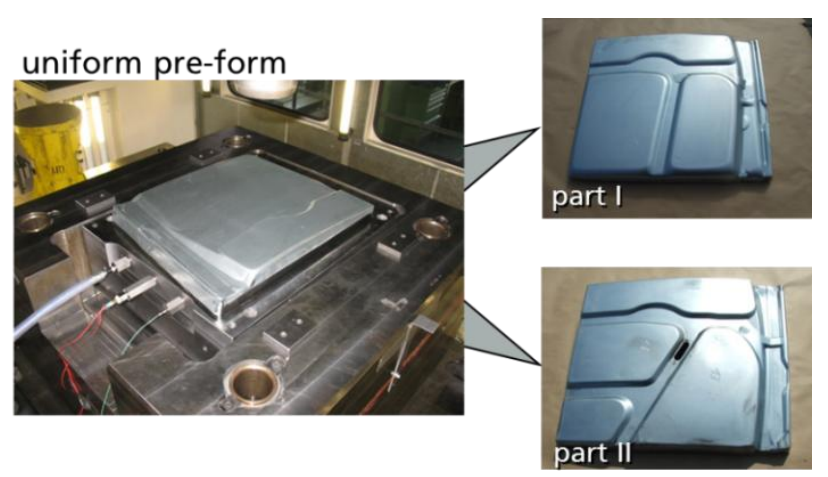

Fig. 48. Process combination of deep drawing and explosive forming

The manufacture of bent tubes made of high-strength materials requires high bending loads, which leads to large springback and eventually distortion of the cross-section. The incremental tube forming process allows significant reduction of the bending moment. This is achieved by combining the continuous bending process with an incremental tube spinning process [22]. Extrusion process and bending deformation was combined to increase flexibility of process and productivity. Due to an unsymmetrical feeding of the reinforcing elements, the curvature generation is influenced by the changed material flow $[82,85]$.

The incremental tube forming process shows a significant advantage concerning bending moment reduction as well as springback reduction compared to conventional tube bending processes due to stress superposition. It was shown that an increase of the process speed leads to a decrease of the bending moment. Furthermore, a higher necking causes a higher reduction of the bending moment due to the higher superposed circumferential stress.

Some researchers investigated the electromagnetic assisted forming process also called as electromagnetic forming [162]. With the electromagnetic forming process, a more defined and flexible geometry can be obtained [72, 174]. Fig. 49 presents integrated electromagnetic forming and extrusion process. Shang and Daehn [174] studied the electromagnetically assisted stamping process. By combining stamping and electromagnetic forming, a more complex shape can be formed [30,31].
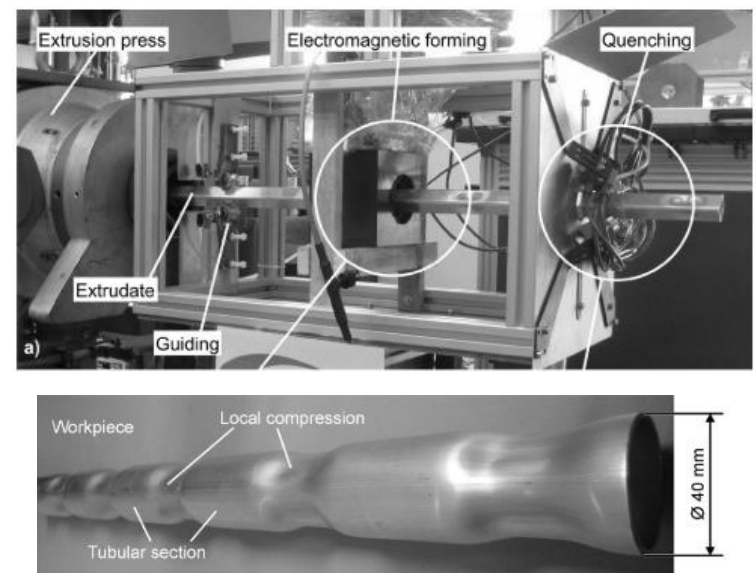

Fig. 49. Integrated electromagnetic forming and extrusion process [72]

4.2 Combination of flexible (incremental) forming process with a conventional forming process

Araghi et al. [14, 19] developed a new hybrid process combining stretch forming with asymmetric incremental sheet forming as shown in Fig. 50. A noticeable reduction of production 
time compared to asymmetric incremental sheet forming is possible. In comparison to asymmetric incremental sheet forming a more uniform thickness distribution with a reduced amount of maximum thinning can be achieved.
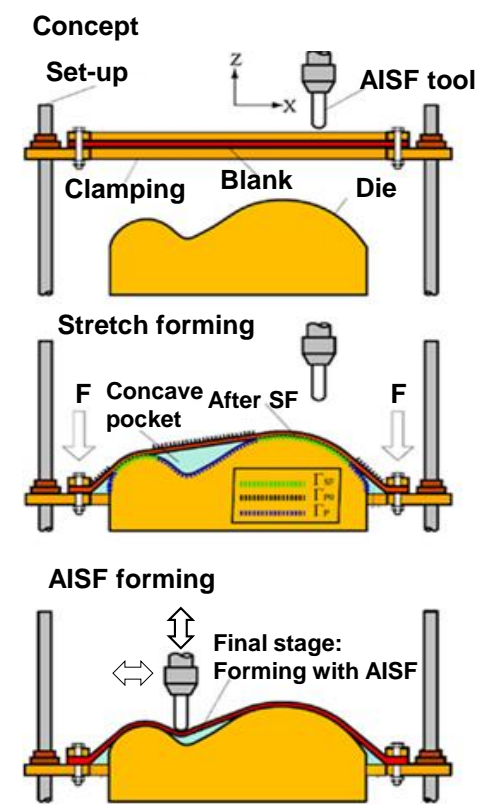

Fig. 50. Procedure of the process combination of stretch forming and incremental sheet forming [14]

The outcome of the investigations showed that, as a result of this combination of procedures, the process chain for manufacturing the two component variants was significantly shortened and it proved possible to reduce the number of forming tools required from 5 to 3 tools in each case.

As already described in chapter 4.1, one promising strategy is the use of a universal pre-forms for realization of part derivatives. Within a cooperation project, the basic feasibility of this approach was studied and verified taking a drive consoles as an example $[151,152]$.

A conventional deep-drawing operation was used to generate the universal preliminary form. The console derivatives (drive console left, drive console four-wheel drive) were subsequently realized by forming of component-specific areas based on incremental forming strategies (Fig. 51).

As one result of this approach, process route for manufacturing the two component variants was significantly shortened. Additionally, the number of forming tools required were reduced from 5 to 3 tools in each case.

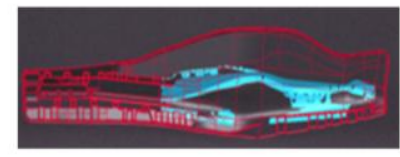

Part areas to be post-formed
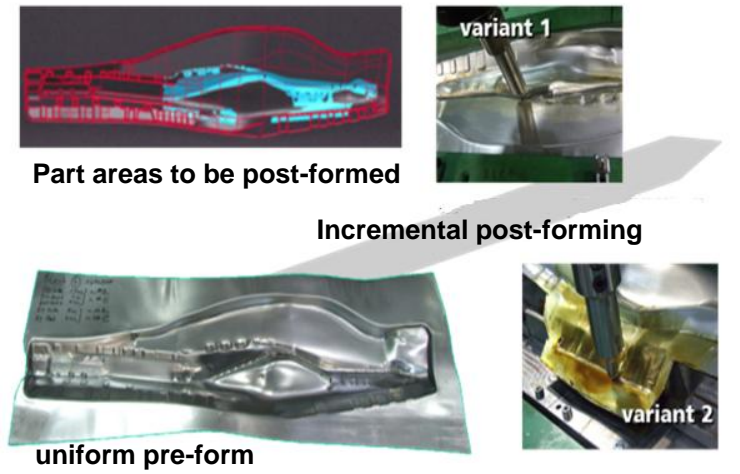

Fig. 51. Process combination "deep drawing - incremental sheet metal forming" [151, 152, 204]

\subsection{Combination of a forming process with non-forming processes}

4.3.1 Increase of flexibility by combining metal forming and additive manufacturing

Both in sheet and bulk metal forming, mass production processes are common which profit from the so-called economies of scale and cannot easily be scaled down to small-scale and individualized production. The cost structure of hot forging and additive manufacturing processes are fundamentally different. Hot forging processes use expensive dies, whose cost increase rapidly with part size and part complexity. Further downsides are that large forgings often are milled to the final product shape with a large volume of wasted material since the microstructure is only appropriate for the final application in a small portion of the workpiece. In the aerospace industry, hot forging is used to produce both structural parts as well as e.g. turbine blades. Hot forging thus offers various possibilities for the design of value chains in combination with additive manufacturing processes, e.g. the production of variants based on a generic shape made by forging to reduce material waste by milling.

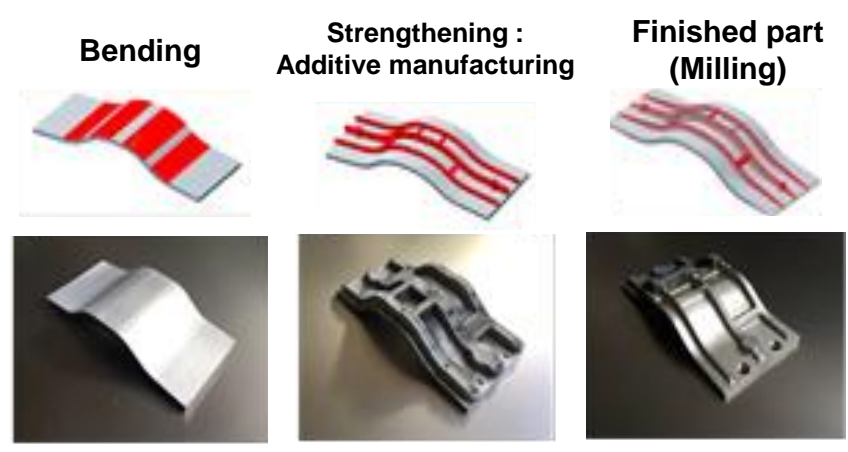

Fig. 52. Pre-form manufacturing and laser powder decomposition [18]

A demonstrator of such a laser assisted metal rapid tooling combination has been manufactured from an aluminum alloy AA6082 using bending as preforming operation and laser powder decomposition, Fig. 52 [18]. The part is a member used as crash reinforcement, typically manufactured by forging. To produce a single prototype, forging is not economically viable. Selective laser melting/sintering is an option but yields long processing times. By the combination of forming and additive manufacturing processes, the part can be produced with $\sim 30-40 \%$ of the time, cost and energy involved in 3DP of the entire part using selective laser melting/sintering. Hence, prototypes or considerable amount of products seem feasible with practical flexibility.

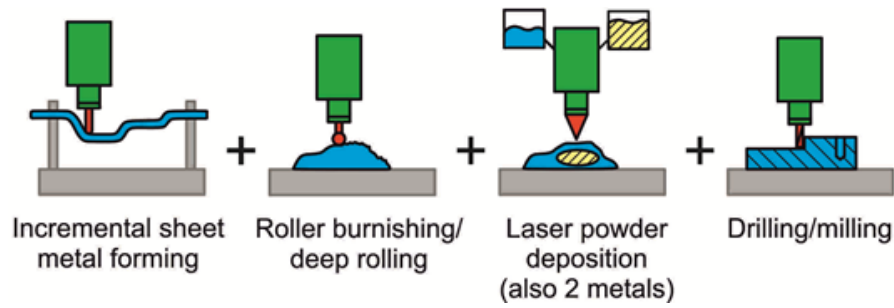

Fig. 53. Four manufacturing methods integrated in one machine [60]

Hölker et al. (2014) [60] developed a concept for the combined manufacturing of workpieces by incremental sheet metal forming and laser powder deposition in one setup (Fig. 53). Workpieces are formed incrementally in one step and in one machine (simultaneously, afterward, or in between) without reclamping. 
Geometrically complex elements can also be additively added by laser powder deposition on curved surfaces.

Furthermore, surface finishing by roller burnishing and deep rolling or drilling/milling can be carried out. Thus the rough surfaces resulting from the additive manufacturing process can be burnished. The process and the machine are based on a fiveaxis-machining center ("Lasertec 65 3D hybrid" from the company Sauer GmbH/DMG Mori), which can automatically pick up different tools:

- a forming tool for incremental sheet metal forming

- a rolling tool

- a nozzle for laser powder depositions

- a die for drilling/milling.

A challenge in using hot-forged parts for subsequent additive manufacturing is, in particular, that the microstructure, the residual stresses and the surface conditions of the semi-finished product will be influenced by the AM process, such that suitable process parameters (laser power, feed rate, etc.) need to be identified. The powder deposition process imposes a cyclic thermal load onto the preformed base material, which triggers both the creation of residual stresses as well as a complex microstructure evolution. In order to predict the microstructure evolution in $\mathrm{AM}$ and process combinations of $\mathrm{AM}$ and forming, models of substantial complexity need to be built.

4.3.2 Increase of flexibility by combining sheet metal forming with heating/heat treatment
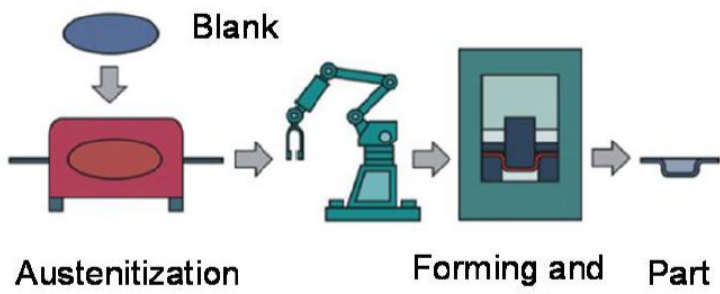

\section{Forming and Part quenching}

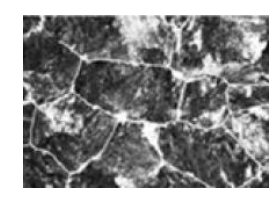

Austenite
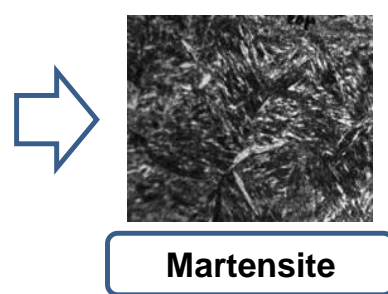

UTS $=1,500 \mathrm{MPa}$

Fig. 54. Schematic figure of the hot stamping process [76, 143]

Due to the interests of vehicle safety and crash requirements in the automotive industry, the use of ultrahigh-strength steels in structural and safety components is rapidly increasing [122]. However, ultra-high strength steel is hard to form at the room temperature due to the high forming load and low formability. Merklein and Lechler [133], Turetta et al. [200], and Bariani et al. [20] show that hot stamping is a good solution to a forming process for ultra-high strength sheets [134]. Hot stamping makes it possible to increase the formability of ultra-high strength steel $[149,186]$, to manufacture more complex shapes and to reduce springback to a minimum by elevating the cooling temperature $[76,143]$. Fig. 54 shows a typical hot stamping process and some automotive applications which are demonstrated by Karbasian and Tekkaya [76].
Among the hot stamping studies, researches works on heating sources have been carried out. Mori et al. [143] showed controllability of the temperature in sheet forming using resistance heating. Resistance heating is one of the most effective heating solutions. Behrens et al. investigated another practical solution of resistance heating for bigger parts [24]. By employing resistance heating, large furnaces are replaced with a power supply. The heating time of the resistance heating requires several seconds, therefore, it is synchronised with holding for die quenching as shown in Fig. 55 [140].

In addition, various heating methods such as induction heating and contact heating are employed on the hot stamping in order to heat the sheet metal effectively [137]. Landgrebe et al. [101]. developed a contact-heating device of sheet metal for hot stamping In the case of hot stamping, Kolleck et al. [87] employed induction heating which brings in the benefit of high heating rates in order to avoid grain coarsening while heating in a short time.

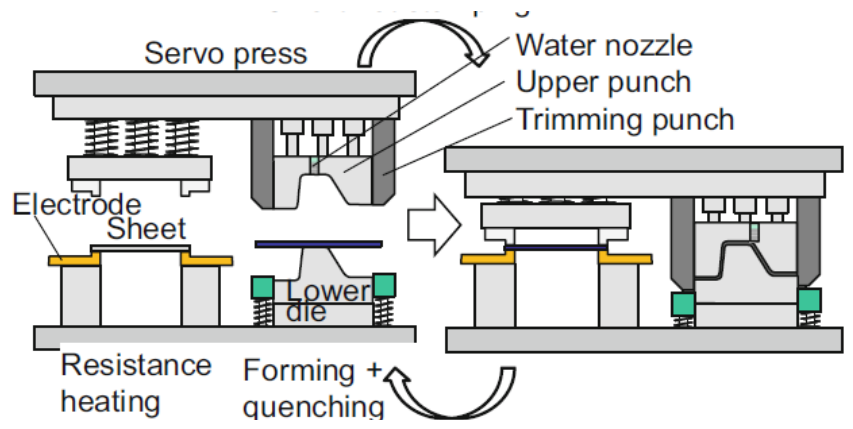

Fig. 55. Smart hot stamping having resistance heating, quenching, servo press and hot trimming [140]

\section{Flexibility by forming $M / C$, system and software operation}

\subsection{Flexibility of Machine operation}

Forming machines are expensive producer durable goods. Provided that they are designed and manufactured in an adequate way their productive lifetime is usually significantly longer than the period of a company's product program planning. Consequently, specifications of forming machines have to anticipate uncertain changes of customer and market requirements. Most forming machines are not designated to manufacture only one specific product, but a limited number of product classes. These classes of products are also termed part families [79]. Although a general definition of part family is missing [79], products produced by metal forming can be assigned to one class when the type of forming process is the same and the tool dimensions as well as the required power and the tool movements range between certain limits. Flexibility of a machine is predefined by the selection of the limits. These limits determine the dimensioning of a forming machine and are the result of a trade-off between flexibility and cost of a machine.

While the aforementioned considerations exist since the first metal forming machines have been designed, new requirements arose in the last decades [104]. Changes in social requirements, consumer behaviour and market conditions necessitate new kinds of flexibility. These kinds of flexibility consider the following requirements in view of machine operation:

1) Lot sizes for machine operation The demand for customized and short-term available products is contradictory to efficient large volume 
forming processes which need long lead times for tool manufacture and process set-up.

2) Shifted process limits in machine operation

New products can be created by overcoming limitations resulting from characteristics of large scale processes. Extended geometrical freedom and improved operating conditions are of special interest.

3) Rearrangement of process chains

Metal forming machines are either used for the production of single components or joining operations. Compared to other manufacturing operations their cycle time is often much shorter. Since modern material flow optimizations minimize storages, multi technology machine-tools for forming and other operations are of high interest.

Two major design principles are used to attain forming machines with these increased flexibilities: improved control of the machine movements and increased number of driven axes. Both approaches are used for forming machines with rotating or translational moving tools.

An improved control of the machine axes can be achieved by servo-drives. They can either serve as direct drives [155] or as additional actuators [215]. Numerous examples show the advantages of this approach for presses [155]. The speed of the ram can be adjusted to the specific requirements. In consequence, set-up times can be reduced [203], process limits can be extended e.g. by using a pulsating or oscillating slide motion [155], noise emission can be reduced [51] and additional manufacturing operations can be integrated into the forming process, see Fig. 56 [51]. Similar benefits have also been achieved in machines with rotating movements. By using a start-stop mode in roll forming the continuous operation is stopped at specific points and additional manufacturing steps like stamping, joining or sawing are carried out [1]. Thus, additional manufacturing processes can be integrated into the roll forming line without major investment and storage of intermediate products is avoided.

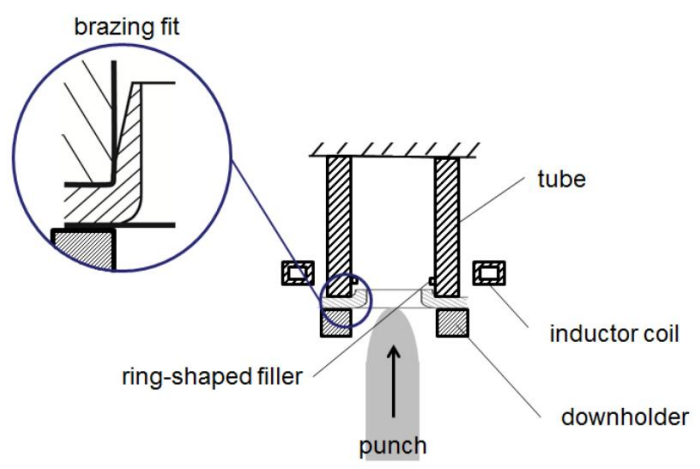

Fig. 56. Design of a combined forming and brazing process [15]

An increased number of driven axes allows for forming machines with more freedom in the relative movement between tools and workpieces. This freedom of tool movement can be used to shape the specific geometry of a workpiece by driving the tools along specific paths. It opens the possibility to customize products and shift geometrical limits of existing processes by using tool paths which lead to advantageous states of stresses or forming zones. Customization is achievable without mechanical changes but only by changing parameters in the CNC control

According to the previous study [167], this property of a manufacturing system is called "reusability". Since the product geometry is determined by the tool's geometry and the relative movement between tool and workpiece tools can be kept geometrically simpler and do not have to include all geometrical features of the product geometry.

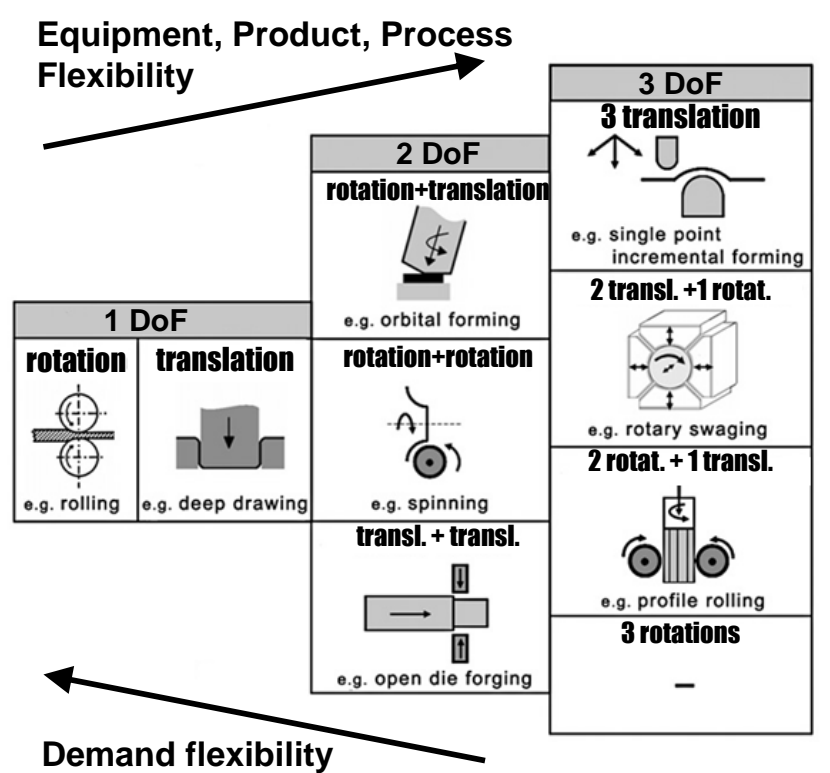

Fig. 57. Classification of forming processes [54]

On the other hand, longer tool paths prolongate production time and therefore reduce demand flexibility, if larger quantities are required. A classification of forming processes according to the necessary degrees of freedom for the tool movements is shown in Fig. 57.

Several authors have studied possibilities to find beneficial compromises between the high productivity of forming machines with low flexibility and the low productivity of those machines with high flexibility.

Adding more degrees of freedom (DoF) to a 1 DoF process with rotating tools permits for products with varying thickness and cross sections. Kopp et al developed rolling processes for strips with defined thickness distributions in lengthwise or crosswise direction [88, 90]. These technologies make use of roll adjustments in the thickness or transverse direction.

Increased flexibility of machines is required when these sheets are used in subsequent forming operations [25]. In roll forming a continuous adjustment of the gaps between the rolls is necessary.

This leads to machines with at least one more translational drive. Adding a translational and a rotational DoF to conventional roll forming or linear flow splitting mills enables the production of profiles with varying cross sections in longitudinal direction $[56,153]$. While the additional degrees of freedom open up new possibilities for geometrical flexibility they create new challenges at the same time. Non-steady states of deformations and loads create deviations in shape which have to be counteracted. Beiter [25] showed that roll forming of flexible rolled strips can be used to create profiles with load optimised cross sections. But due to the different thicknesses spring back and the position of the neutral axis are changing in lengthwise direction. This requires additional adjustments which can be carried out by closed loop controlled operations [6].

Adding more degrees of freedom to a 1 DoF process with translationally moved tools permits the implementation of both, press operations and incremental processes like orbital or single point incremental forming (Fig. 58).

One approach is the installation of a separate device for the additional movement patterns (Fig. 58 left) [50]. Alternatively, the main drive can be split into independent drives (Fig. 58 right). Then, all drives can support all kind of operation modes [54]. By 
changing the control parameters for the individual drives a conventional press stroke as well as tool trajectories in several DoF are possible.

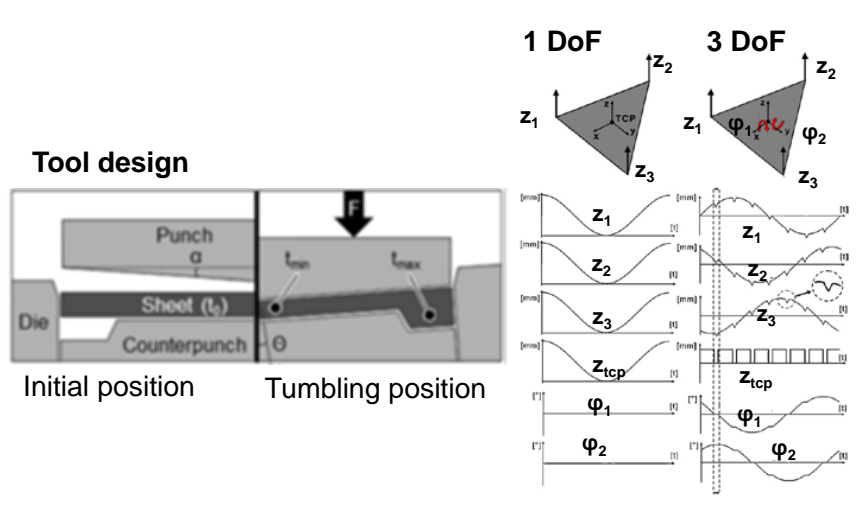

Fig. 58. Increased number of DoF by additional drives: left: additional device [50], right: split drive system [54]

Free forging of integrated press and multi-axis freedom robot have been investigated. Lilly and Melligeri [115], Kopp and Beckmann [89] studied the effect of integrated press and multiaxis freedom robot. Akasaki et al. [4] studied metal flow in lateral and axial directions, and manipulation of the workpiece. Wang et al. [203] studied the effects of the incremental bulk forging by integrating a 6-axial freedom robot and an 80 -ton link servo press. By integrating 6-axis robot and servo-press, the incremental forging process have high flexibility in the forming process of complex product with some simple tools. The optimized forming process of an arbitrary shape and process condition has been studied numerically and experimentally.

The conventional metal forming process has been characterized by a high productivity for mass production. This characteristics of the metal forming process leads to a rigid product and process spectrum [161]. The mechanical servo press improves the flexibility of the metal forming process with the speed, accuracy and reliability as well as with improved formability[155].

The major challenge for the design of flexible forming machines is the bridging of the gap between high flexibility and low productivity on the one and low flexibility and high productivity on the other side. One approach could be the multiple use of the installed drives in a forming machine: power increase in lower DoF mode and extension of motion pattern for higher DoF modes [54]. One other approach is the combination of multiple flexible machines like demonstrated in $[203,206]$.

\subsection{Flexibility for smart system operation}

The geometric inaccuracy arises mainly from the accumulation of elastic springback in the sheet metal during forming (local springback) and the global springback after unclamping (global springback) [124]. To overcome this difficulty, effort has been put into modifying the toolpath prior to the physical experiment and applying the pre-described toolpath in an open-loop manner to reduce the geometric deviation. The most common of these efforts include: non-z-level feature-based slicing [118] and multipass strategy $[19,75]$.

Additionally, closed loop control has been used most extensively to control errors in geometry (including springback). An adaptive control scheme for the multi-axis bending and twisting process based on system identification of process models was presented by Sun et al. [192] as shown in Fig. 59. The shape errors between the intrinsic geometric quantities of the actual and desired parts are applied to the inverse identified process models to calculate incremental changes in axis commands for subsequent iterations.

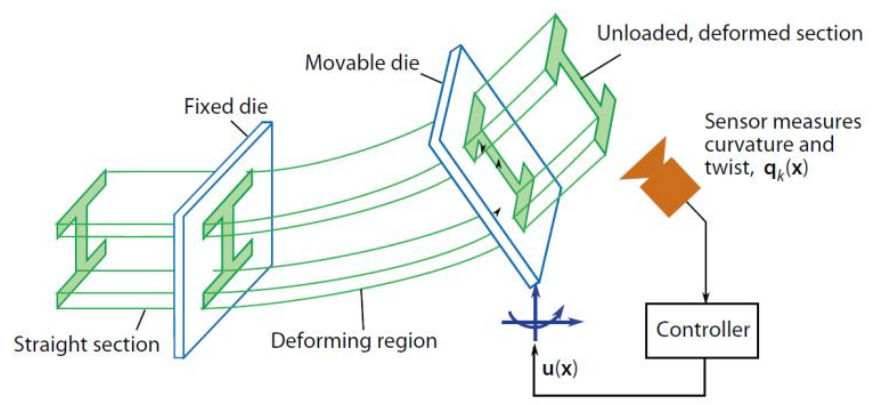

Fig. 59. Multi-axis bending and twisting [192]

Filice et al. [10] tried to form a cone with a larger wall angle to compensate for springback. To generalize this approach, Behera et al. [23] proposed a feature-based framework to automatically detect different features for a complex geometry.

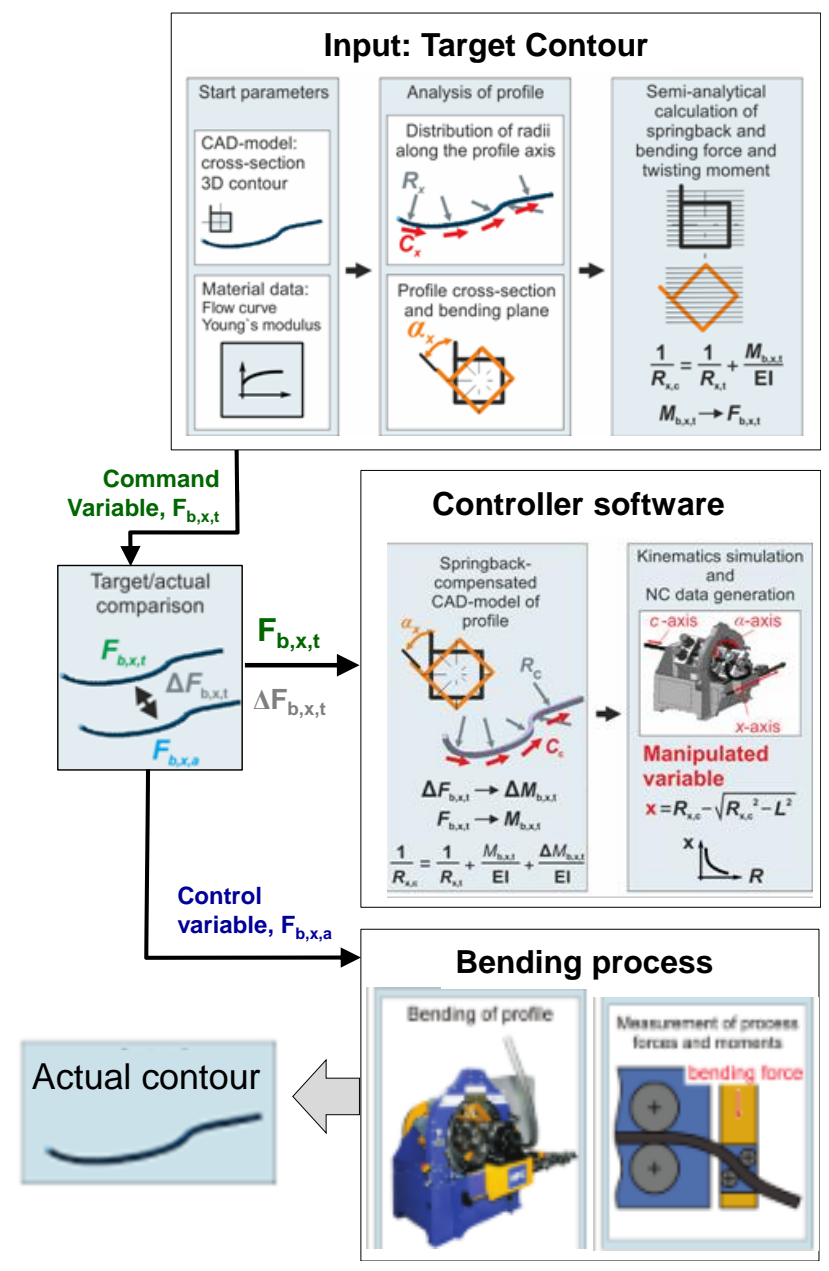

Fig. 60. Closed loop control of 3D profile bending [189]

While the new kinematic profile bending processes offers a great flexibility in production, kinematic bending these processes cause a high part springback and as a result, in the need for compensatory methods are needed to achieve target contours. Chatti et al. [28] developed a model for springback compensation of profiles with 3D bending lines to generate NC data prior to the actual bending process. Staupendahl and Tekkaya [188] noticed that the control of the orientation of the cross-section during 3D 
profile bending results in shear stresses in addition to the bending stresses and affect part springback. They presented an analytical model to predict the distribution of bending stresses as well as shear stresses over the cross section and use it in bending moment and springback calculations. Material variations inside a batch, however, cannot be detected and cause contour deviations. To counter this error, a closed-loop control system can be used, which can quickly adapt axes' movements to produce target shapes and thus reduce scrap. Staupendahl et al. [189] applied developed the closed loop control concepts tofor 3D profile bending. Using the Torque Superposed Spatial profile bending process as an example they described a method for direct closed loop control, using the measured curvature after springback as a control variable, and an indirect method, using the bending force as a control variable as shown in Fig. 60.

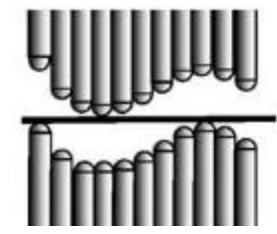

Initial state

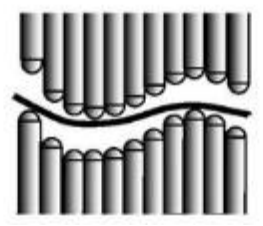

Intermediate state

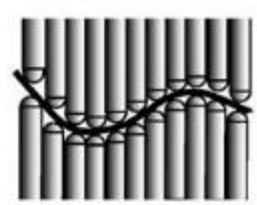

Final state
Fig. 61. Flexible forming with digitized die [112]

Digitized-die forming (DDF) is a flexible manufacturing technology through which a variety of three-dimensional sheet metal parts can be produced in a DDF system [112] shown in Fig. 61. It eliminates the need to design and produce the conventional die [113]. The central component of DDF system is a pair of matrices of punches, the punches are controlled by computer and the desired shape of die is constructed by changing the heights of punches. Based on the flexibility of DDF, new forming processes are designed that cannot be realized in conventional stamping.

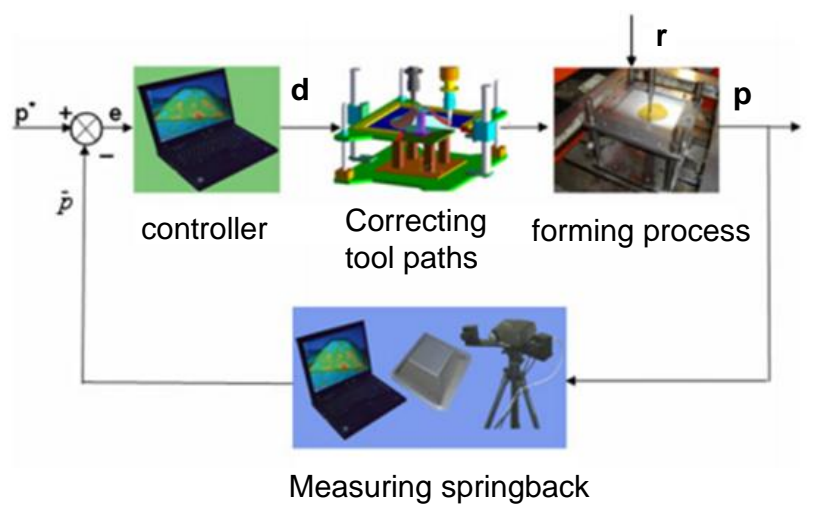

Fig. 62. Tool path design of incremental forming [43]

However, the determination of the value of the deviations from the desired shape is mostly empirical, and the application is confined with respect to the complexity of the desired geometry and the model accuracy. In the contrary to the aforementioned open-loop geometric profile error compensation methods, other research works are focused on the development of an effective closed-loop toolpath correction algorithm based on the optical measurement of the different part shapes, so that any discrepancy will be compensated iteratively. In 2005, Hirt et al. [67] proposed using the off-line scanned geometry to compensate for geometric errors. Following the same philosophy, Rauch et al. [165] combined B-spline and morphing techniques with the compensation algorithm to enhance the model capability regarding complex geometric features. Fu et al. utilized a wavelet transformation to determine the compensation function, and parts of the physical iteration process for their algorithm are supplemented with numerical simulations to reduce the possible experimental cost as shown in Fig. 62 [43].

Although the aforementioned methods are geometry independent, the efficiency of these off-line compensation methods are all still limited by the multiple physical or numerical iterations required in the algorithm. Thus, an online compensation method has been proposed with the combination of the optimal control theory and an online stereo-vision geometric measurement system [9]. The proposed framework is further extended to the general part geometry [63]. Fiorentinno et al. [40] also proposed an artificial cognitive system based on the Iterative Learning Control (ILC) to modify the target geometry at discrete time steps.

\section{Summary and future prospects}

Metal forming products are key components in various industries. The manufacturing and market environment has necessitated the increase of flexibility to tackle the problems of market-responsiveness and manufacturing competitiveness. In the future, flexibility will continue to increase.

In this work, taking into account the current state of the art and future trend as well, flexibility in forming is classified in terms of increased degree of freedom, physical parameter variation, process combination and flexibilization of operation for machine, structure, system and software.

As an important means of increased degree of freedom, various incremental forming processes have been reviewed. It is expected to have the expansion of application of incremental sheet forming processes in the automobile industry, due to the increasing number of car models with diversified designs. The use of very simple undevoted tools in sheet manufacture is advantageous in forming complicated parts with incoming new information and electronic technologies. To make incremental forming more flexible, multiple tools and robotic assistance have been introduced in various incremental forming processes with the aid of more precise automatic control and advanced sensor techniques. Hard-to-form materials are more and more used for light weight construction and incremental forming is conveniently employed by applying heat at the desired areas, which would open a new potential once the temperature can be properly controlled during the process.

Long channel-like products or large 3D-rolled plates or sheets are good success examples of flexible roll forming; flexible roll forming and roll forming of large plates with generally curved surface. With further refinement of advanced tooling schemes for better geometric control of the products, more practical applications would be expected to be developed.

Generally curved tubes, round or noncircular, are formed by die-less incremental bending with properly devised tools. Large tubes or channels can be formed with simple tools by incremental forming using heat properly.

Incremental bulk forming has long been used by discretely incremental forming schemes for small and large products at cold or hot state. The use of robots in forging machine (press) or specialized CNC controlled incremental radial and/or axial flexible forming machine have been developed to make geometrically complex parts including rings.

Flexibility in forming can be effectively enhanced by varying physical parameters such as new geometric variation even for continuous forming process such as in plate rolling. This type of flexibility is important in manufacturing light weight products to have increased strength in some desired direction or region. The 
change of thickness in some specific direction in the rolling process and various tailored blank preparation by introducing different thickness at the desired location enables the customized material strengthening of products.

Flexibility can also be achieved by material disposition using different materials by introducing joining either by welding or forming, resulting in differentiated local strength. Another type of material disposition is to introduce a sandwich structure with skin sheets and inner core material for the purpose of light weight construction. It is expected to introduce innovative design and manufacture of inner structure or new materials with good bondability and reasonable formability for widened practical application of light weight products in the industry.

3D printing of metals has introduced flexibility in making metallic products and especially dies/molds for complicated geometry with diversified high grade materials. New materials and innovative 3D printing technology would further extend the application areas of 3D printing as extended concept of forming products for facilitated increase of flexibility.

The use of local or incremental heating is found to be an effective method for tailor tempered metal sheets either in conventional forming or in incremental forming as a means of flexibility increase. Tailored tempering gives flexibility in keeping the high strength in the untempered zone and high shock absorbing capability in the tempered zone. Flexible local heating in conventional forming or in incremental forming such as in spinning, roll forming or pointed tool incremental forming by laser, gas heating, resistance heating, or infrared heating showed increased formability.

Process combination increases flexibility in various ways in metal forming either by combining between conventional forming processes or combining a conventional forming process with an incremental forming process. Since incremental forming takes a long time, incremental forming can be successfully combined with stretch forming or with deep drawing with good advantages, saving the whole processing time. The combination of sheet forming and bulk forming has been successfully tried creating new products with desired properties: forging or tooth forming after sheet metal forming, precision forging after deep drawing, etc.

Metal forming can be also combined with non-forming process such as additive manufacturing opening up a good future possibilities. Preform manufactured by sheet forming was conveniently combined with laser assisted 3D printing reducing the tool manufacturing time, cost and significantly.

Flexibility in forming can be considered from the systemic viewpoint of forming machine, system and related software even for the existing machines. In order to increase the flexibility (mostly geometrical) for the same machine principle, the degree of freedom of the machine should be increased. The increased degree of freedom requires more refined control of the machine to ensure the desirable quality of the product. The servo-press or 3D servo-press provides higher flexibility for forming of complex parts with accuracy, productivity and reliability. The flexible change of forming schedule in servo press through more advanced forming path control has enabled flexible manufacture of complex products. The challenge coming from the conflict between flexibility and flexibility can be tackled either by multiple use of the installed drives or combination of multiple flexible machines.

As mentioned before, the increased degree of freedom by newly adding moving device or die requires advanced adaptive closed loop control scheme to control the geometry precisely.

As shown in this review, numerous flexible forming processes have been developed up to the present day. Some processes readily found their way into industrial application. Examples are flexible rolling processes, open die forging as well as tube bending processes. Flexibilization of a forming process seems industrially viable for a certain range of product spectrum when the introduction of additional degrees of freedom does not sacrifice productivity, typically as in the case for flexible rolling processes. In addition, the loss in productivity caused by flexibilization is leveled by the added value of the individualized product as can be found in aerospace and military applications as well as in production of customized premium consumer goods. Another successful application for flexible forming may be that workpieces are too large to be deformed by dedicated dies. Examples are open die forging and incremental bending of plates for production of large-scale tubes. Several flexible processes use the plastic deformation of primary actuators, which plastically deform the parts cross section, to introduce secondary actuators, which flexibly bend or twist the plastically deformed cross section to accommodate more part shape complexity; for example, open-die forging with combined bending and twisting as well as 3D bending of tubes and profiles. Shape complexity has been greatly enhanced by introducing incremental forming processes which maximizes degree of freedom, especially in sheet forming, while sacrificing the productivity or lot size capability.

However, further flexibility can be secured with increased productivity by introducing physical parameter variation, which can be achieved effectively through geometric variation, material disposition and local heating, etc. The possibility of controlling the product properties and the level of productivity is open to further innovation. Flexibility and productivity obviously are often conflicting requirements in forming processes. Innovation of processes is, therefore, greatly required to make compromise between flexibility and productivity or to make destructive innovation and breakthrough. Future research directions in flexible discontinuous forming processes should focus on redesigning and flexibilizing dedicated tooling towards actuated systems, thus introducing flexibility with minimally sacrificing productivity. Great potentials can be also sought by introducing combination of processes, i.e. either by combining between conventional processes or combining a conventional forming process with a flexible forming process, or by combining a forming process with a non-forming process, still demanding creative endeavour.

Various approaches are being tried to increase flexibility through flexibilization of machines, intelligent machine system and machine-operating softwares. Greater innovative potentials lie in more effective introduction and use of artificial intelligence.

Even in mass production system, for example, continuous forming system such as rolling system will depend on the progress of distributed process control. Besides industrial demands, there are numerous applications were productivity does not play a central role, e.g. in the production of customized consumer goods. With the advent of industry 4.0 and increasing connectivity of customers and production processes requiring more flexibility, flexible forming processes and methodologies could find various new applications in the individualization of products.

\section{Conclusions}

The manufacturing and market environment has necessitated the increase of more flexibility to tackle with the problems of marketresponsiveness and manufacturing competitiveness. In this paper, taking into account the current state of the art and future trend as well, flexibility in forming is extensively treated and discussed in terms of increased degree of freedom, physical parameter variation, process combination and flexibilization of operation for machine, structure, system and software. It is expected to develop more relevant technologies to enhance the 
flexibility to meet mass customization and on-demand manufacturing requirements with desirable productivity.

\section{Acknowledgements}

The authors would like to gratefully acknowledge the kind contributions and assistance of Prof. J.M. Alwood, University of Cambridge, Prof. S. Bruschi, University of Padua, Dr. A. Ghiotti, University of Padova, Prof. M. Liewald, University of Stuttgart, and Prof. W. Volk, Technical University of Munich through special session presentations for flexibility in forming and informative discussions.

\section{References}

[1] Abele, E., Stein M. S. S. Joint cutting and forming processes for multi-chambered sheet metal profiles. Proceedings of the 9th international Conference on Technology of Plasticity. 2008:767-8.

[2] Ahmetoglu, M. A., Brouwers D., Shulkin L., Taupin L., Kinzel G. L., Altan T. Deep drawing of round cups from tailor-welded blanks. Journal of Materials Processing Technology. 1995;53:684-94.

[3] Ahn, D.-G. Applications of laser assisted metal rapid tooling process to manufacture of molding \& forming tools - state of the art. International Journal of Precision Engineering and Manufacturing. 2011;12:925.

[4] Aksakal, B., Osman F. H., Bramley A. N. Determination of experimental axial and sideways metal flow in open die forging. Materials \& Design. 2008:29:576-83.

[5] Al-Obaidi, A., Kräusel V., Landgrebe D. Hot single-point incremental forming assisted by induction heating. The International Journal of Advanced Manufacturing Technology. 2016;82:1163-71.

[6] Allwood, J., Duncan S., Cao J., Groche P., Hirt G., Kinsey B., Kuboki T., Liewald M. Sterzing A., Tekkaya A. Closed-loop control of product properties in metal forming. CIRP Annals-Manufacturing Technology. 2016;65:573-96.

[7] Allwood, J., Kopp R., Michels D., Music 0., Öztop M., Stanistreet T., Tekkaya A Tiedemman I. The technical and commercial potential of an incremental ring rolling process. CIRP Annals-Manufacturing Technology. 2005;54:233-6.

[8] Allwood, J., Utsunomiya H. A survey of flexible forming processes in Japan International Journal of Machine Tools and Manufacture. 2006;46:1939-60.

[9] Allwood, J. M., Music O., Raithathna A., Duncan S. R. Closed-loop feedback control of product properties in flexible metal forming processes with mobile tools. CIRP Annals - Manufacturing Technology. 2009;58:287-90.

[10] Ambrogio, G., Costantino I., De Napoli L., Filice L., Fratini L., Muzzupappa M Influence of some relevant process parameters on the dimensional accuracy in incremental forming: a numerical and experimental investigation. Journal of Materials Processing Technology. 2004;153:501-7.

[11] Ambrogio, G., Filice L., Gagliardi F. Formability of lightweight alloys by hot incremental sheet forming. Materials \& Design. 2012;34:501-8.

[12] Ambrogio, G., Filice L., Manco G. L. Warm incremental forming of magnesium alloy AZ31. CIRP Annals - Manufacturing Technology. 2008;57:257-60.

[13] Araghi, B. T., Göttmann A., Bambach M., Hirt G., Bergweiler G., Diettrich I. Steiners M., Saeed-Akbari A. Review on the development of a hybrid incremental sheet forming system for small batch sizes and individualized production. Production Engineering. 2011;5:393-404

[14] Araghi, B. T., Manco G. L., Bambach M., Hirt G. Investigation into a new hybrid forming process: Incremental sheet forming combined with stretch forming. CIRP Annals - Manufacturing Technology. 2009;58:225-8.

[15] Avemann, J., Calmano S., Schmitt S., Groche P. Total Flexibility in Forming Technology by Servo Presses. Advanced Materials Research. 2014;907:99-112.

[16] Awiszus, B., Härtel S. Numerical simulation of non-circular spinning: a rotationally non-symmetric spinning process. Production Engineering. 2011;5:60512.

[17] Awiszus, B., Meyer F. Metal spinning of non-circular hollow parts. Proceedings of the 8th International Conference on Technology of Plasticity2005. p. 353-5.

[18] Bambach, M. Recent Trends in Metal Forming: From Process Simulation and Microstructure Control In Classical Forming Processes to Hybrid Combinations Between Forming and Additive Manufacturing. Journal of Machine Engineering. 2016;Vol. 16, No. 2:5-17.

[19] Bambach, M., Araghi B. T., Hirt G. Strategies to improve the geometric accuracy in asymmetric single point incremental forming. Production Engineering. 2009;3:145-56.

[20] Bariani, P. F., Bruschi S., Ghiotti A., Turetta A. Testing formability in the hot stamping of HSS. CIRP Annals - Manufacturing Technology. 2008;57:265-8.

[21] Becker, C., Staupendahl D., Hermes M., Chatti S., Tekkaya A. E. Incremental Tube Forming and Torque Superposed Spatial Bending-A View on Process Parameters. STEEL RESEARCH INTERNATIONAL. 2012:415-8.

[22] Becker, C., Tekkaya A. E., Kleiner M. Fundamentals of the incremental tube forming process. CIRP Annals - Manufacturing Technology. 2014;63:253-6. [23] Behera, A. K., Lauwers B., Duflou J. R. Tool path generation framework for accurate manufacture of complex 3D sheet metal parts using single point incremental forming. Computers in Industry. 2014;65:563-84.
[24] Behrens, B., Hübner S., Demir M. Conductive heating system for hot sheet metal forming. 1st International Conference on Hot Sheet Metal Forming of HighPerformance Steel, Kassel, Germany2008. p. 63-8.

[25] Beiter, P., Groche P. On the development of novel light weight profiles for automotive industries by roll forming of tailor rolled blanks. Key Engineering Materials: Trans Tech Publ; 2011.p. 45-52.

[26] Cai, Z.-Y., Sui Z., Cai F.-X., Liu L. Continuous flexible roll forming for threedimensional surface part and the forming process control. The International Journal of Advanced Manufacturing Technology. 2013;66:393-400.

[27] Carruth, M. A., Allwood J. M. The development of a hot rolling process for variable cross-section I-beams. Journal of Materials Processing Technology. 2012;212:1640-53.

[28] Chatti, S., Hermes M., Tekkaya A. E., Kleiner M. The new TSS bending process: 3D bending of profiles with arbitrary cross-sections. CIRP Annals - Manufacturing Technology. 2010;59:315-8

[29] Cleaver, C. J., Arthington M. R., Mortazavi S., Allwood J. M. Ring rolling with variable wall thickness. CIRP Annals - Manufacturing Technology. 2016;65:281-4

[30] Cui, X., Li J., Mo J., Fang J., Zhou B., Xiao X., Feng F. Incremental electromagneticassisted stamping (IEMAS) with radial magnetic pressure: A novel deep drawing method for forming aluminum alloy sheets. Journal of Materials Processing Technology. 2016;233:79-88.

[31] Cui, X., Mo J., Li J., Xiao X., Zhou B., Fang J. Large-scale sheet deformation process by electromagnetic incremental forming combined with stretch forming. Journal of Materials Processing Technology. 2016;237:139-54.

[32] Davarpanah, M. A., Mirkouei A., Yu X., Malhotra R., Pilla S. Effects of incremental depth and tool rotation on failure modes and microstructural properties in Single Point Incremental Forming of polymers. Journal of Materials Processing Technology. 2015;222:287-300.

[33] Duflou, J., Verbert J., Belkassem B., Gu J., Sol H., Henrard C., Habraken A. Process window enhancement for single point incremental forming through multi-step toolpaths. CIRP Annals-Manufacturing Technology. 2008;57:253-6.

[34] Duflou, J. R., Callebaut B., Verbert J., De Baerdemaeker H. Improved SPIF performance through dynamic local heating. International Journal of Machine Tools and Manufacture. 2008;48:543-9.

[35] Duflou, J. R., Callebaut B., Verbert J., De Baerdemaeker H. Laser Assisted Incremental Forming: Formability and Accuracy Improvement. CIRP Annals Manufacturing Technology. 2007;56:273-6.

[36] Emmens, W. C., Sebastiani G., van den Boogaard A. H. The technology of Incremental Sheet Forming-A brief review of the history. Journal of Materials Processing Technology. 2010;210:981-97.

[37] Fan, G., Gao L., Hussain G., Wu Z. Electric hot incremental forming: A novel technique. International Journal of Machine Tools and Manufacture. 2008;48:168892.

[38] Fang, Y., Lu B., Chen J., Xu D. K., Ou H. Analytical and experimental investigations on deformation mechanism and fracture behavior in single point incremental forming. Journal of Materials Processing Technology. 2014;214:1503-15.

[39] Filice, L., Ambrogio G., Micari F. On-line control of single point incremental forming operations through punch force monitoring. CIRP annals-Manufacturing technology. 2006;55:245-8.

[40] Fiorentino, A., Feriti G. C., Giardini C., Ceretti E. Part precision improvement in incremental sheet forming of not axisymmetric parts using an artificial cognitive system. Journal of Manufacturing Systems. 2015;35:215-22.

[41] Ford, S., Despeisse M. Additive manufacturing and sustainability: an exploratory study of the advantages and challenges. Journal of Cleaner Production. 2016;137:1573-87.

[42] Frazier, W. E. Metal Additive Manufacturing: A Review. Journal of Materials Engineering and Performance. 2014;23:1917-28.

[43] Fu, Z., Mo J., Han F., Gong P. Tool path correction algorithm for single-point incremental forming of sheet metal. The International Journal of Advanced Manufacturing Technology. 2013;64:1239-48

[44] Furushima, T., Manabe K. A novel superplastic dieless drawing process of ceramic tubes. CIRP Annals - Manufacturing Technology. 2017;66:265-8.

[45] Gantner, P., Bauer H., Harrison D. K., De Silva A. K. M. Free-Bending-A new bending technique in the hydroforming process chain. Journal of Materials Processing Technology. 2005;167:302-8.

[46] Gatea, S., Ou H., McCartney G. Review on the influence of process parameters in incremental sheet forming. The International Journal of Advanced Manufacturing Technology. 2016;87:479-99.

[47] Geiger, M., Merklein M., Kerausch M. Finite Element Simulation of Deep Drawing of Tailored Heat Treated Blanks. CIRP Annals - Manufacturing Technology. 2004;53:223-6

[48] Geiger, M., Sprenger A. Controlled Bending of Aluminium Extrusions. CIRP Annals - Manufacturing Technology. 1998;47:197-202.

[49] Goodarzi, M., Kuboki T., Murata M. Deformation analysis for the shear bending process of circular tubes. Journal of Materials Processing Technology. 2005;162:492-

[50] Gröbel, D., Schulte R., Hildenbrand P., Lechner M., Engel U., Sieczkarek P., Wernicke S., Gies S., Tekkaya A. E., Behrens B.-A. Manufacturing of functional elements by sheet-bulk metal forming processes. Production Engineering. 2016;10:63-80.

[51] Groche, P., Brüninghaus, G. and Avemann, J. . Wandlungsfähige Blechumformung. Möglichkeiten der Servopressen-Technologie Ludwigsburg: LOG_X 2015.

[52] Groche, P., Fritsche D., Tekkaya E. A., Allwood J. M., Hirt G., Neugebauer R. Incremental Bulk Metal Forming. CIRP Annals - Manufacturing Technology. 2007;56:635-56 
[53] Groche, P., Mirtsch M. Tailored Profiles Made of Tailor Rolled Strips by Roll Forming - Part 2 of 2. steel research international. 2012;83:106-14.

[54] Groche, P., Scheitza M., Kraft M., Schmitt S. Increased total flexibility by 3D Servo Presses. CIRP Annals - Manufacturing Technology. 2010;59:267-70.

[55] Groche, P., Von Breitenbach G., Jockel M., Zettler A. New tooling concepts for future roll forming applications. Proc ICIT2003.

[56] Groche, P., Zettler A., Berner S., Schneider G. Development and verification of a one-step-model for the design of flexible roll formed parts. International Journal of Material Forming. 2011;4:371-7.

[57] Grzancic, G., Becker C., Hermes M., Tekkaya A. E. Innovative machine design for incremental profile forming. Key Engineering Materials: Trans Tech Publ; 2014. p. 413-9.

[58] Grzancic, G., Becker C., Khalifa N. B. Basic Analysis of the Incremental Profile Forming Process. Journal of Manufacturing Science and Engineering. 2016;138:091002--6.

[59] Guo, N., Leu M. C. Additive manufacturing: technology, applications and research needs. Frontiers of Mechanical Engineering. 2013;8:215-43.

[60] Hölker, R., Ben Khalifa N., Tekkaya A. E. Process and Apparatus for the Combined Manufacturing of Workpieces by Incremental Sheet Metal Forming and Manufacturing Methods in One Set-up. German Patent Application, DE 102014014 2027, 2014. 2014.

[61] Hagan, E., Jeswiet J. A review of conventional and modern single-point sheet metal forming methods. Proceedings of the Institution of Mechanical Engineers, Part B: Journal of Engineering Manufacture. 2003;217:213-25.

[62] Halevi, G., Weill R. Principles of process planning: a logical approach: Springer Science \& Business Media; 2012

[63] Hao, W., Duncan S. Optimization of tool trajectory for Incremental Sheet Forming using closed loop control. 2011 IEEE International Conference on Automation Science and Engineering2011. p. 779-84.

[64] Hermes, M., Chatti S., Weinrich A., Tekkaya A. E. Three-Dimensional Bending of Profiles with Stress Superposition. International Journal of Material Forming. 2008;1:133-6

[65] Herrmann, M., Schenck C., Kuhfuss B. Dry Rotary Swaging with Structured Tools. Procedia CIRP. 2016;40:653-8.

[66] Herzog, D., Seyda V., Wycisk E., Emmelmann C. Additive manufacturing of metals. Acta Materialia. 2016;117:371-92.

[67] Hirt, G., Ames J., Bambach M., Kopp R. Forming strategies and process modelling for CNC incremental sheet forming. CIRP Annals-Manufacturing Technology. 2004;53:203-6.

[68] Hirt, G., Dávalos-Julca D. H. Tailored Profiles Made of Tailor Rolled Strips by Roll Forming - Part 1 of 2. steel research international. 2012;83:100-5.

[69] Hu, Z., Li J. Q. Computer simulation of pipe-bending processes with smal bending radius using local induction heating. Journal of Materials Processing Technology. 1999;91:75-9.

[70] Huang, Y., Leu M. C., Mazumder J., Donmez A. Additive Manufacturing: Current State, Future Potential, Gaps and Needs, and Recommendations. Journal of Manufacturing Science and Engineering. 2015;137:014001--10.

[71] Ingarao, G., Di Lorenzo R., Micari F. Sustainability issues in sheet metal forming processes: an overview. Journal of Cleaner Production. 2011;19:337-47

[72] Jäger, A., Risch D., Tekkaya A. E. Thermo-mechanical processing of aluminum profiles by integrated electromagnetic compression subsequent to hot extrusion. Journal of Materials Processing Technology. 2011;211:936-43.

[73] Jeswiet, J., Micari F., Hirt G., Bramley A., Duflou J., Allwood J. Asymmetric Single Point Incremental Forming of Sheet Metal. CIRP Annals - Manufacturing Technology. 2005;54:88-114.

[74] Jin, J.-S., Deng L., Wang X.-Y., Xia J.-C. A new rotary forming process for rim thickening of a disc-like sheet metal part. Journal of Materials Processing Technology. 2012;212:2247-54.

[75] Junchao, L., Junjian S., Bin W. A multipass incremental sheet forming strategy of a car taillight bracket. The International Journal of Advanced Manufacturing Technology. 2013;69:2229-36.

[76] Karbasian, H., Tekkaya A. E. A review on hot stamping. Journal of Materials Processing Technology. 2010;210:2103-18.

[77] Kasaei, M. M., Naeini H. M., Abbaszadeh B., Mohammadi M., Ghodsi M., Kiuchi M., Zolghadr R., Liaghat G., Tafti R. A., Tehrani M. S. Flange Wrinkling in Flexible Roll Forming Process. Procedia Engineering. 2014;81:245-50.

[78] Kasaei, M. M., Naeini H. M., Liaghat G. H., Silva C. M. A., Silva M. B., Martins P. A. F. Revisiting the wrinkling limits in flexible roll forming The Journal of Strain Analysis for Engineering Design. 2015;50:528-41.

[79] Katz, R. Design principles of reconfigurable machines. The International Journal of Advanced Manufacturing Technology. 2007;34:430-9.

[80] Kim, S. W., Lee Y. S., Kang S. H., Lee J. H. Incremental forming of Mg alloy sheet at elevated temperatures. Journal of Mechanical Science and Technology. 2007;21:1518.

[81] Kinsey, B., Liu Z., Cao J. A novel forming technology for tailor-welded blanks. Journal of Materials Processing Technology. 2000;99:145-53.

[82] Klaus, A., Becker D., Kleiner M. Three-Dimensional Curved Profile ExtrusionFirst Results on the Influence of Gravity. Advanced Materials Research: Trans Tech Publ; 2006. p. 5-12.

[83] Kleiner, M., Chatti S., Klaus A. Metal forming techniques for lightweight construction. Journal of Materials Processing Technology. 2006;177:2-7.

[84] Kleiner, M., Geiger M., Klaus A. Manufacturing of Lightweight Components by Metal Forming. CIRP Annals - Manufacturing Technology. 2003;52:521-42.

[85] Kleiner, M., Tekkaya A. E., Becker D., Pietzka D., Schikorra M. Combination of curved profile extrusion and composite extrusion for increased lightweight properties. Production Engineering. 2009;3:63-8.
[86] Klocke, F., Brummer C. M. Laser-assisted Metal Spinning of Challenging Materials. Procedia Engineering. 2014:81:2385-90.

[87] Kolleck, R., Veit R., Merklein M., Lechler J., Geiger M. Investigation on induction heating for hot stamping of boron alloyed steels. CIRP Annals - Manufacturing Technology. 2009;58:275-8.

[88] Kopp, R., Böhlke P. A New Rolling Process for Strips with a Defined Cross Section. CIRP Annals - Manufacturing Technology. 2003;52:197-200.

[89] Kopp, R., Beckmann T. 'Open-Die Forging with a Six-Axis Robot as Forging Manipulator. Proceedings of the 5th International Conference on the Technology of Plasticity (ICTP): Columbus, Ohio: Springer; 1996. p. 7-10.

[90] Kopp, R., Boehlke, P., Hohmeier, P., Wiedner, C. Metal Forming of Lightweight Structures. Proceedings of the ESAFORM Conference. 2002.

[91] Kopp, R., Wiedner C., Meyer A. Flexibly rolled sheet metal and its use in sheet metal forming. Advanced Materials Research: Trans Tech Publ; 2005. p. 81-92.

[92] Kuboki, T., Azrie A., Jin Y. A new incremental in-plane bending of thin sheet metals for micro machine components by using a tiltable punch. CIRP Annals Manufacturing Technology. 2014;63:249-52.

[93] Kuboki, T., Furugen M., Osaka S., Ono T. The 7th International Conference on Steel Rolling. 1998:981-7.

[94] Kuboki, T., Takahashi K., Ono K., Yano K. A new schedule-free mandrel-less bending method for straight/pre-shaped long tubes. CIRP Annals - Manufacturing Technology. 2013;62:303-6.

[95] Kusuda, H., Takasago T., Natsumi F. Formability of tailored blanks. Journal of Materials Processing Technology. 1997;71:134-40.

[96] Kwiatkowski, L., Urban M., Sebastiani G., Tekkaya A. E. Tooling concepts to speed up incremental sheet forming. Production Engineering. 2010;4:57-64.

[97] Löbbe, C., Hering O., Hiegemann L., Tekkaya A. E. Setting mechanical properties of high strength steels for rapid hot forming processes. Materials. 2016;9:229.

[98] Löbbe, C., Hoppe C., Becker C., Tekkaya A. E. Closed loop springback control in progressive die bending by induction heating. International Journal of Precision Engineering and Manufacturing. 2015;16:2441-9.

[99] Lamprecht, K., Geiger M. Experimental and numerical investigation of the formability of laser welded patchwork blanks. Advanced Materials Research: Trans Tech Publ; 2005. p. 689-96.

[100] Landgrebe, D., Putz, M., Schieck, F., Sterzing, A., Rennau, A. Towards Efficient, Interconnected and Flexible Value Chains - Examples and Innovations from Research on Production Technologies. Proc of the 5th ICAFT and the 22nd SFU, Chemnitz, (Germany). 2015:61-78.

[101] Landgrebe, D., Schönherr J., Pierschel N., Polster S., Mosel A., Schieck F. New Approaches for Improved Efficiency and Flexibility in Process Chains of Press Hardening. ASME 2015 International Mechanical Engineering Congress and Exposition: American Society of Mechanical Engineers; 2015. p. V02ATA033V02AT02A.

[102] Landgrebe D, S. J., Lorenz B. Potentials for Increase and Saving of Resources. Proc of the 8th International Conference and Exhibition on Design and Production of Machines and Dies / Molds, Kusadasi. 2015:57-60.

[103] Lange, K. Cost minimization in small quantity production of stepped shafts by combined NC-radial forging and NC-turning. A new approach to flexible manufacturing systems. CIRP Annals-Manufacturing Technology. 1985;34:549-55.

[104] Lange, K. Modern metal forming technology for industrial production. Journal of materials processing technology. 1997;71:2-13.

[105] Larrañaga, L., Galdos L., C.García, R.Ortubay, G.Arrizabalaga. Flexible roll forming process reliability and optimization methods. Proceedings of ICTP 2008. 2008:1795-800.

[106] Lauwers, B., Klocke F., Klink A., Tekkaya A. E., Neugebauer R., McIntosh D. Hybrid processes in manufacturing. CIRP Annals - Manufacturing Technology. 2014;63:561-83.

[107] Lee, E.-H., Hwang J.-S., Lee C.-W., Yang D.-Y., Yang W.-H. A local heating method by near-infrared rays for forming of non-quenchable advanced high-strength steels. Journal of Materials Processing Technology. 2014;214:784-93.

[108] Lee, K., Lee S., Yang D. Rigid-plastic finite element analysis of incremental radial forging process using the automatic expansion of domain scheme. Engineering Computations. 2004;21:470-87.

[109] LEE, K. H. Study on incremental radial-axial forging of flanged shaft parts, Ph. D Thesis, KAIST. 2002.

[110] Lee, Y., Lee M., Park S., Lee I., Moon Y., Barlat F., Moon Y., Lee M. Process Design by FEM Simulation for Shape Ring Rolling of Large-Sized Ring. AIP Conference Proceedings: AIP; 2010. p. 964-71.

[111] Levy, G. N., Schindel R., Kruth J. P. Rapid manufacturing and rapid tooling with layer manufacturing (LM) technologies, state of the art and future perspectives. CIRP Annals - Manufacturing Technology. 2003;52:589-609.

[112] Li, M.-Z., Cai Z.-Y., Liu C.-G. Flexible manufacturing of sheet metal parts based on digitized-die. Robotics and Computer-Integrated Manufacturing. 2007;23:107-15. [113] Li, M. Z., Cai Z. Y., Sui Z., Yan Q. G. Multi-point forming technology for sheet metal. Journal of Materials Processing Technology. 2002;129:333-8.

[114] Li, Y., Daniel W. J. T., Liu Z., Lu H., Meehan P. A. Deformation mechanics and efficient force prediction in single point incremental forming. Journal of Materials Processing Technology. 2015;221:100-11.

[115] Lilly, K. W., Melligeri A. S. Dynamic simulation and neural network compliance control of an intelligent forging center. Journal of Intelligent and Robotic Systems. 1996;17:81-99.

[116] Lindgren, M. 3D roll-forming of hat-profile with variable depth and width. 1st International Congress on RollForming, RollFORM'09. Bilbao, Spain2009.

[117] Lindgren, M., Bexell U., Wikström L. Roll forming of partially heated cold rolled stainless steel. Journal of materials processing technology. 2009;209:3117-24. 
[118] Lu, B., Chen J., Ou H., Cao J. Feature-based tool path generation approach for incremental sheet forming process. Journal of Materials Processing Technology. 2013;213:1221-33

[119] Lu, B., Fang Y., Xu D. K., Chen J., Ai S., Long H., Ou H., Cao J. Investigation of material deformation mechanism in double side incremental sheet forming International Journal of Machine Tools and Manufacture. 2015;93:37-48.

[120] Lu, B., Fang Y., Xu D. K., Chen J., Ou H., Moser N. H., Cao J. Mechanism investigation of friction-related effects in single point incremental forming using a developed oblique roller-ball tool. International Journal of Machine Tools and Manufacture. 2014:85:14-29.

[121] Madeira, T., Silva C. M. A., Silva M. B., Martins P. A. F. Failure in single point incremental forming. The International Journal of Advanced Manufacturing Technology. 2015;80:1471-9.

[122] Maeno, T., Mori K.-i., Nagai T. Improvement in formability by control of temperature in hot stamping of ultra-high strength steel parts. CIRP Annals Manufacturing Technology. 2014;63:301-4

[123] Malhotra, R., Cao J., Ren F., Kiridena V., Xia Z. C., Reddy N. Improvement of geometric accuracy in incremental forming by using a squeezing toolpath strategy with two forming tools. Journal of manufacturing science and engineering. 2011;133:061019.

[124] Martins, P., Bay N., Skjødt M., Silva M. Theory of single point incrementa forming. CIRP Annals-Manufacturing Technology. 2008;57:247-52.

[125] Matsubara, S. Incremental backward bulge forming of a sheet metal with a hemispherical head tool-a study of a numerical control forming system II. JournalJapan Society for Technology of Plasticity. 1994;35:1311-.

[126] McAnulty, $T$, Jeswiet J. Doolan M. Formability in single point incremental forming: A comparative analysis of the state of the art. CIRP Journal of Manufacturing Science and Technology. 2017;16:43-54.

[127] Mega-trends. and future of metal forming. Meeting note of Working Group of ICFG (2012). 2012.

[128] Meier, H., Magnus C., Smukala V. Impact of superimposed pressure on dieless incremental sheet metal forming with two moving tools. CIRP Annals Manufacturing Technology. 2011;60:327-30.

[129] Meier, H., Smukala V., Dewald O., Zhang J. Two point incremental forming with two moving forming tools. Key Engineering Materials: Trans Tech Publ; 2007. p. 599-605.

[130] Merklein, M., Allwood J. M., Behrens B. A., Brosius A., Hagenah H., Kuzman K. Mori K., Tekkaya A. E., Weckenmann A. Bulk forming of sheet metal. CIRP Annals Manufacturing Technology. 2012;61:725-45.

[131] Merklein, M., Geiger M. New materials and production technologies for innovative lightweight constructions. Journal of Materials Processing Technology. 2002;125:532-6

[132] Merklein, M., Johannes M., Lechner M., Kuppert A. A review on tailored blanks-Production, applications and evaluation. Journal of Materials Processing Technology. 2014;214:151-64.

[133] Merklein, M., Lechler J. Investigation of the thermo-mechanical properties of hot stamping steels. Journal of Materials Processing Technology. 2006;177:452-5.

[134] Merklein, M., Lechler J., Geiger M. Characterisation of the flow properties of the quenchenable ultra high strength steel 22MnB5. CIRP Annals-Manufacturing Technology. 2006;55:229-32.

[135] Merklein, M., Opel S. Investigation Of Tailored Blank Production By The Process Class Sheet-Bulk Metal Forming. AIP Conference Proceedings. 2011;1315:395-400

[136] Merklein, M., Plettke R., Opel S. Orbital forming of tailored blanks from sheet metal. CIRP Annals - Manufacturing Technology. 2012;61:263-6.

[137] Merklein, M., Wieland M., Lechner M., Bruschi S., Ghiotti A. Hot stamping of boron steel sheets with tailored properties: A review. Journal of Materials Processing Technology. 2016;228:11-24.

[138] Meyer, A., Wietbrock B., Hirt G. Increasing of the drawing depth using tailor rolled blanks-Numerical and experimental analysis. International Journal of Machine Tools and Manufacture. 2008;48:522-31.

[139] Mohanty, S., Regalla S. P., Rao Y. V. D. Multi-stage and Robot Assisted Incremental Sheet Metal Forming: A Review of the State of Art and Comparison of Available Technologie. Proceedings of the 2015 Conference on Advances In Robotics. 2015

[140] Mori, K. Smart Hot Stamping for Ultra-high Strength Steel Parts. In: Tekkaya AE, Homberg W, Brosius A, editors. 60 Excellent Inventions in Metal Forming. Berlin Heidelberg: Springer Berlin Heidelberg; 2015. p. 403-8.

[141] Mori, K., Abe Y., Osakada K., Hiramatsu S. Plate forging of tailored blanks having local thickening for deep drawing of square cups. Journal of Materials Processing Technology. 2011;211:1569-74.

[142] Mori, K., Maeno T., Mongkolkaji K. Tailored die quenching of steel parts having strength distribution using bypass resistance heating in hot stamping. Journal of Materials Processing Technology. 2013;213:508-14.

[143] Mori, K., Maki S., Tanaka Y. Warm and Hot Stamping of Ultra High Tensile Strength Steel Sheets Using Resistance Heating. CIRP Annals - Manufacturing Technology. 2005;54:209-12.

[144] Mori, K., Okuda Y. Tailor die quenching in hot stamping for producing ultrahigh strength steel formed parts having strength distribution. CIRP Annals Manufacturing Technology. 2010;59:291-4.

[145] Moser, N., Zhang Z., Ren H., Zhang H., Shi Y., Ndip-Agbor E. E., Lu B., Chen J., Ehmann K. F, Cao J. Effective forming strategy for double-sided incremental formin considering in-plane curvature and tool direction. CIRP Annals - Manufacturing Technology. 2016;65:265-8.
[146] Murata, M., Kuboki T., Murai T. Compression spinning of circular magnesium tube using heated roller tool. Journal of materials processing technology. $2005 ; 162: 540-5$

[147] Murata, M., Kuboti T., Takahashi K. Characteristics of tube bending by MOS bending machine. Proc of the 2nd Int Conf on New Forming Technology, Bremen, Germany2007. p. 135-44.

[148] Music, O., Allwood J. M. Flexible asymmetric spinning. CIRP Annals Manufacturing Technology. 2011;60:319-22.

[149] Naderi, M., Durrenberger L., Molinari A., Bleck W. Constitutive relationships for $22 \mathrm{MnB5}$ boron steel deformed isothermally at high temperatures. Materials Science and Engineering: A. 2008;478:130-9.

[150] Neugebauer, R., Altan T., Geiger M., Kleiner M., Sterzing A. Sheet metal forming at elevated temperatures. CIRP Annals - Manufacturing Technology. 2006;55:793816.

[151] Neugebauer, R., Putz M., Sterzing A. Forschungsergebnisse des Fraunhofer IWU im Karosseriebau. Proc of the 4th CBC 2005, Chemnitz (Germany). 2005:4172.

[152] Neugebauer, R., Sterzing A. Resource Efficiency - Driver for Innovations in Forming Technology. International Science and Technology Congress, Moscow, Russia. 2014:13-20.

[153] Neuwirth, M., Özel M., Groche P. Process Characteristics in Flexible Flow Splitting. steel research international. 2017.

[154] Nowak, J., Madej L., Ziolkiewicz S., Plewinski A., Grosman F., Pietrzyk M. Recent development in orbital forging technology. International Journal of Material Forming. 2008;1:387-90.

[155] Osakada, K., Mori K., Altan T., Groche P. Mechanical servo press technology for metal forming. CIRP Annals - Manufacturing Technology. 2011;60:651-72.

[156] Pallett, R. J., Lark R. J. The use of tailored blanks in the manufacture of construction components. Journal of Materials Processing Technology. 2001;117:249-54.

[157] Palumbo, G., Brandizzi M. Experimental investigations on the single point incremental forming of a titanium alloy component combining static heating with high tool rotation speed. Materials \& Design. 2012;40:43-51.

[158] Park, J.-C., Yang D.-Y., Cha M., Kim D., Nam J.-B. Investigation of a new incremental counter forming in flexible roll forming to manufacture accurate profiles with variable cross-sections. International Journal of Machine Tools and Manufacture. 2014;86:68-80.

[159] Paukert, R., Lange K. Investigations into metal flow in radial-forging. CIRP Annals-Manufacturing Technology. 1983;32:211-4.

[160] Pauskar, P. Incremental Forming Processes and Applications at the Timken Company. Workshop on Modelling of Incremental Bulk Forming Processes, Darmstadt, Germany2006.

[161] Polyblank, J. A., Allwood J. M., Duncan S. R. Closed-loop control of product properties in metal forming: A review and prospectus. Journal of Materials Processing Technology. 2014;214:2333-48.

[162] Psyk, V., Risch D., Kinsey B. L., Tekkaya A. E., Kleiner M. Electromagnetic forming-A review. Journal of Materials Processing Technology. 2011;211:787-829. [163] Qiu, X. G., Chen W. L. The study on numerical simulation of the laser tailor welded blanks stamping. Journal of Materials Processing Technology. 2007;187188:128-31.

[164] Rathmann, T., Groche P. Development of a Technological Processor for 3D-FEA of Rotary Swaging Processes. 4th ICFG Workshop, Shanghai, China2004.

[165] Rauch, M., Hascoet J.-Y., Hamann J.-C., Plenel Y. Tool path programming optimization for incremental sheet forming applications. Computer-Aided Design. 2009:41:877-85

[166] Ryabkov, N., Jackel F., van Putten K., Hirt G. Production of blanks with thickness transitions in longitudinal and lateral direction through 3D-Strip Profile Rolling. International Journal of Material Forming. 2008;1:391-4.

[167] Sanchez-Salmeron, A., Ricolfe-Viala C. A flexible packaging station for microbulk-forming applications based on a standard carrier. The International Journal of Advanced Manufacturing Technology. 2012;61:529-36.

[168] Santos, E. C., Shiomi M., Osakada K., Laoui T. Rapid manufacturing of metal components by laser forming. International Journal of Machine Tools and Manufacture. 2006;46:1459-68.

[169] Schuh, G., Kreysa J., Orilski S. Roadmap, Hybride Produktion “ Wie 1+ 1= 3 Effekte in der Produktion maximiert werden können. ZWF Zeitschrift für wirtschaftlichen Fabrikbetrieb. 2009:104:385-91.

[170] Schwab, K. The fourth industrial revolution: Crown Business; 2017.

[171] Seong, D. Y., Jung C. G., Yang D. Y., Ahn J., Na S. J., Chung W. J., Kim J. H. Analysis of core shear stress in welded deformable sandwich plates to prevent de-bonding failure during U-bending. Journal of Materials Processing Technology. 2010;210:1171-9.

[172] Seong, D. Y., Jung C. G., Yang D. Y., Kim J. H., Chung W. J., Lee M. Y. Bendable metallic sandwich plates with a sheared dimple core. Scripta Materialia. 2010;63:81-

[173] Shamsaei, N., Yadollahi A., Bian L., Thompson S. M. An overview of Direct Laser Deposition for additive manufacturing; Part II: Mechanical behavior, process parameter optimization and control. Additive Manufacturing. 2015;8:12-35.

[174] Shang, J., Daehn G. Electromagnetically assisted sheet metal stamping. Journal of Materials Processing Technology. 2011;211:868-74.

[175] Shim, D.-S., Yang D.-Y., Chung S.-W., Han M.-S. Optimization of Forming Steps in the Incremental Forming of Twisted Shapes using a Line Array Roll Set (LARS) International Journal of Precision Engineering and Manfacturing. 2010;11:715-23.

[176] Shim, D. S., Yang D. Y., Kim K. H., Chung S. W., Han M. S. Investigation into forming sequences for the incremental forming of doubly curved plates using the 
line array roll set (LARS) process. International Journal of Machine Tools and Manufacture. 2010;50:214-8.

[177] Shim, D. S., Yang D. Y., Kim K. H., Han M. S., Chung S. W. Numerical and experimental investigation into cold incremental rolling of doubly curved plates for process design of a new LARS (line array roll set) rolling process. CIRP Annals Manufacturing Technology. 2009;58:239-42.

[178] Shimada, N., Tomizawa A., Kubota H., Mori H., Hara M., Kuwayama S. Development of Three-dimensional Hot Bending and Direct Quench Technology. Procedia Engineering. 2014;81:2267-72.

[179] Shivpuri, R. Past developments and future trends in the rotary or orbital forging process. Journal of Materials Shaping Technology. 1988;6:55-71.

[180] Sieczkarek, P., Kwiatkowski L., Ben Khalifa N., Tekkaya A. E. Novel five-axis forming press for the incremental sheet-bulk metal forming. Key Engineering Materials: Trans Tech Publ; 2013. p. 1478-83.

[181] Sieczkarek, P., Wernicke S., Gies S., Tekkaya A., Krebs E., Wiederkehr P. Biermann D., Tillmann W., Stangier D. Improvement strategies for the formfilling in incremental gear forming processes. Production Engineering. 2017:1-9.

[182] Sieczkarek, P., Wernicke S., Weddeling C., Martins P. A., Erman Tekkaya A Local forming of gears by indentation of sheets. Proceedings of the Institution of Mechanical Engineers, Part B: Journal of Engineering Manufacture. 2016:0954405416654190.

[183] Sieczkarek, P., Wernicke S., Weddeling C., Martins P. A. F., Erman Tekkaya A Local forming of gears by indentation of sheets. Proceedings of the Institution of Mechanical Engineers, Part B: Journal of Engineering Manufacture. 2016:0954405416654190.

[184] Siemens. Umsetzungsempfehlung fuer das Zukunftsproject Industie 4.0, Acatech2013.

[185] Skjødt, M., Bay N., Endelt B., Ingarao G. Multi stage strategies for single point incremental forming of a cup. International Journal of Material Forming 2008;1:1199-202.

[186] So, H., Faßmann D., Hoffmann H., Golle R., Schaper M. An investigation of the blanking process of the quenchable boron alloyed steel 22MnB5 before and after hot stamping process. Journal of Materials Processing Technology. 2012;212:437-49.

[187] Stanistreet, T. F., Allwood J. M., Willoughby A. M. The design of a flexible mode ring rolling machine. Journal of Materials Processing Technology. 2006;177:630-3.

[188] Staupendahl, D., AE T. The reciprocal effects of bending and torsion on springback during 3D bending of profiles. ICTP2017 - to be published in Procedia Engineering. 2017.

[189] Staupendahl, D., Chatti S., Tekkaya A. E., Chinesta F., Cueto E., AbissetChavanne E. Closed-loop control concept for kinematic 3D-profile bending. AIP Conference Proceedings: AIP Publishing; 2016. p. 150002.

[190] Steger, J., Leichtmetallen Q. v. 4. VDI-Fachtagung Warmmassivumformung, Düsseldorf (Germany) 2018

[191] SUGITA, Y., ARAI H. Development of synchronous multipath metal-spinning method for forming nonaxisymmetric shapes. TRANSACTIONS OF THE JAPAN SOCIETY OF MECHANICAL ENGINEERS Series C. 2012;78:1004-12.

[192] Sun, W.-C., Stelson K. A. System Identification and Adaptive Control of the Multi-Axis Bending and Twisting Process. Journal of Dynamic Systems, Measurement, and Control. 1997;119:782-90.

[193] Supriadi, S., Manabe K. Enhancement of dimensional accuracy of dieless tubedrawing process with vision-based fuzzy control. Journal of Materials Processing Technology. 2013;213:905-12.

[194] Suzuki, N., Maeda R., Yokota D., Takeuchi O. The Proc. of the 115th conf. of JILM.207-8.

[195] Sypeck, D. J. Cellular Truss Core Sandwich Structures. Applied Composite Materials. 2005;12:229-46.

[196] Taleb Araghi, B., Göttmann A., Bambach M., Hirt G., Bergweiler G., Diettrich J., Steiners M., Saeed-Akbari A. Review on the development of a hybrid incremental sheet forming system for small batch sizes and individualized production. Production Engineering. 2011;5:393-404

[197] Tekkaya, A. E., Kwiatkowski L., Urban M., Abel H.-J. Verfahren und Vorrichtung zur inkrementellen Blechumformung. Patent number DE102009025726.8; 2009.

[198] Thompson, M. K., Moroni G., Vaneker T., Fadel G., Campbell R. I., Gibson I, Bernard A., Schulz J., Graf P., Ahuja B., Martina F. Design for Additive Manufacturing: Trends, opportunities, considerations, and constraints. CIRP Annals - Manufacturing Technology. 2016;65:737-60.

[199] Tisza, M. General overview of sheet incremental forming. Journal of achievements in materials and Manufacturing Engineering. 2012;55:113-20.

[200] Turetta, A., Bruschi S., Ghiotti A. Investigation of 22MnB5 formability in hot stamping operations. Journal of Materials Processing Technology. 2006;177:396400.

[201] Vollertsen, F., Sprenger A., Kraus J., Arnet H. Extrusion, channel, and profile bending: a review. Journal of Materials Processing Technology. 1999;87:1-27.

[202] Wadley, H. N. G. Multifunctional periodic cellular metals. Philosophical Transactions of the Royal Society A: Mathematical, Physical and Engineering Sciences. 2006;364:31-68

[203] Wang, X.-y., Yukawa N., Yoshita Y., Sukeda T., Ishikawa T. Research on some basic deformations in free forging with robot and servo-press. Journal of Materials Processing Technology. 2009;209:3030-8.

[204] Weise, D., Landgrebe D. Highly flexible forming technologies - approach for rising diversity of variants. . Proc of the 5th ICAFT and the 22nd SFU, Chemnitz, (Germany). 2015:91-105.

[205] Wernicke, S., Sieczkarek P., Martins P., Tekkaya A. Local sheet thickening by inplane swaging. International Journal of Mechanical Sciences. 2016;119:59-67.
[206] Wolfgarten, M., Hirt G. New method for the manufacturing of curved workpieces by open-die forging. CIRP Annals-Manufacturing Technology. 2016;65:285-8

[207] Wong, K. V., Hernandez A. A Review of Additive Manufacturing. ISRN Mechanical Engineering. 2012;2012:10.

[208] Xu, D., Lu B., Cao T., Chen J., Long H., Cao J. A Comparative Study on Process Potentials for Frictional Stir- and Electric Hot-assisted Incremental Sheet Forming. Procedia Engineering. 2014;81:2324-9.

[209] Xu, R., Shi X., Xu D., Malhotra R., Cao J. A preliminary study on the fatigue behavior of sheet metal parts formed with accumulative-double-sided incremental forming. Manufacturing Letters. 2014;2:8-11.

[210] Yang, H., Li H., Zhang Z., Zhan M., Liu J., Li G. Advances and Trends on Tube Bending Forming Technologies. Chinese Journal of Aeronautics. 2012;25:1-12.

[211] Yoshihara, S., Mac Donald B., Hasegawa T., Kawahara M., Yamamoto H. Design improvement of spin forming of magnesium alloy tubes using finite element. Journal of materials processing technology. 2004;153:816-20.

[212] Yoshihara, S., Yamamoto H., Manabe K., Nishimura H. Formability enhancement in magnesium alloy deep drawing by local heating and cooling technique. Journal of Materials Processing Technology. 2003;143-144:612-5.

[213] Zhang, K., Yin D., Wu D. Formability of AZ31 magnesium alloy sheets at warm working conditions. International Journal of machine tools and manufacture. 2006;46:1276-80.

[214] Zhang, Q.-F., Cai Z.-Y., Zhang Y., Li M.-Z. Springback compensation method for doubly curved plate in multi-point forming. Materials \& Design. 2013;47:377-85. [215] Zhang, Q., Jin K., Mu D., Zhang Y., Li Y. Energy-controlled rotary swaging process for tube workpiece. The International Journal of Advanced Manufacturing Technology. 2015;80.

[216] Zhang, Z., Furushima T., Manabe K.-i., Tada K., Sasaki O. Development of dieless metal bellows forming process with local heating technique. Proc IMechE Part B: J Engineering Manufacture. 2015;229:664-9.

[217] Zhu, Z., Dhokia V. G., Nassehi A., Newman S. T. A review of hybrid manufacturing processes - state of the art and future perspectives. International Journal of Computer Integrated Manufacturing. 2013;26:596-615. 


\section{List of Figures}

Fig. 1. Three key factors pursued in industry 4.0

Fig. 2. Mega-trends and future of metal forming [127]

Fig. 3. Flexibility level with respect to Lot size and Shape complexity

Fig. 4. Major factors influencing flexibility

Fig. 5. Basic elements of sheet metal incremental forming [36]

Fig. 6. Double sided incremental forming [145]

Fig. 7. Roboforming with two robots [129]

Fig. 8. Tools for flexible incremental forming (a) Twin tool (b) Multi-tool concept [96]

Fig. 9. Asymmetric spinning [148]

Fig. 10. Produced examples of non-circular spinning $[16,17]$

Fig. 11. Rectangular box shape through a synchronous multipath metal-spinning method [191]

Fig. 12. Tube fabrication by spinning utilizing elastomer [194]

Fig. 13. Schematic of concept of flexible roll forming with additional forming unit (a) Apparatus (b) Design of blank [55]

Fig. 14. Schematic of 3D-roll forming (a) Apparatus (b) Product [116]

Fig. 15. Flexible roll forming using incremental counter forming [158]

Fig. 16. Machine system for incremental profile forming [57]

Fig. 17. Product examples of incremental profile forming [58]

Fig. 18. Incremental rolling of doubly curved plates [177]

Fig. 19. Schematic of a machine setup-up of the TSS bending process [28]

Fig. 20. Dieless U-bending process [93]

Fig. 21. Schematic figure of the three-dimensional hot bending and direct quench [178]

Fig. 22. Incremental forging with a robot and formed products with various shape [203]

Fig. 23. Radial forming machine RUMX $2000[103,159]$

Fig. 24. Schematic of incremental radial-axial forging of flanged shaft parts (a) Concept of the incremental radial-axial forging (b) Radial forging (c) Axial forging [109]

Fig. 25. Open die forging for curved workpieces [206]

Fig. 26. Flexible ring rolling machine and the module of the experimental ring rolling machine [187]

Fig. 27. Tailored blank by orbital forging [136]

Fig. 28. Five-axis forming press for the incremental sheet-bulk metal forming [180]

Fig. 29. Schematic presentation of the processing of a) the sheet plane and b) the sheet edge. [181]

Fig. 30. Schematic figure of the axial feed cross rolling process and products [100]

Fig. 31. Prototype machine for axial feed cross rolling [190]

Fig. 32. Hot rolling for variable cross-section [27]

Fig. 33. 3D-profiled blank [166]

Fig. 34. Flexible rolling for defined cross section [88]

Fig. 35. Plate forming of tailored blanks [141]

Fig. 36. Automotive components with patches [99]

Fig. 37. Examples of the tailor welded blanks [132]

Fig. 38. Schematic composition of multi-material additively manufactured sandwich sheets with integrated functions

Fig. 39. Metallic sandwich sheets manufactured by selective laser melting with different core structures after bending to the same bending angle showing different spring-back.

Fig. 40. Application of the bendable metallic sandwich plate $[171,172]$

Fig. 41. Restoration of hot forging tools using laser assisted material deposition [3]

Fig. 42. Tailored heat treated blank (THTB) [132]

Fig. 43. Tailored tempering [76]

Fig. 44. Spinning process using gas burners (a) Photograph of experimental equipment in spinning (b) Geometry of the cross-section in formed magnesium alloy pipe

Fig. 45. Sheet incremental forming process using dynamic local heating (a) Experimental setup (b) Clamped workpiece and tool stylus with cooling flow locally re-moved by means of an air jet, and visible, dynamically moving heated spot [34] 
Fig. 46. B-pillar forming test using near infrared sources [107]

Fig. 47. Bellows forming and diametral expansion by local heating [216]

Fig. 48. Process combination of deep drawing and explosive forming

Fig. 49. Integrated electromagnetic forming and extrusion process [72]

Fig. 50. Procedure of the process combination of stretch forming and incremental sheet forming [14]

Fig. 51. Process combination "deep drawing - incremental sheet metal forming" [151, 152, 204]

Fig. 52. Pre-form manufacturing and laser powder decomposition [18]

Fig. 53. Four manufacturing methods integrated in one machine [60]

Fig. 54. Schematic figure of the hot stamping process [76, 143]

Fig. 55. Smart hot stamping having resistance heating, quenching, servo press and hot trimming [140]

Fig. 56. Design of a combined forming and brazing process [15]

Fig. 57. Classification of forming processes [54]

Fig. 58. Increased number of DoF by additional drives: left: additional device [50], right: split drive system [54]

Fig. 59. Multi-axis bending and twisting [192]

Fig. 60. Closed loop control of 3D profile bending [189]

Fig. 61. Flexible forming with digitized die [112]

Fig. 62. Tool path design of incremental forming [43]

\section{List of Tables}

Table 1. Means of flexibility level increase in relation to four major influencing factors $(\mathrm{H}=\mathrm{High}, \mathrm{M}=\mathrm{Medium}, \mathrm{L}=\mathrm{Low})$ 


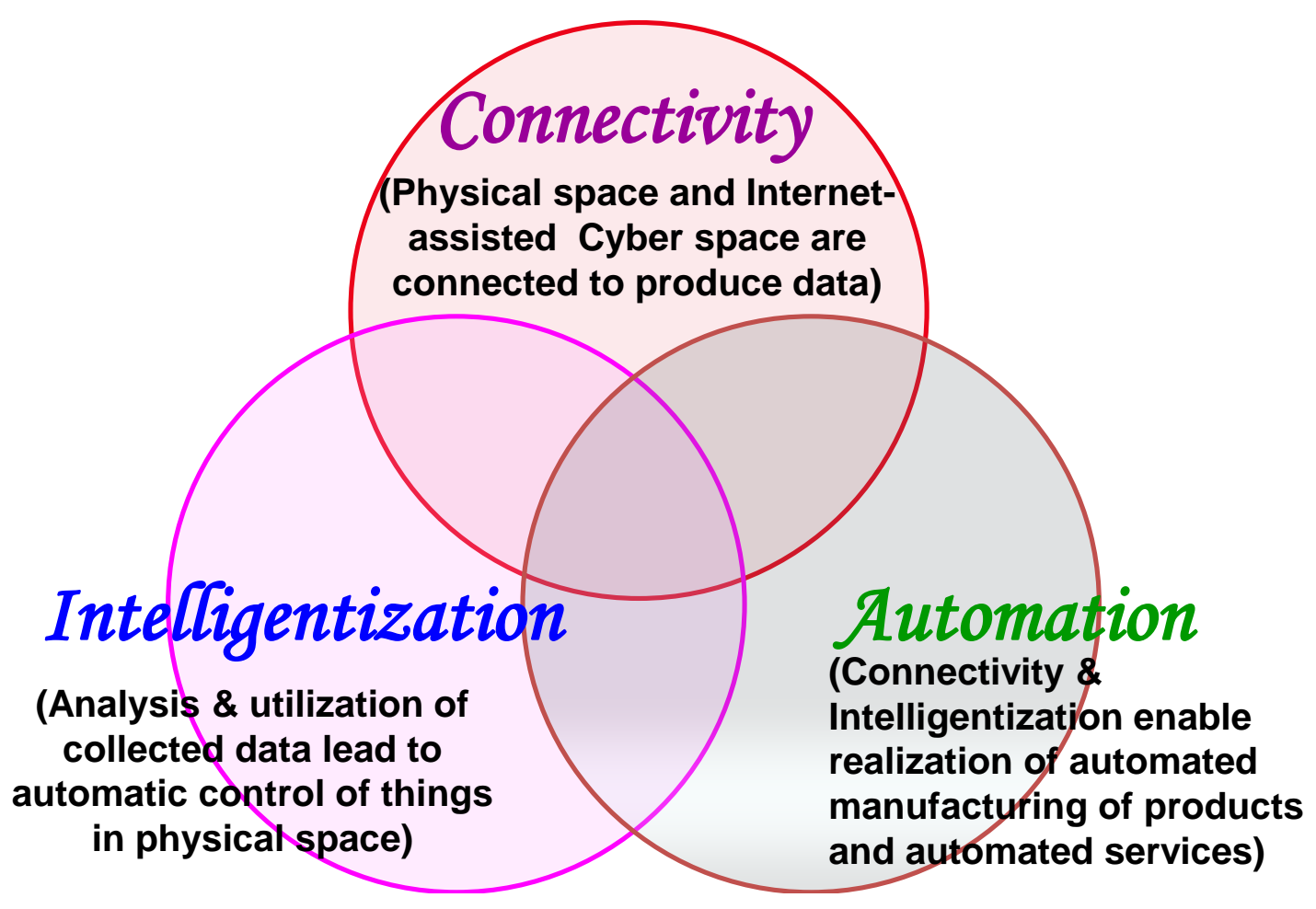

Fig. 1. Three key factors pursued in industry 4.0 


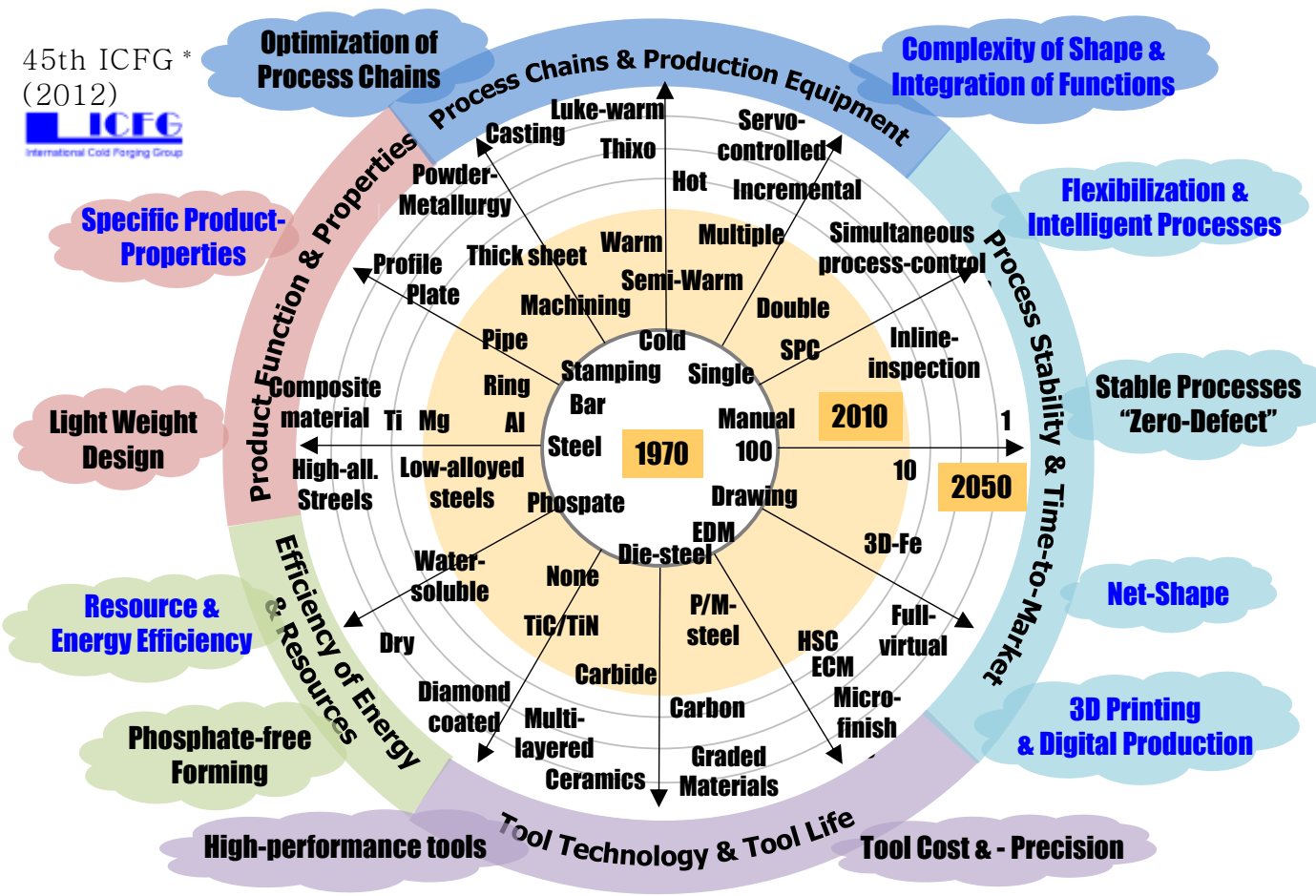

Fig. 2. Mega-trends and future of metal forming [127] 


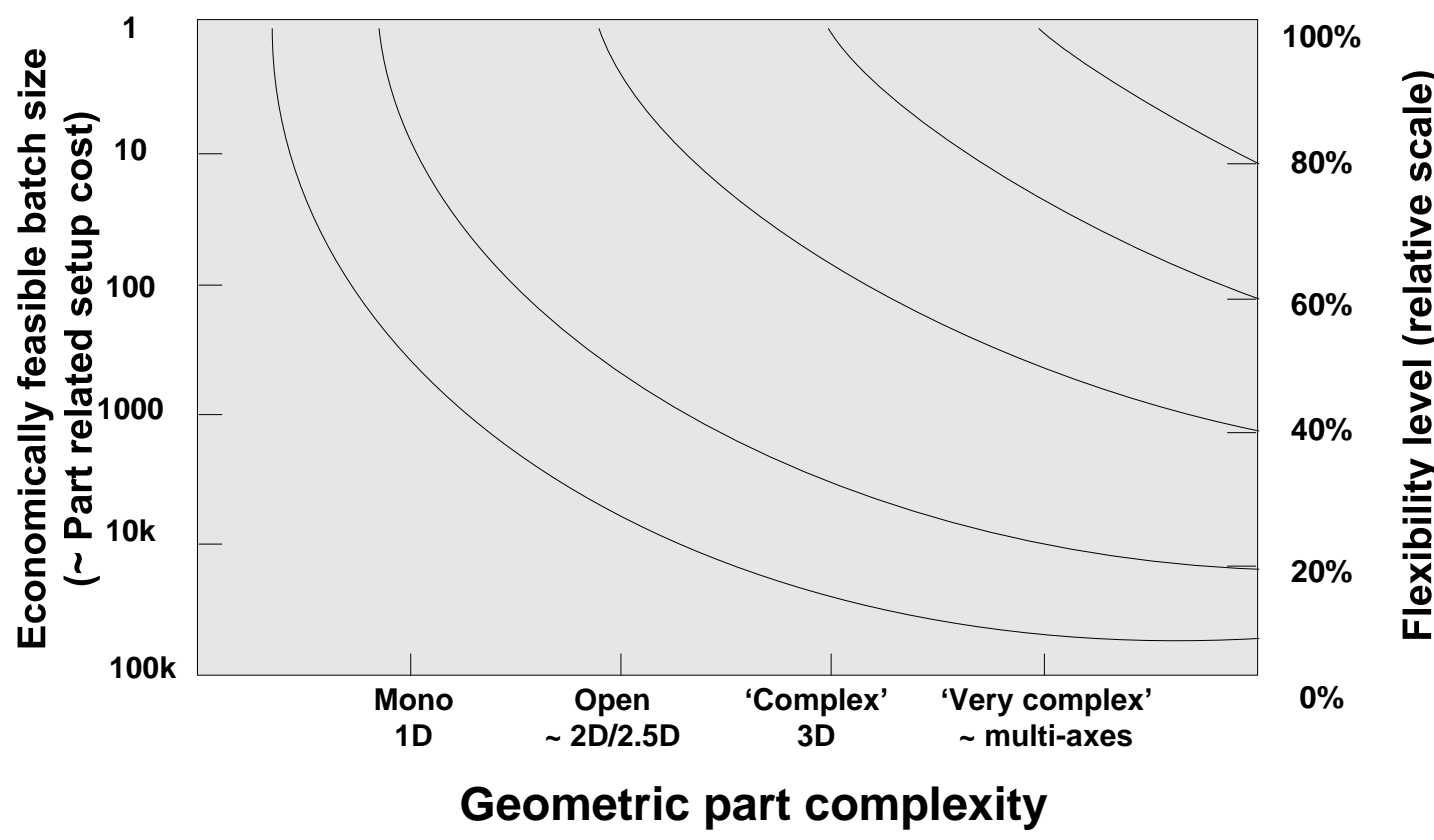

Fig. 3. Flexibility level with respect to Lot size and Shape complexity 


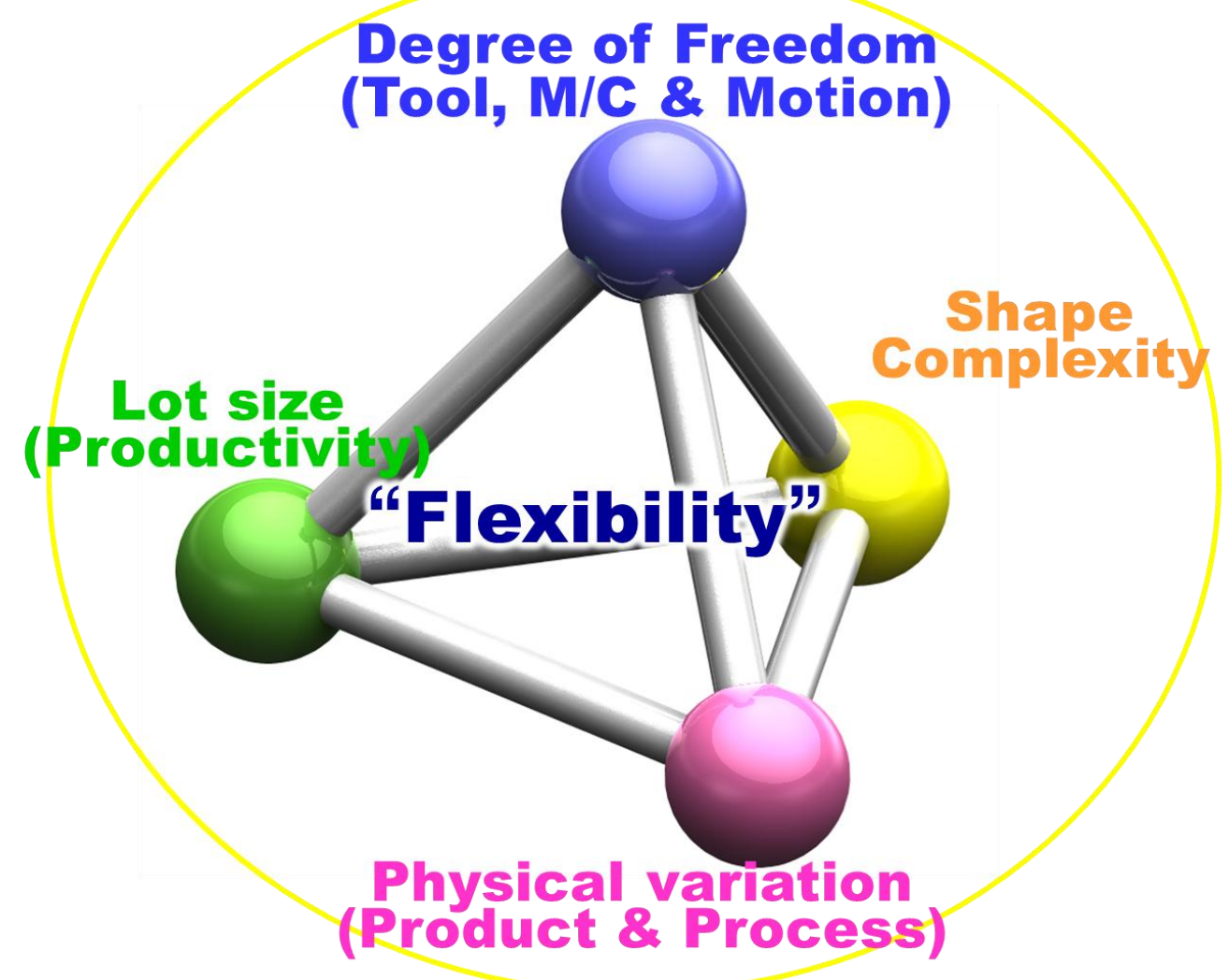

Fig. 4. Major factors influencing flexibility 


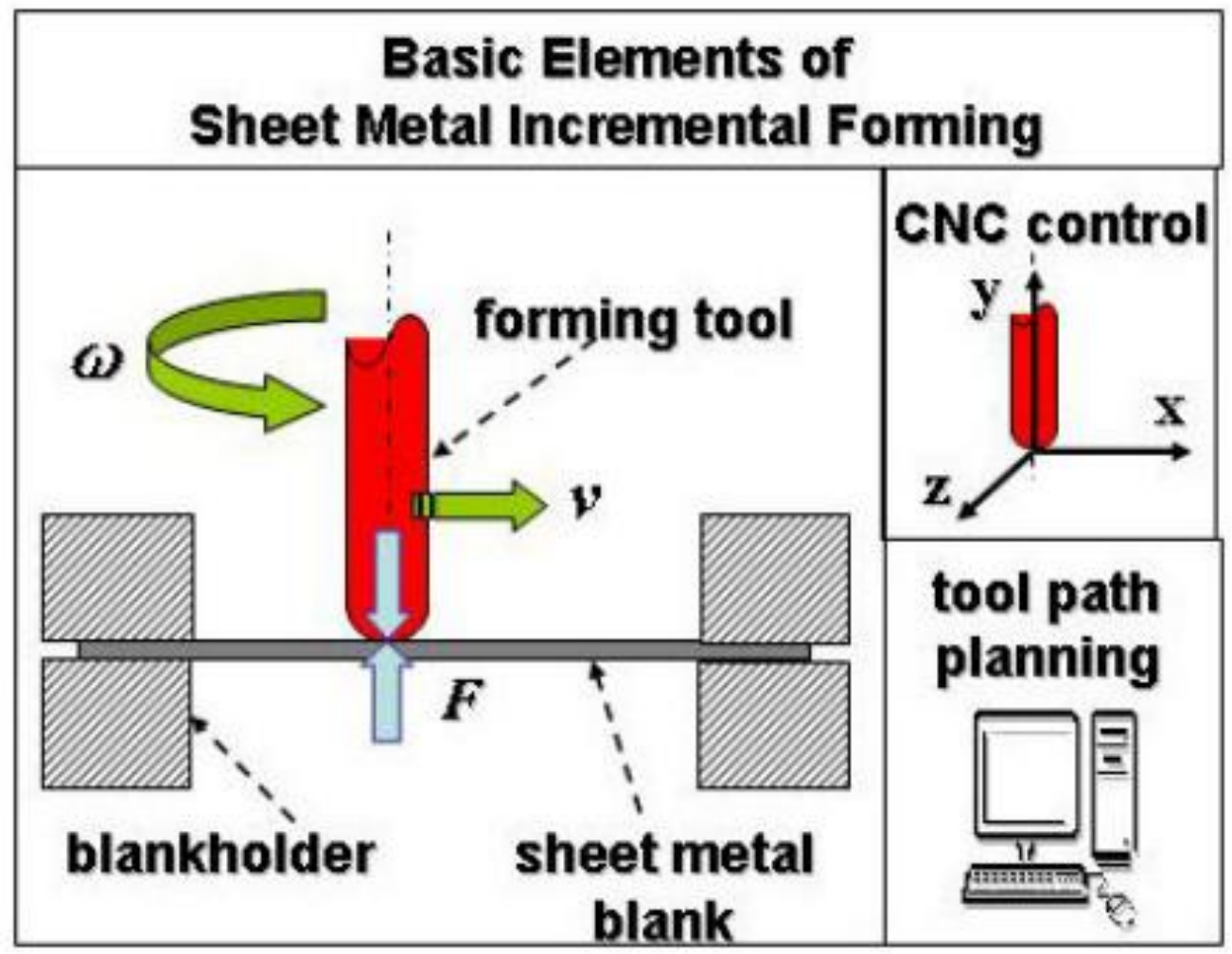

Fig. 5. Basic elements of sheet metal incremental forming [36] 

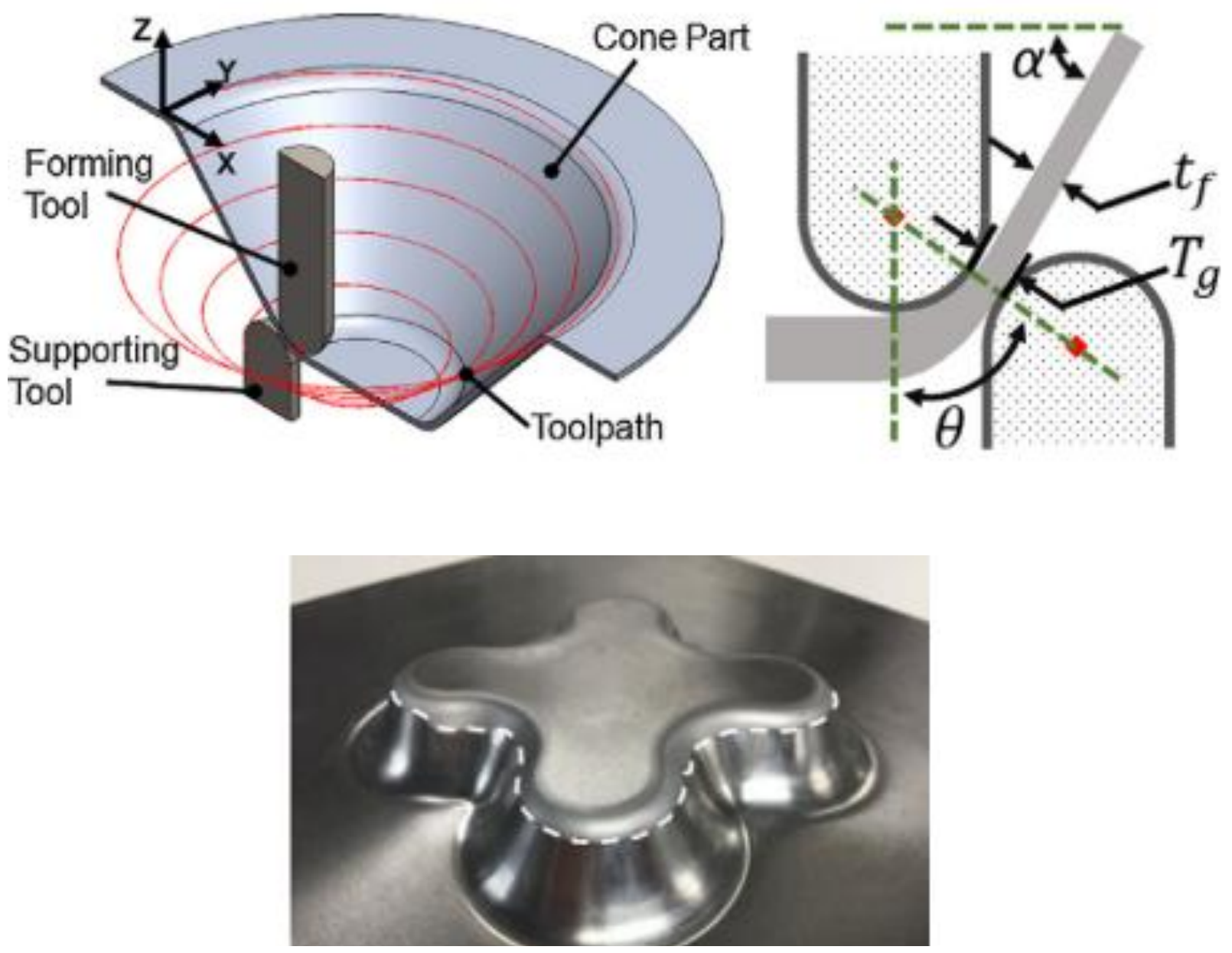

Fig. 6. Double sided incremental forming [145] 


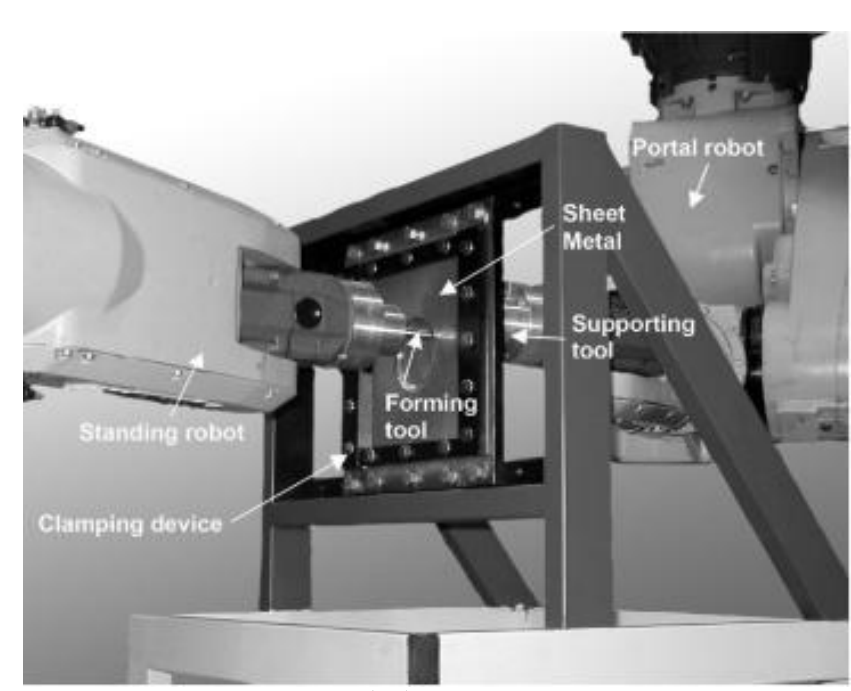

(a)

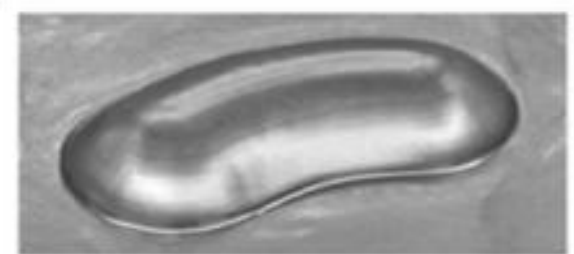

(b)

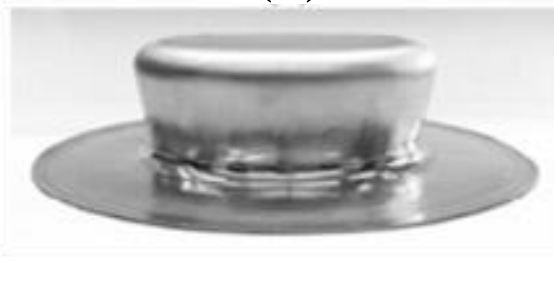

(c)

Fig. 7. Roboforming with two robots [129] 

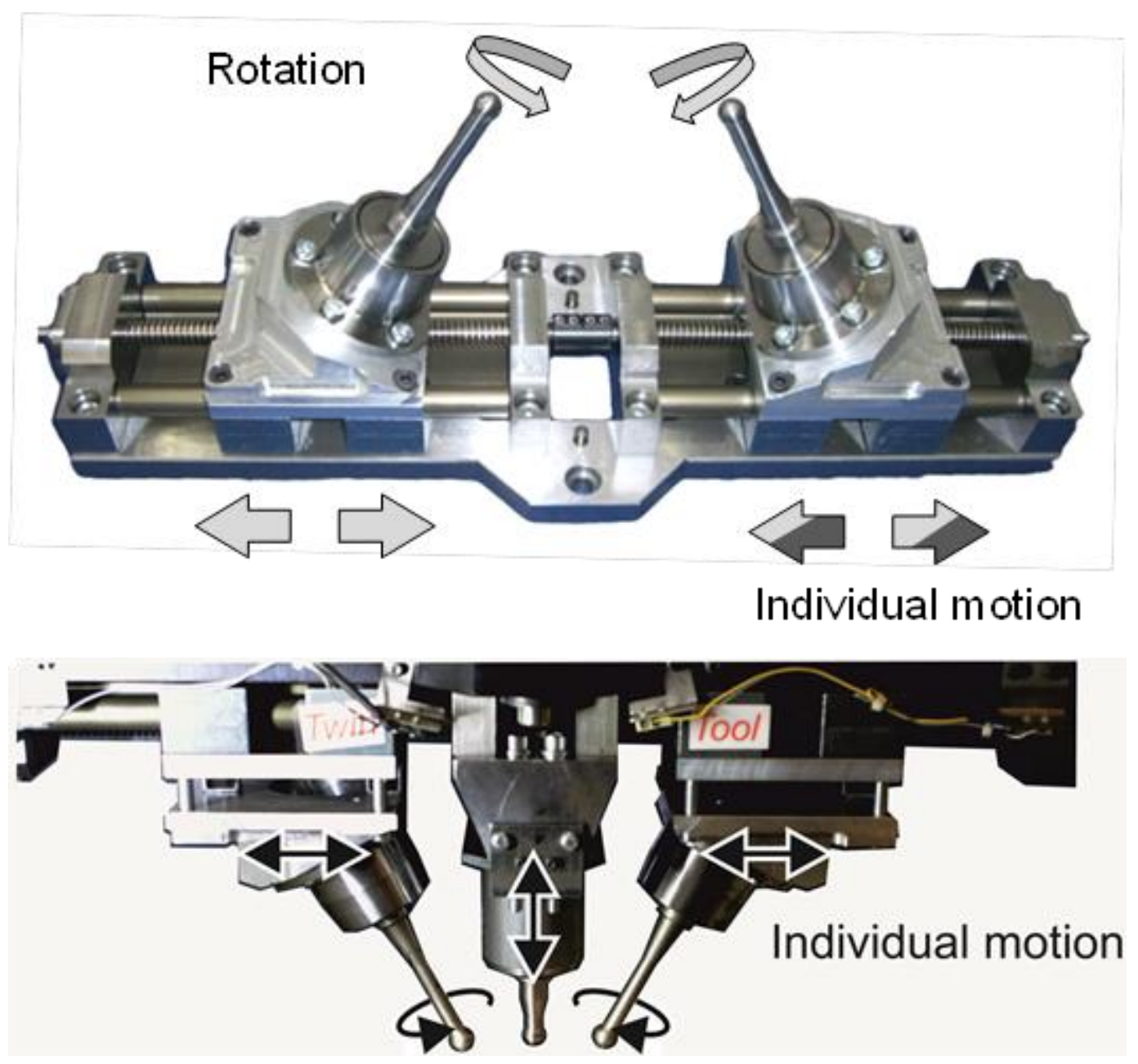

Fig. 8. Tools for flexible incremental forming (a) Twin tool (b) Multi-tool concept [96] 


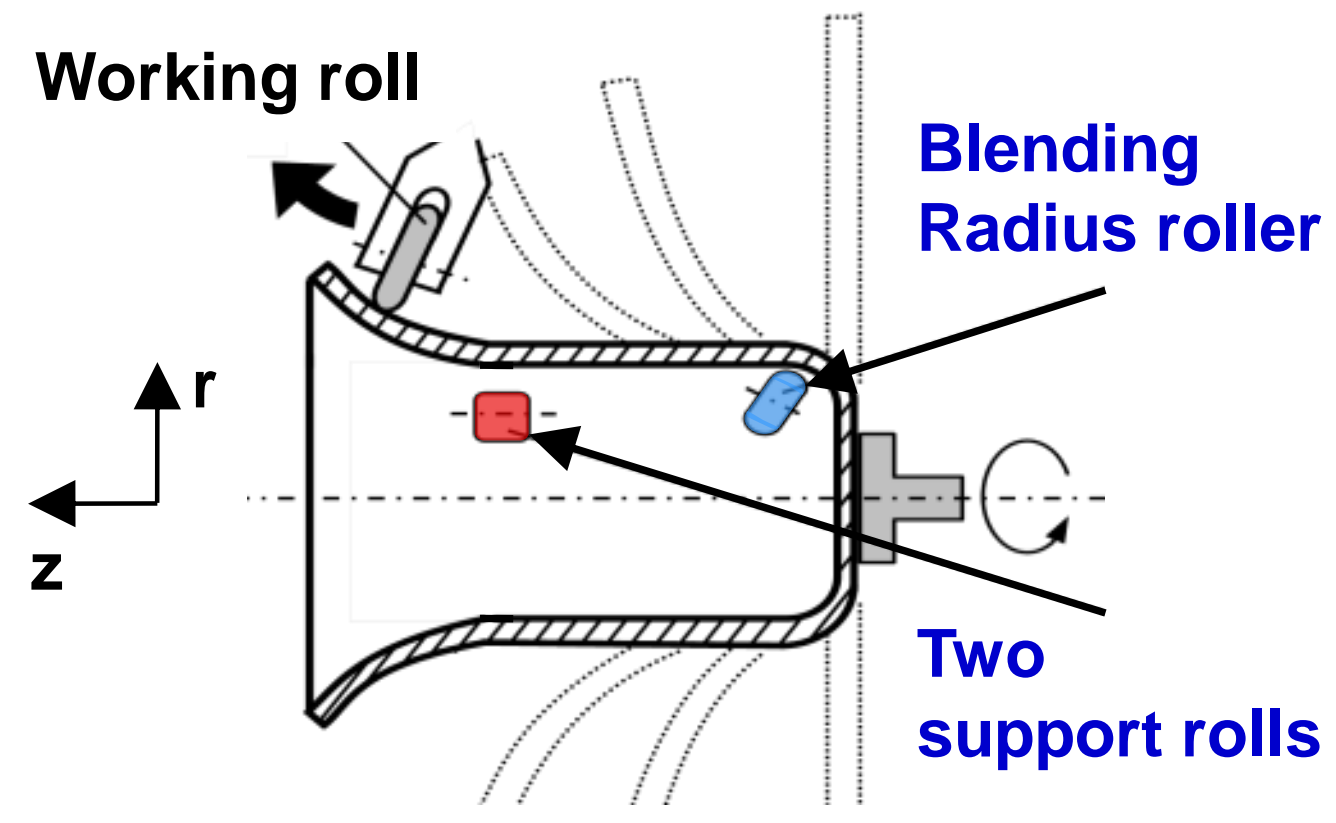

Fig. 9. Asymmetric spinning [148] 
Tripode

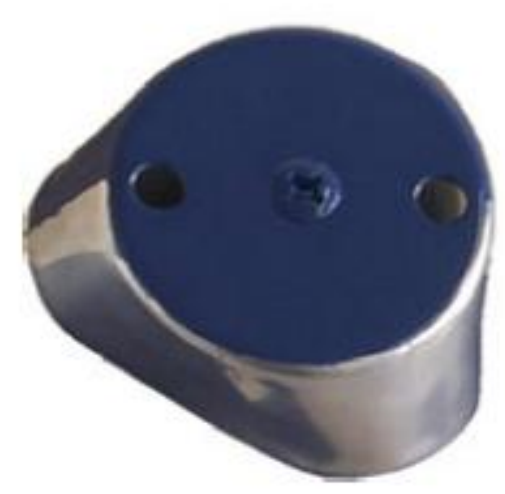

Reuleaux

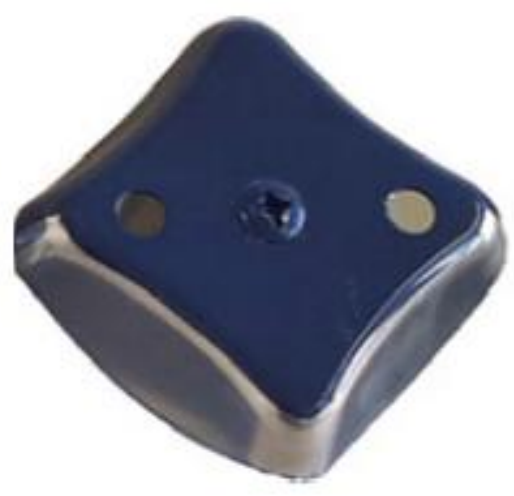

Pagode

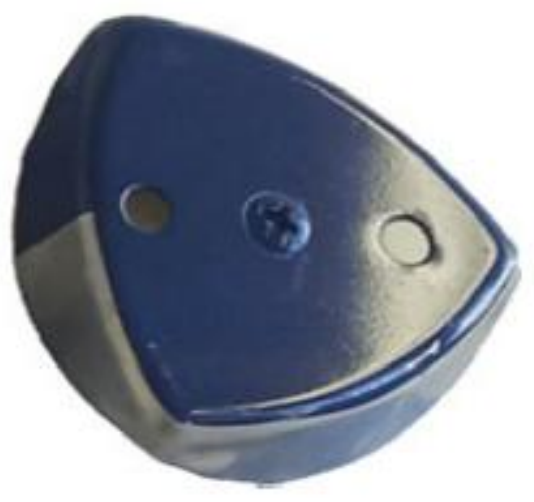

Fig. 10. Produced examples of non-circular spinning [16, 17] 


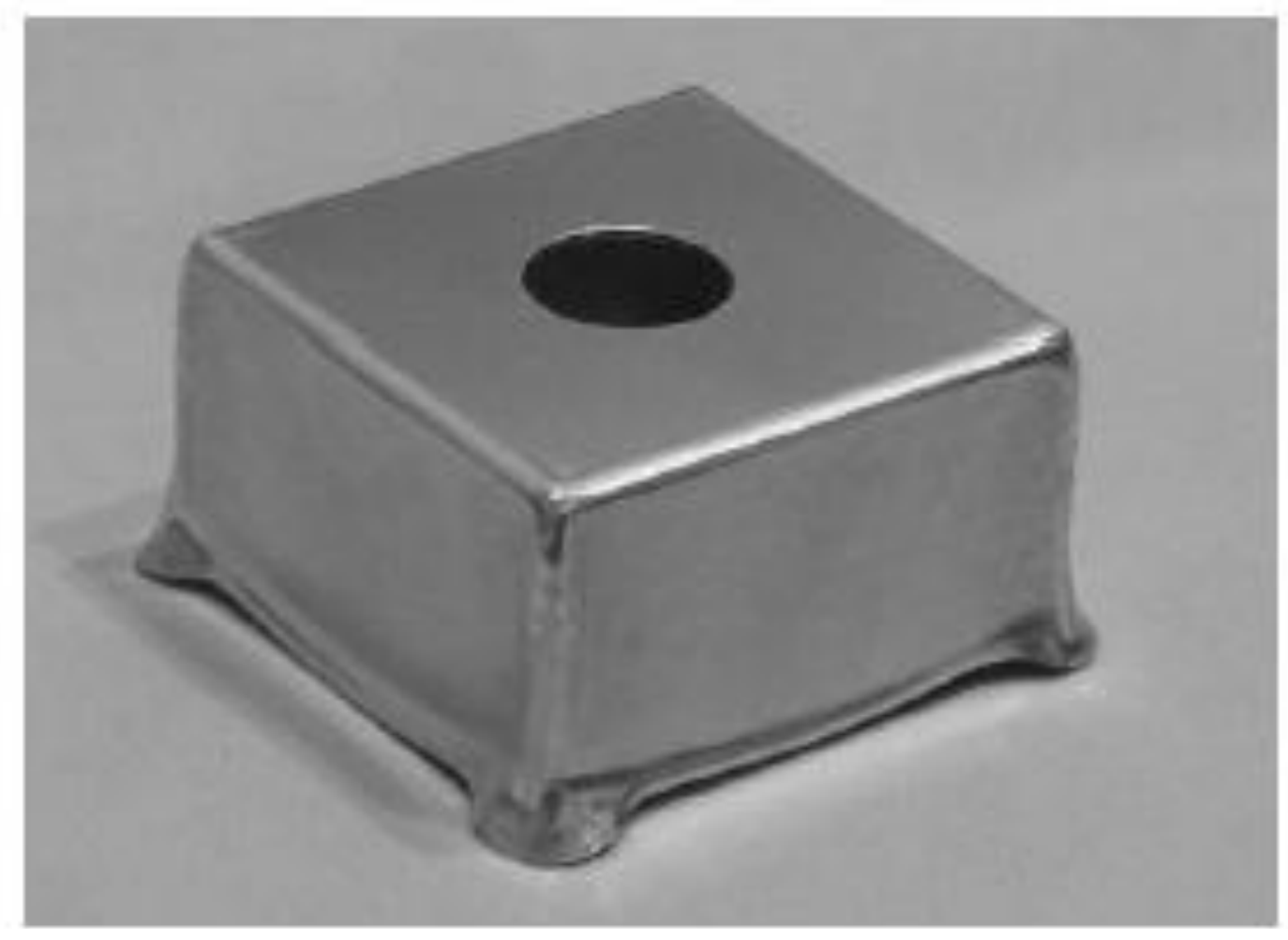

Fig. 11. Rectangular box shape through a synchronous multipath metal-spinning method [191] 


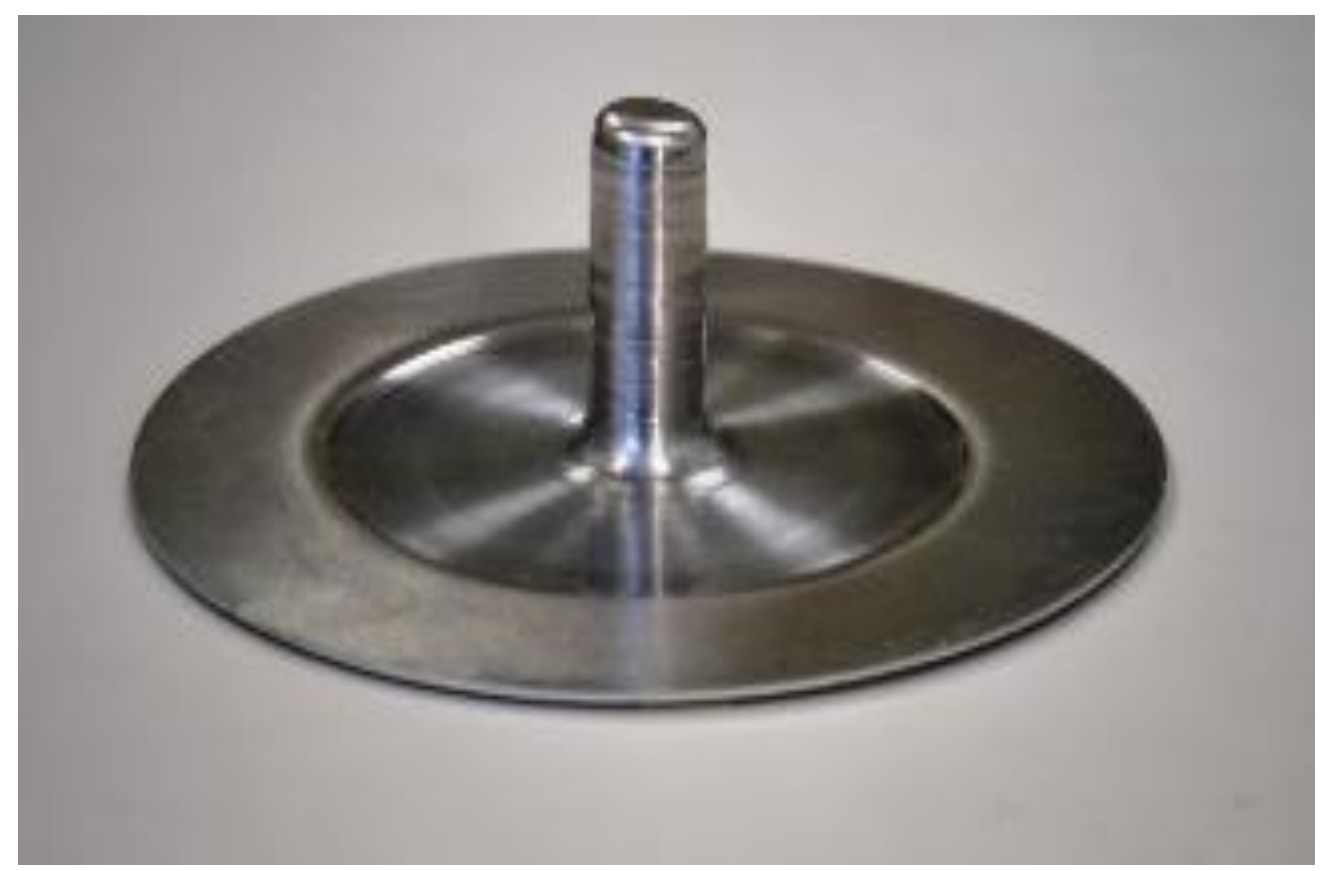

Fig. 12. Tube fabrication by spinning utilizing elastomer [194] 


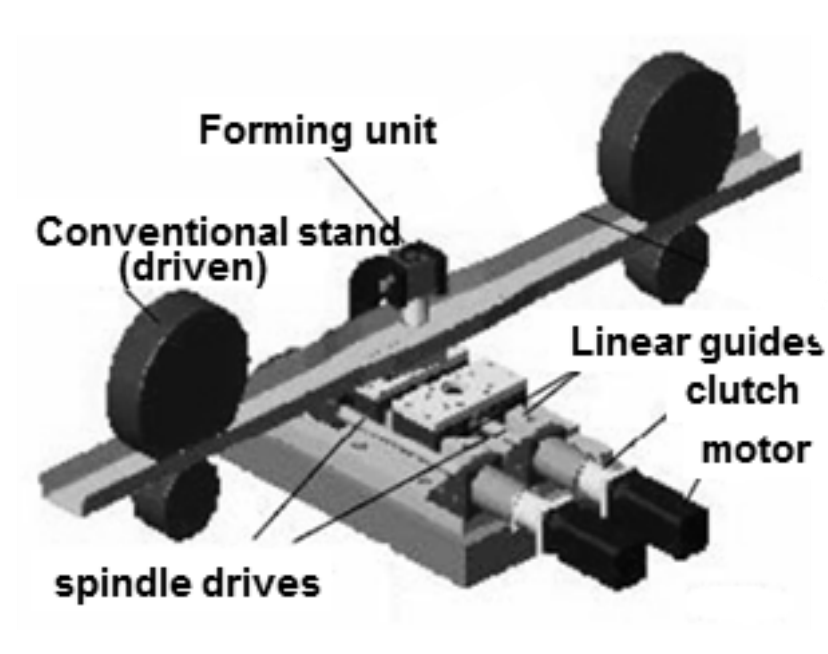

(a)

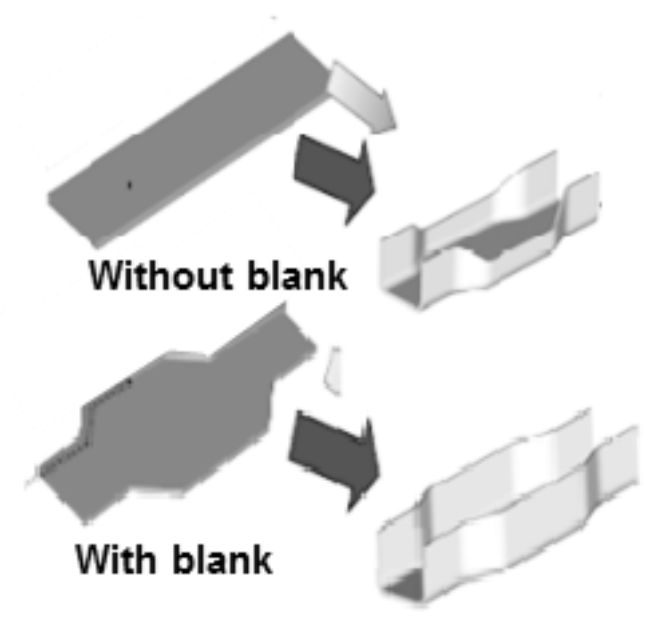

(b)

Fig. 13. Schematic of concept of flexible roll forming with additional forming unit (a) Apparatus (b) Design of blank [55] 


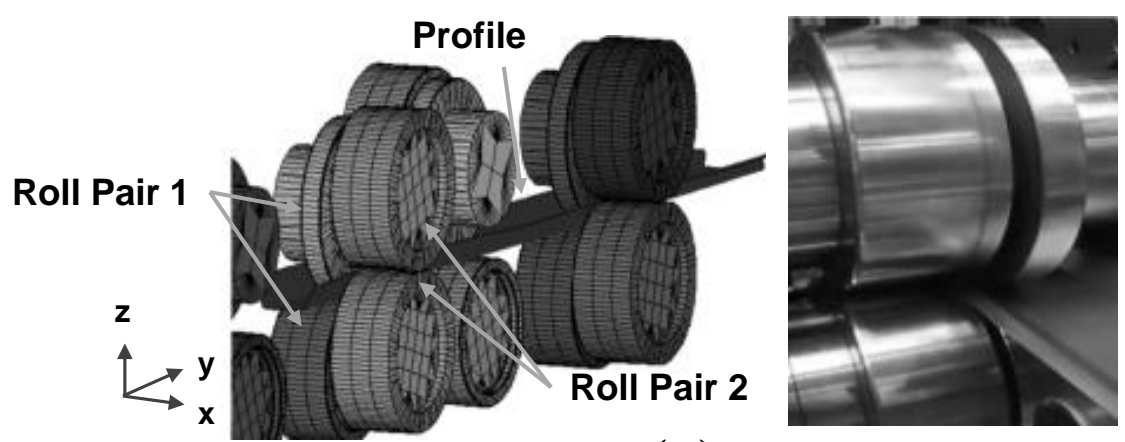

(a)

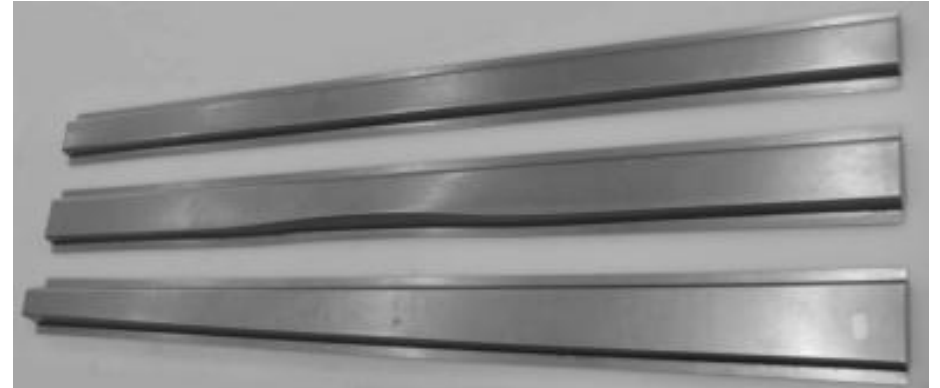

\section{Straight}

Middle Waist

Conical

(b)

Fig. 14. Schematic of 3D-roll forming (a) Apparatus (b) Product [116] 

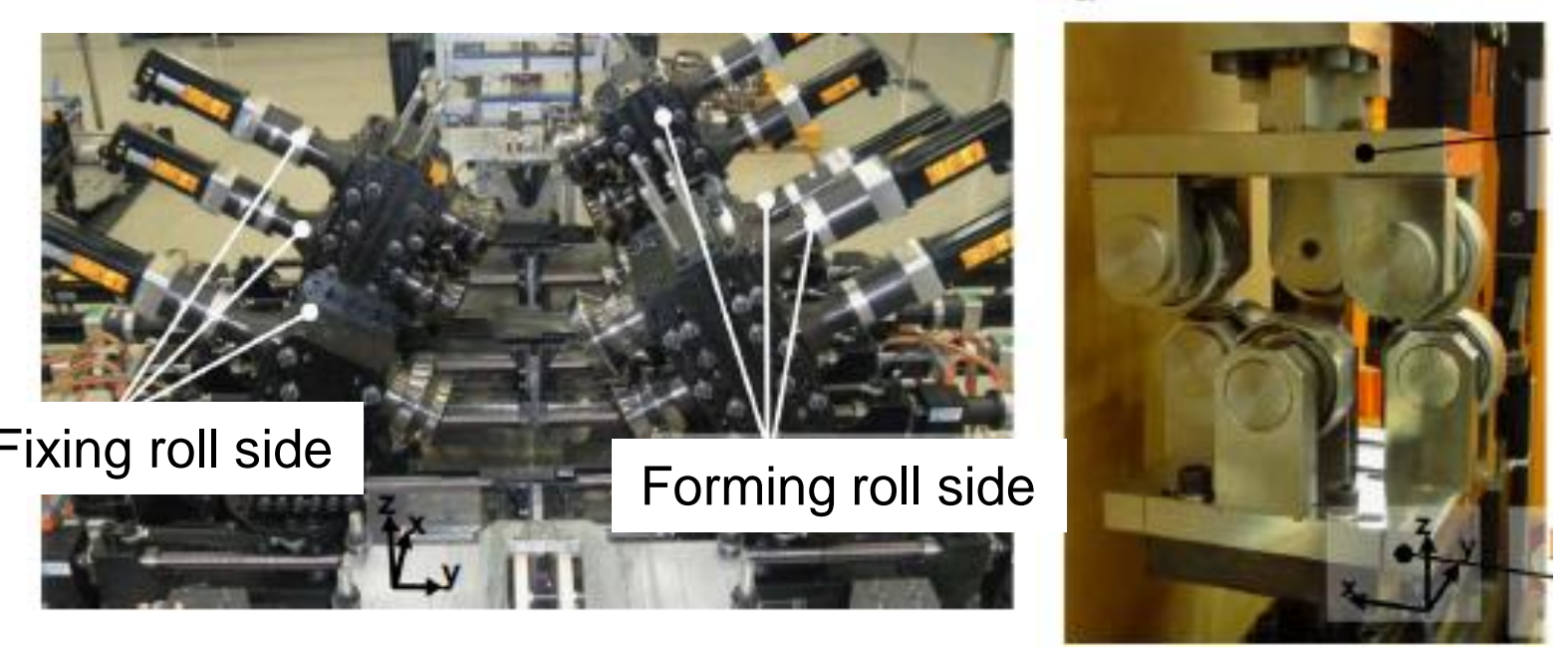

Fig. 15. Flexible roll forming using incremental counter forming [158] 


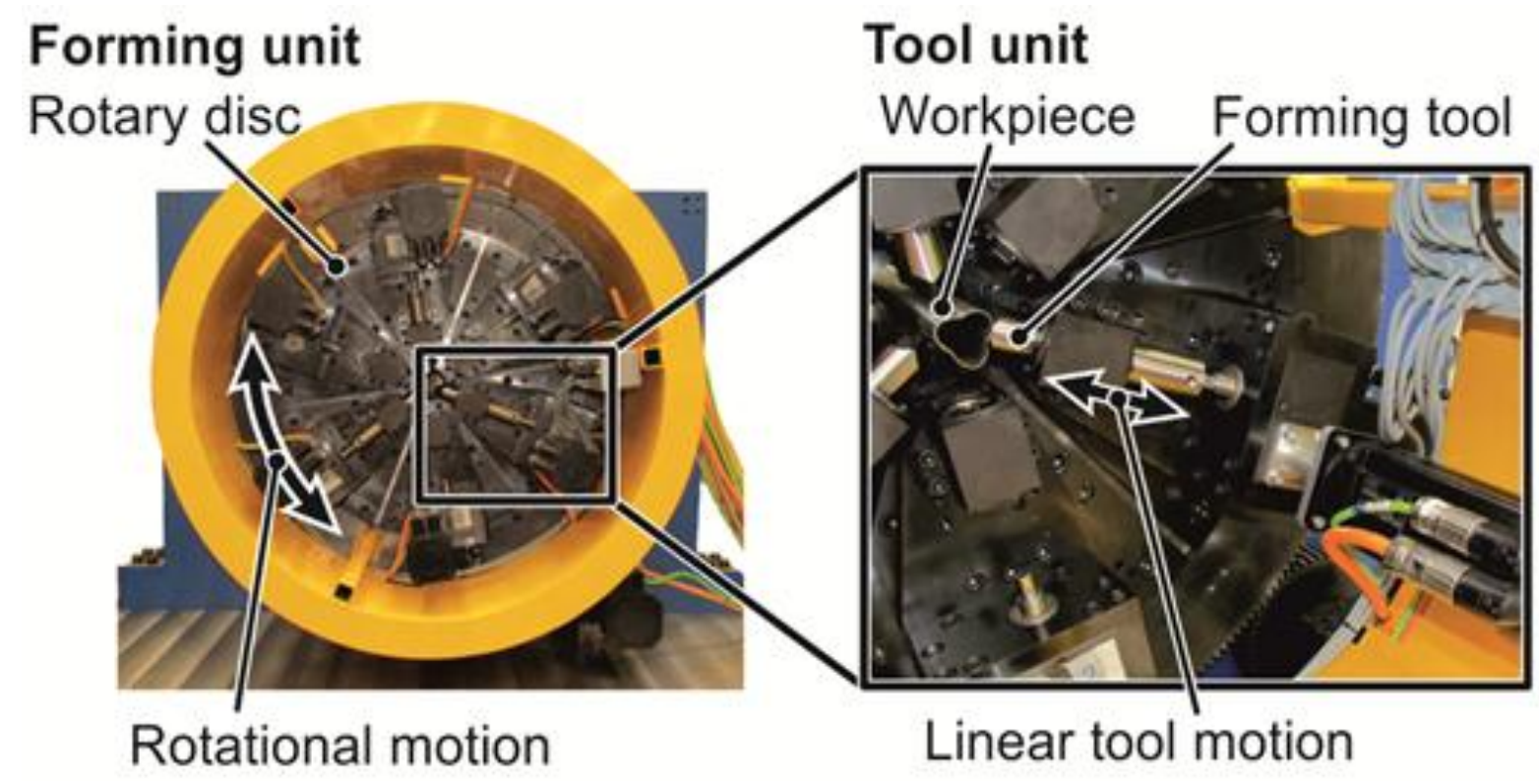

Fig. 16. Machine system for incremental profile forming [57] 


\begin{tabular}{|l|l|l|}
\hline Kinematic & Form closed & Combined \\
\hline & & \\
\hline
\end{tabular}

Fig. 17. Product examples of incremental profile forming [58] 

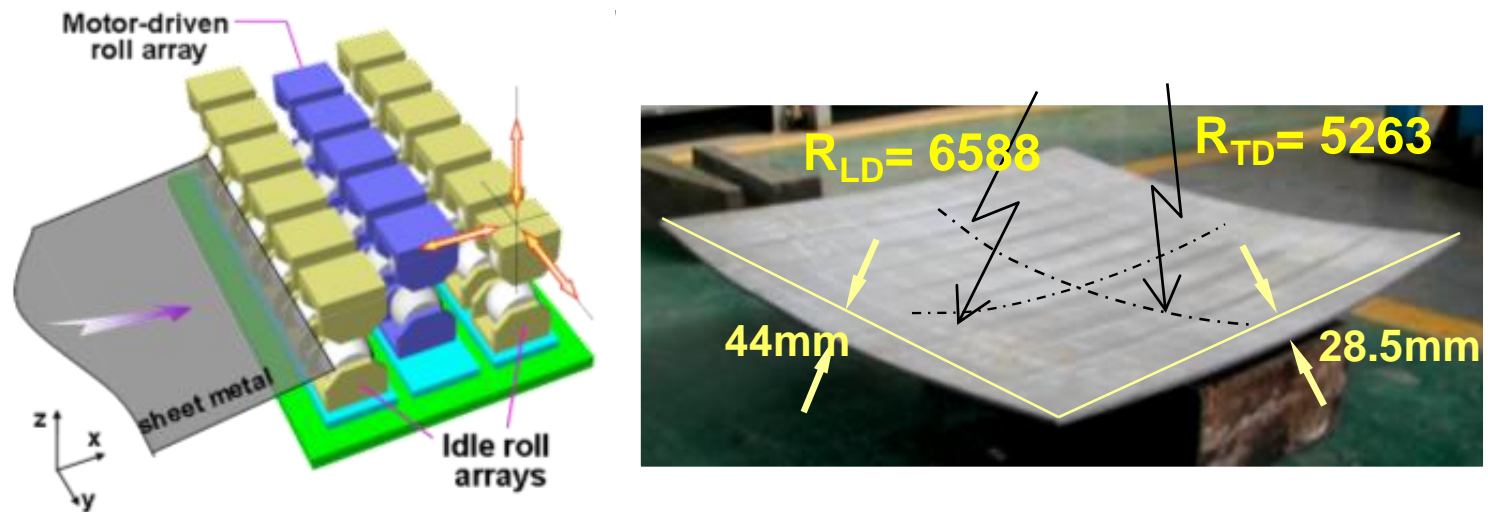

Fig. 18. Incremental rolling of doubly curved plates [177] 


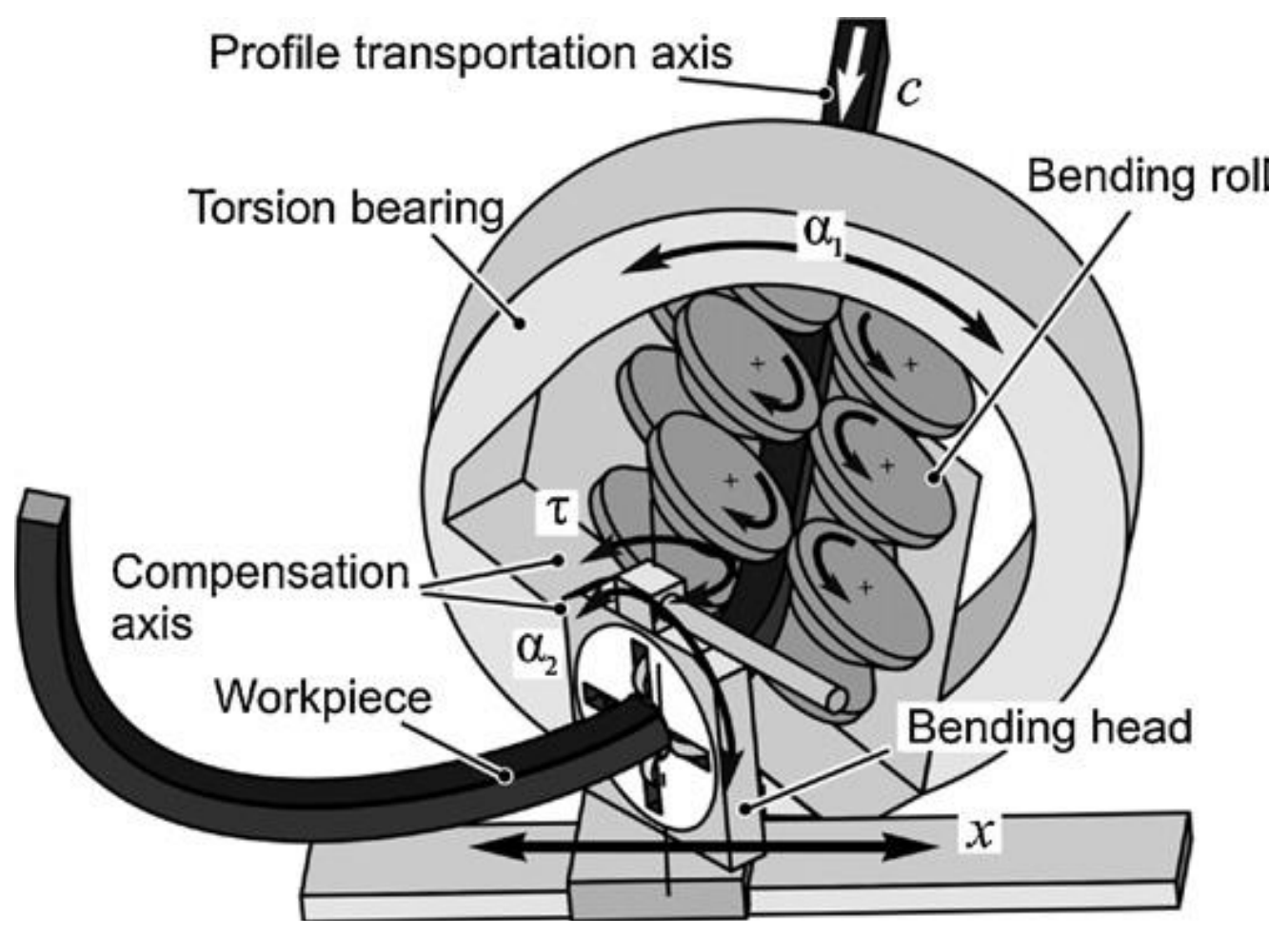

Fig. 19. Schematic of a machine setup-up of the TSS bending process [28] 


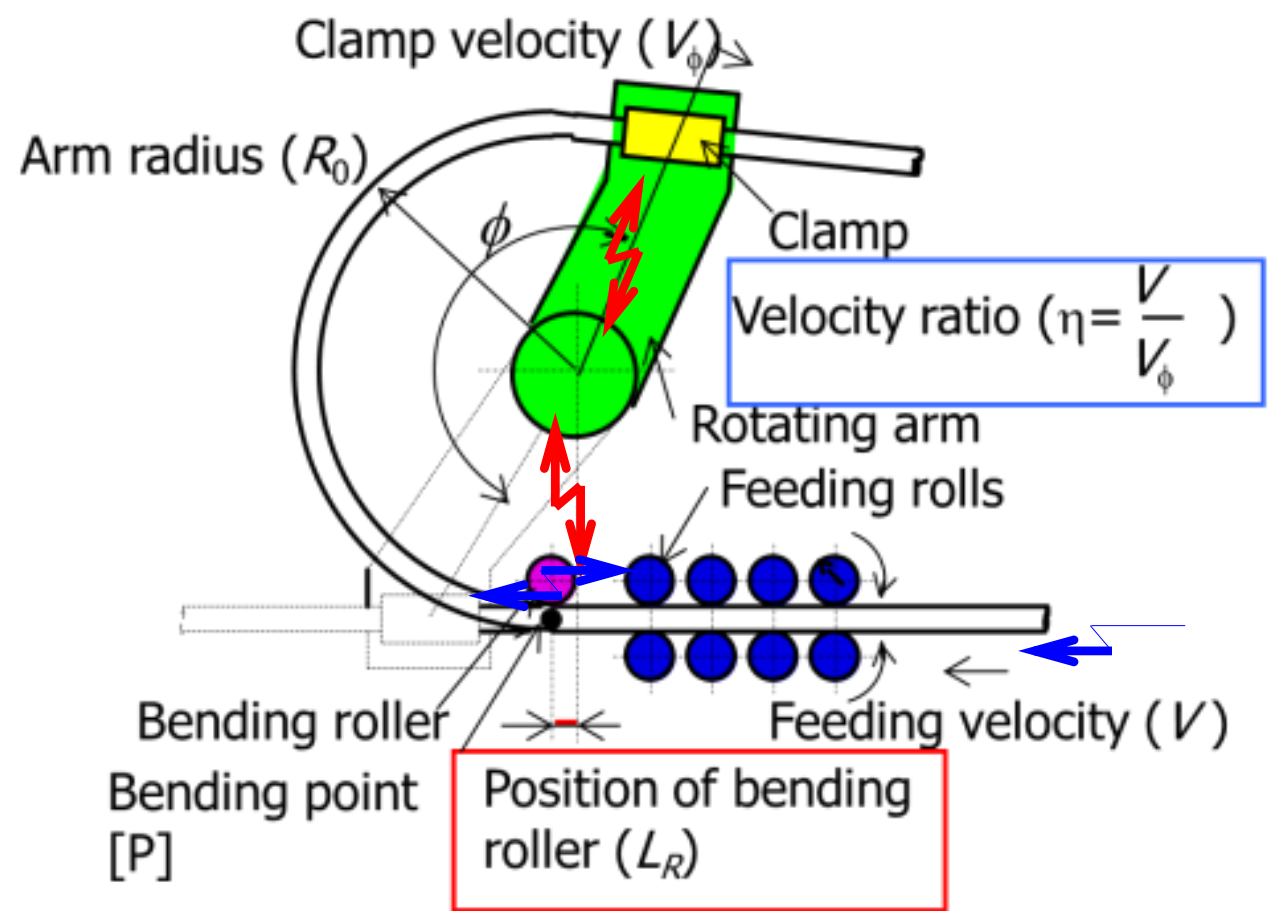

Fig. 20. Dieless U-bending process [93] 


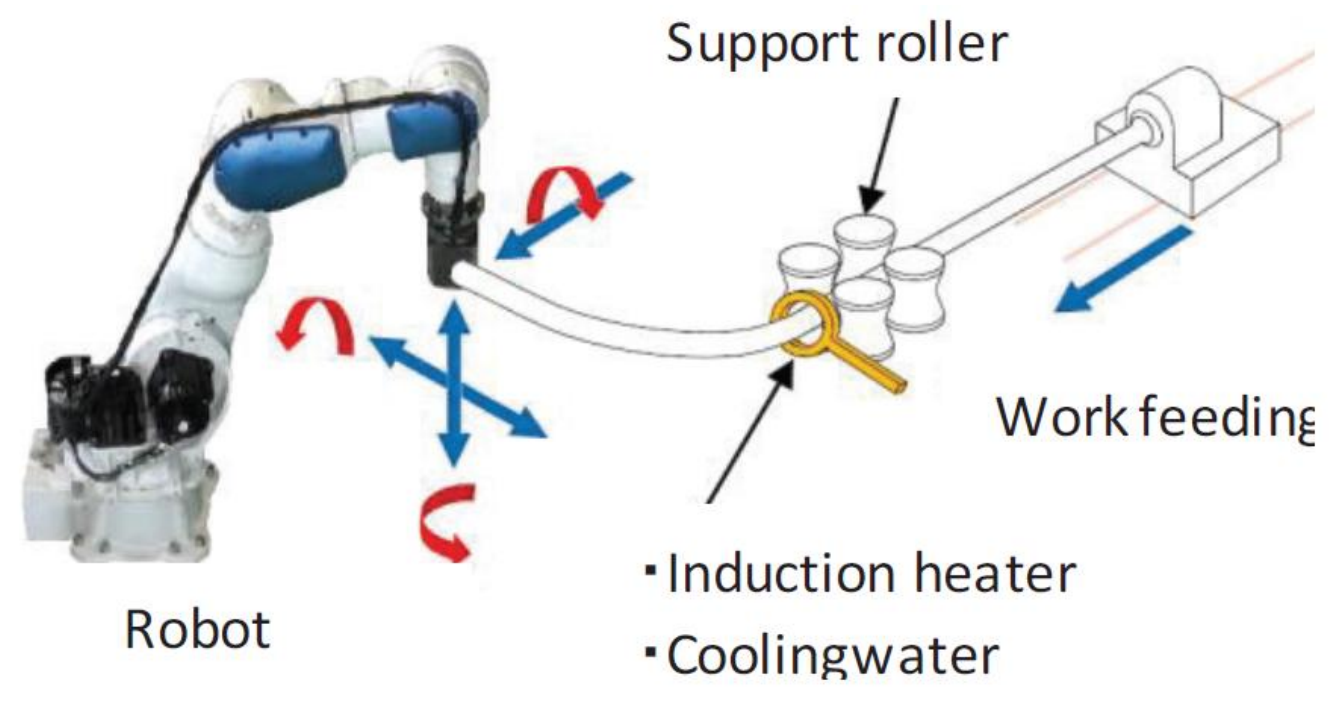

Fig. 21. Schematic figure of the three-dimensional hot bending and direct quench [178] 

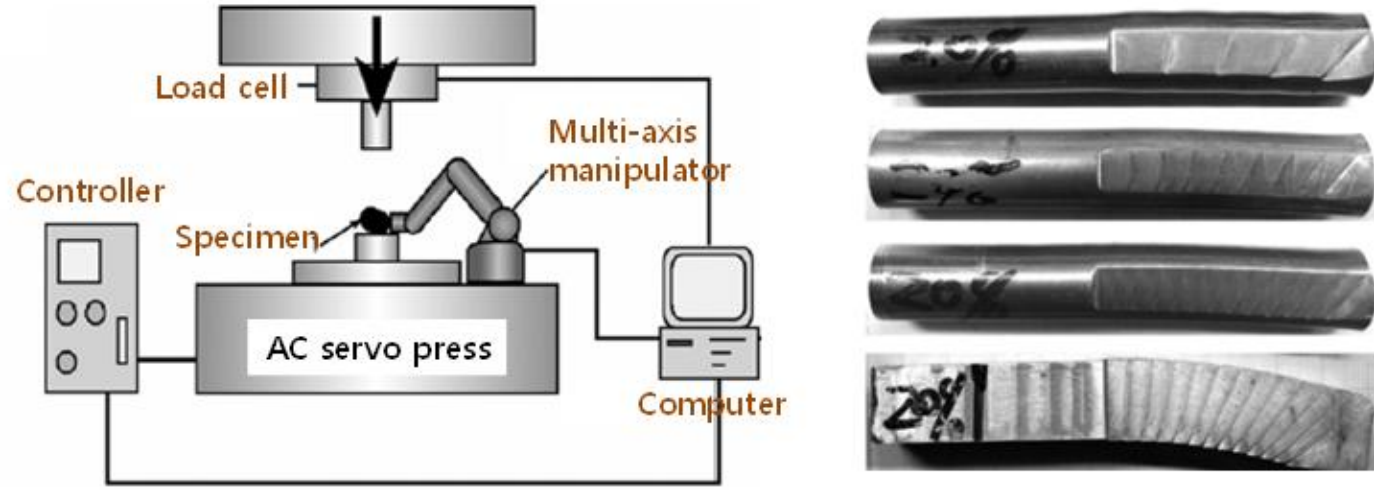

Fig. 22. Incremental forging with a robot and formed products with various shape [203] 


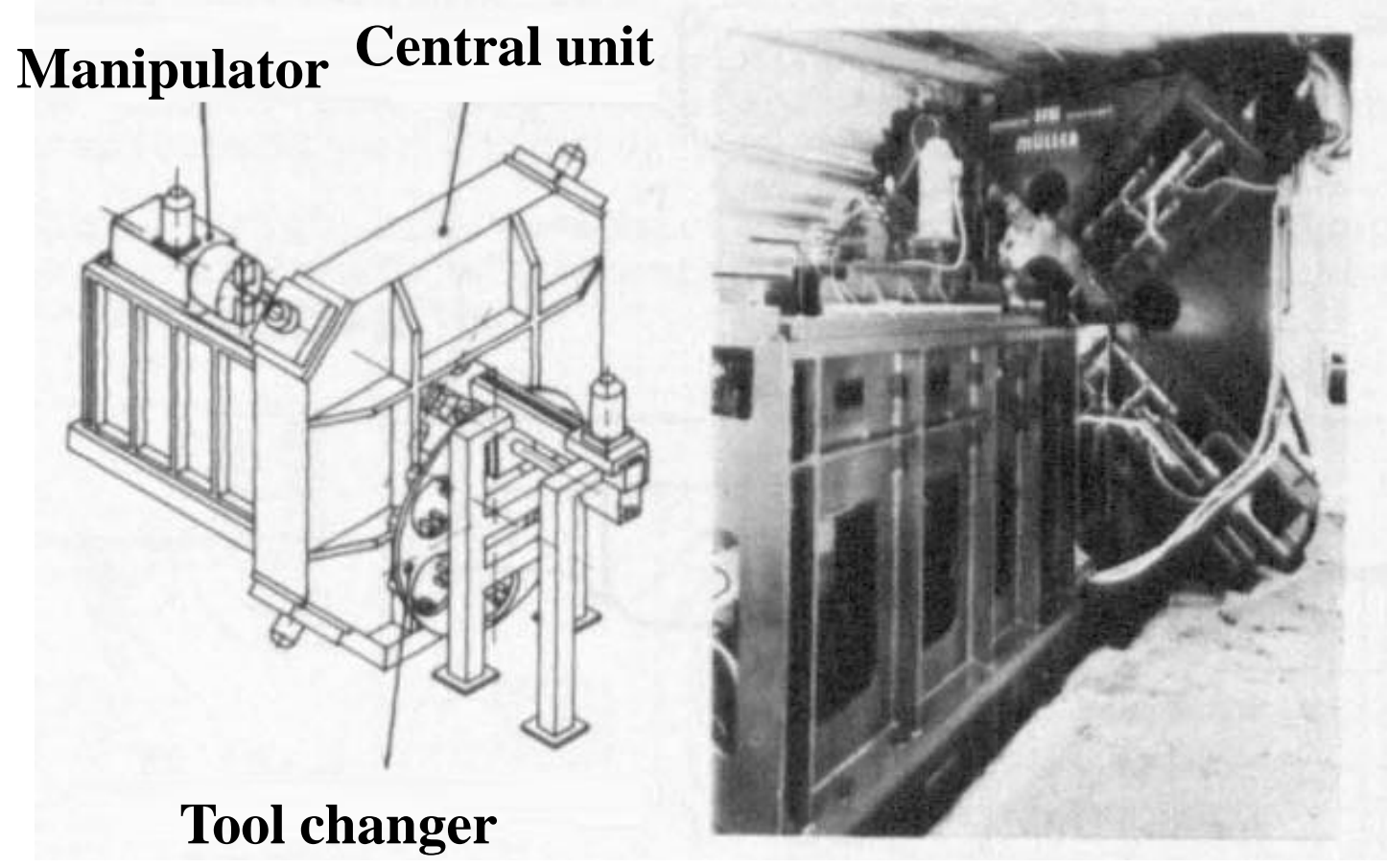

Fig. 23. Radial forming machine RUMX 2000 [103, 159] 


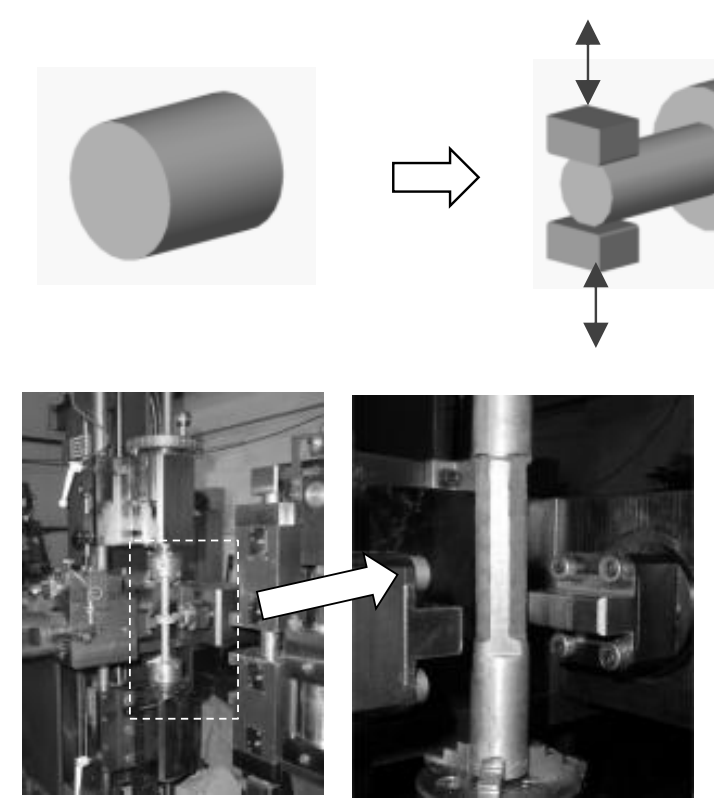

(b)

(a)

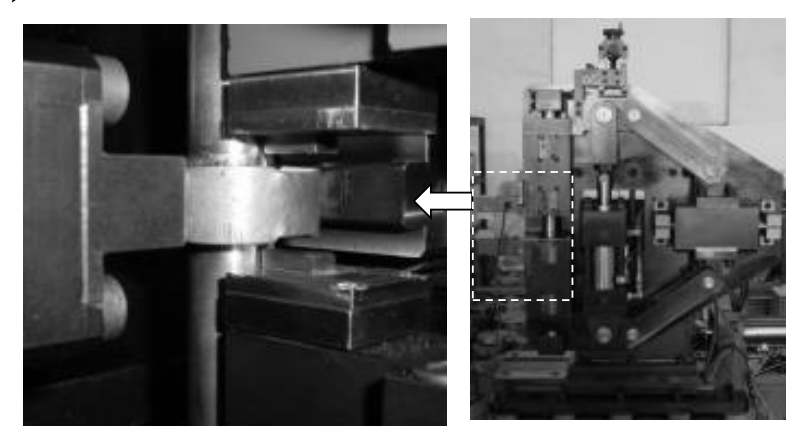

(c)

Fig. 24. Schematic of incremental radial-axial forging of flanged shaft parts (a) Concept of the incremental radial-axial forging (b) Radial forging (c) Axial forging [109] 


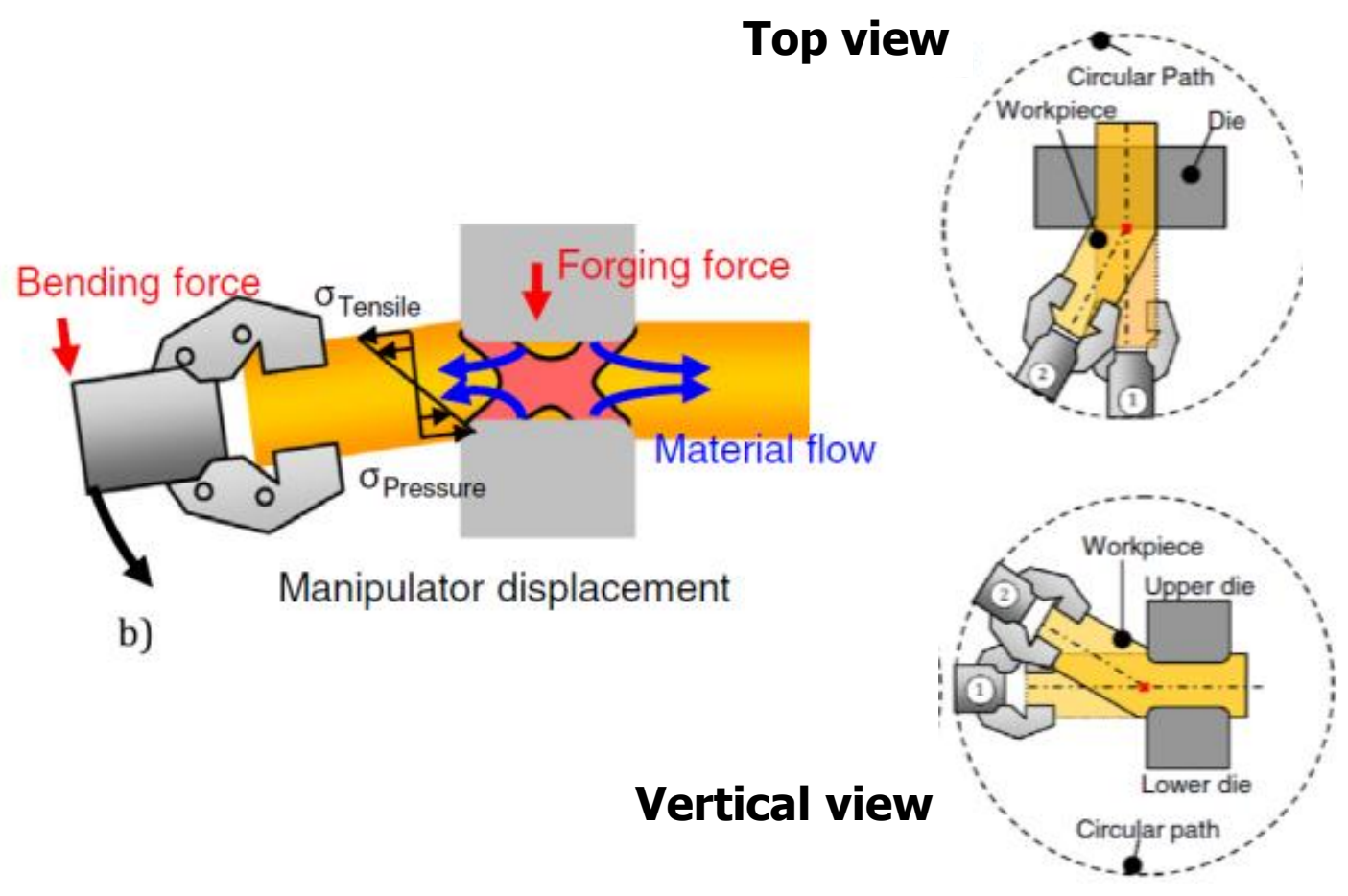

Fig. 25. Open die forging for curved workpieces [206] 

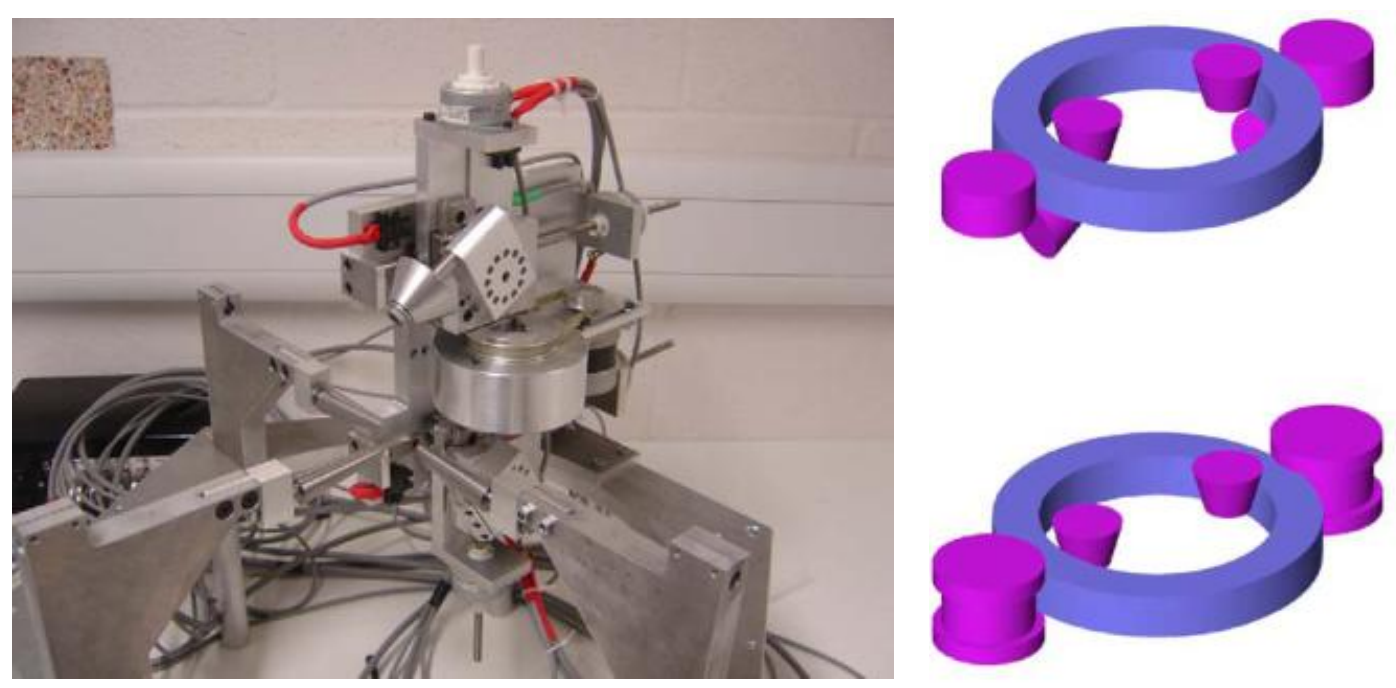

Fig. 26. Flexible ring rolling machine and the module of the experimental ring rolling machine [187] 

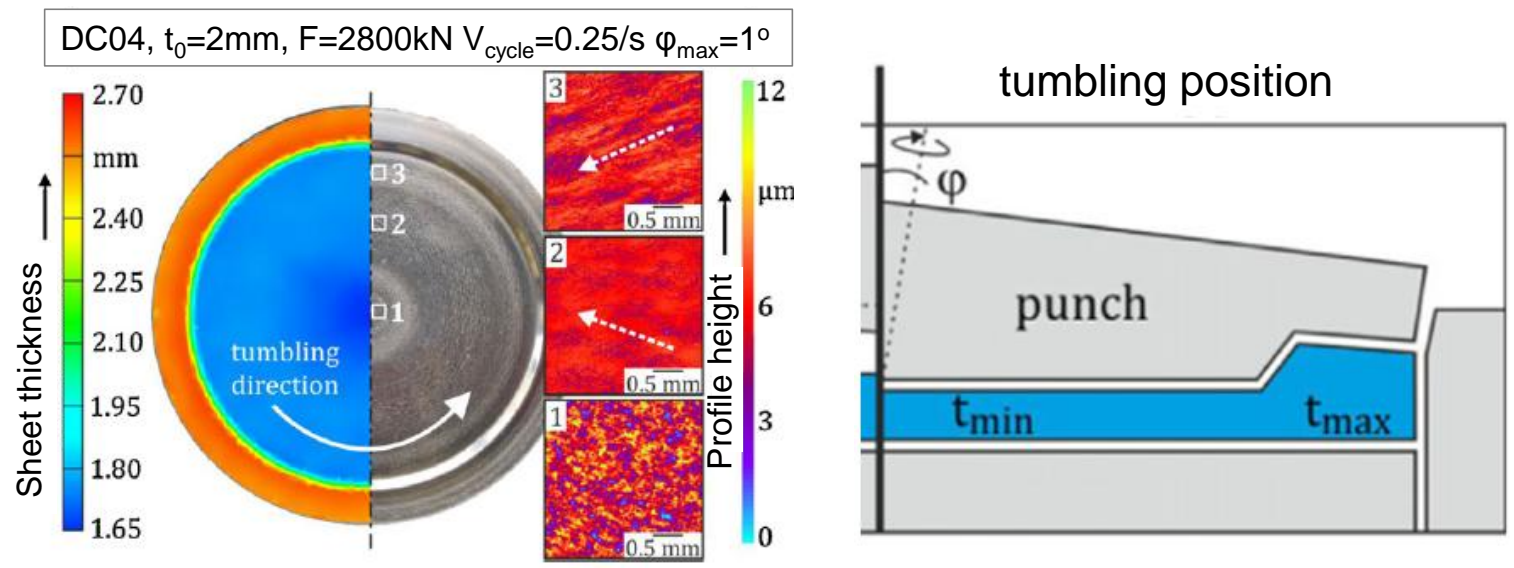

Fig. 27. Tailored blank by orbital forging [136] 

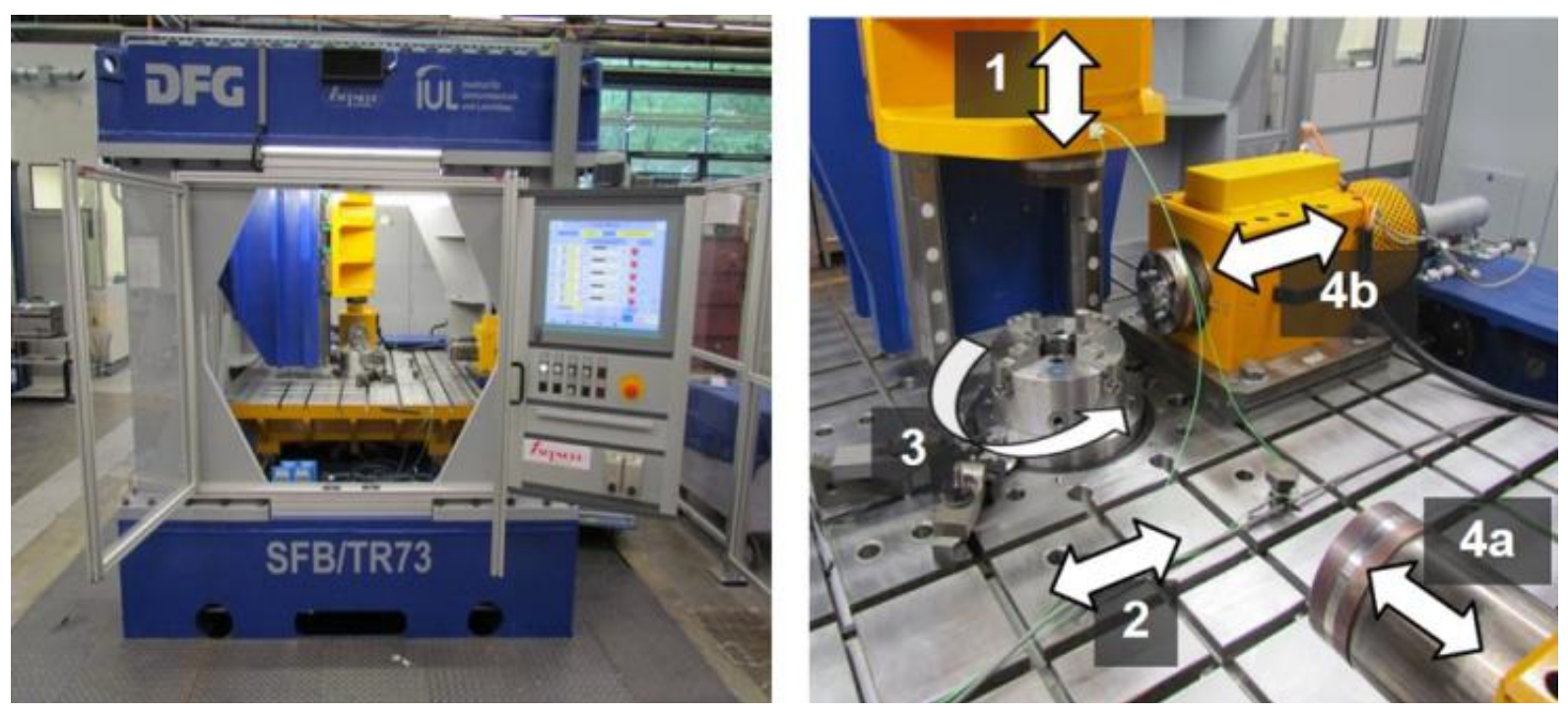

Fig. 28. Five-axis forming press for the incremental sheet-bulk metal forming [180] 
a)

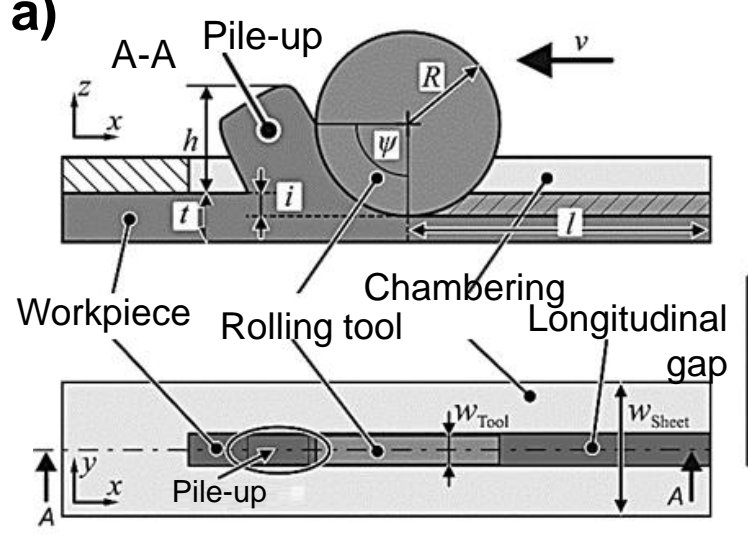

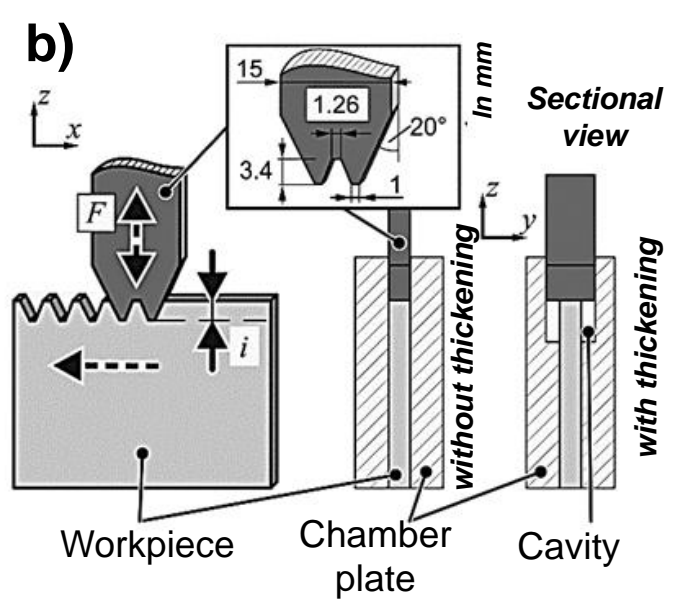

Fig. 29. Schematic presentation of the processing of a) the sheet plane and b) the sheet edge. [181] 


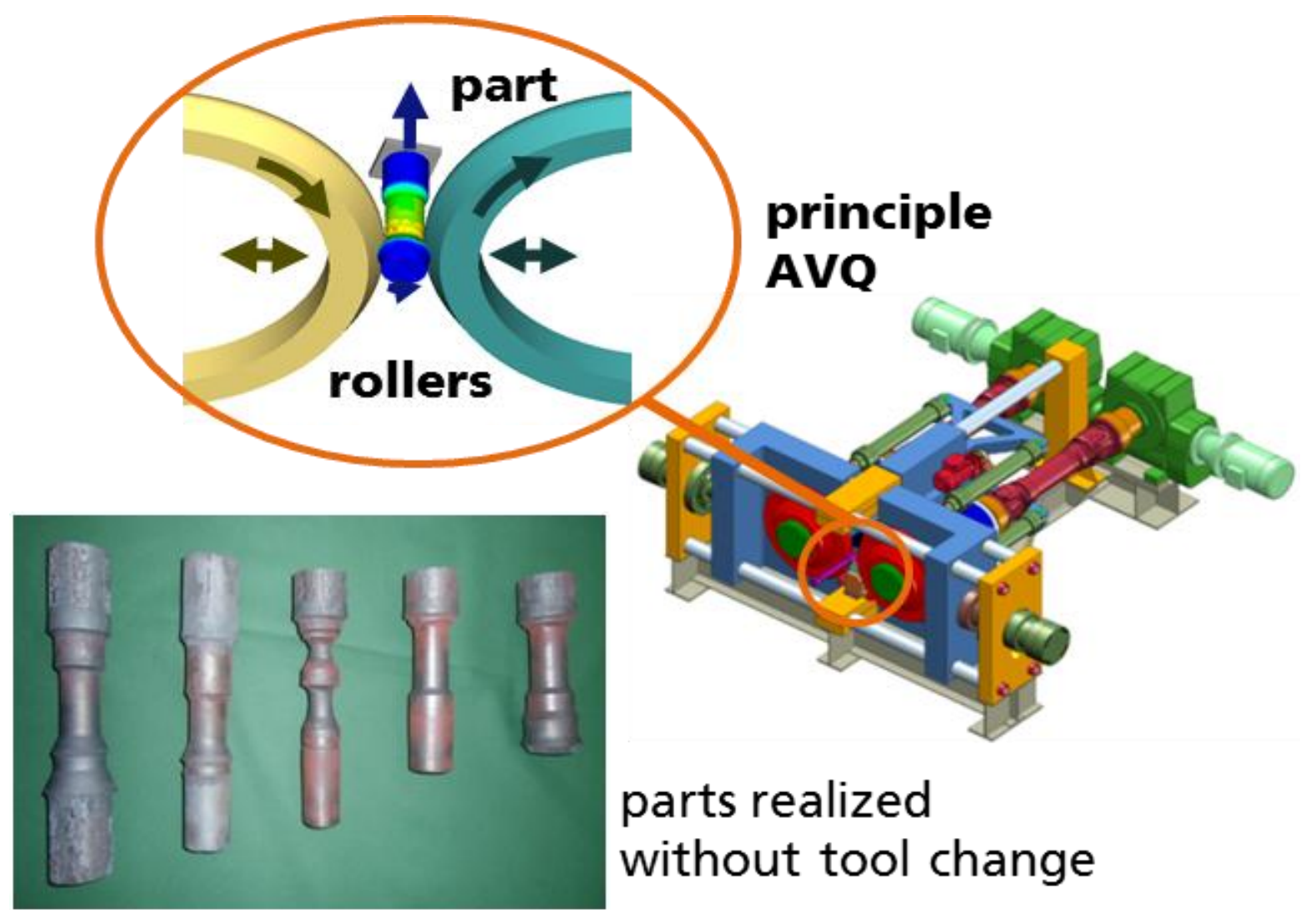

Fig. 30. Schematic figure of the axial feed cross rolling process and products [100] 


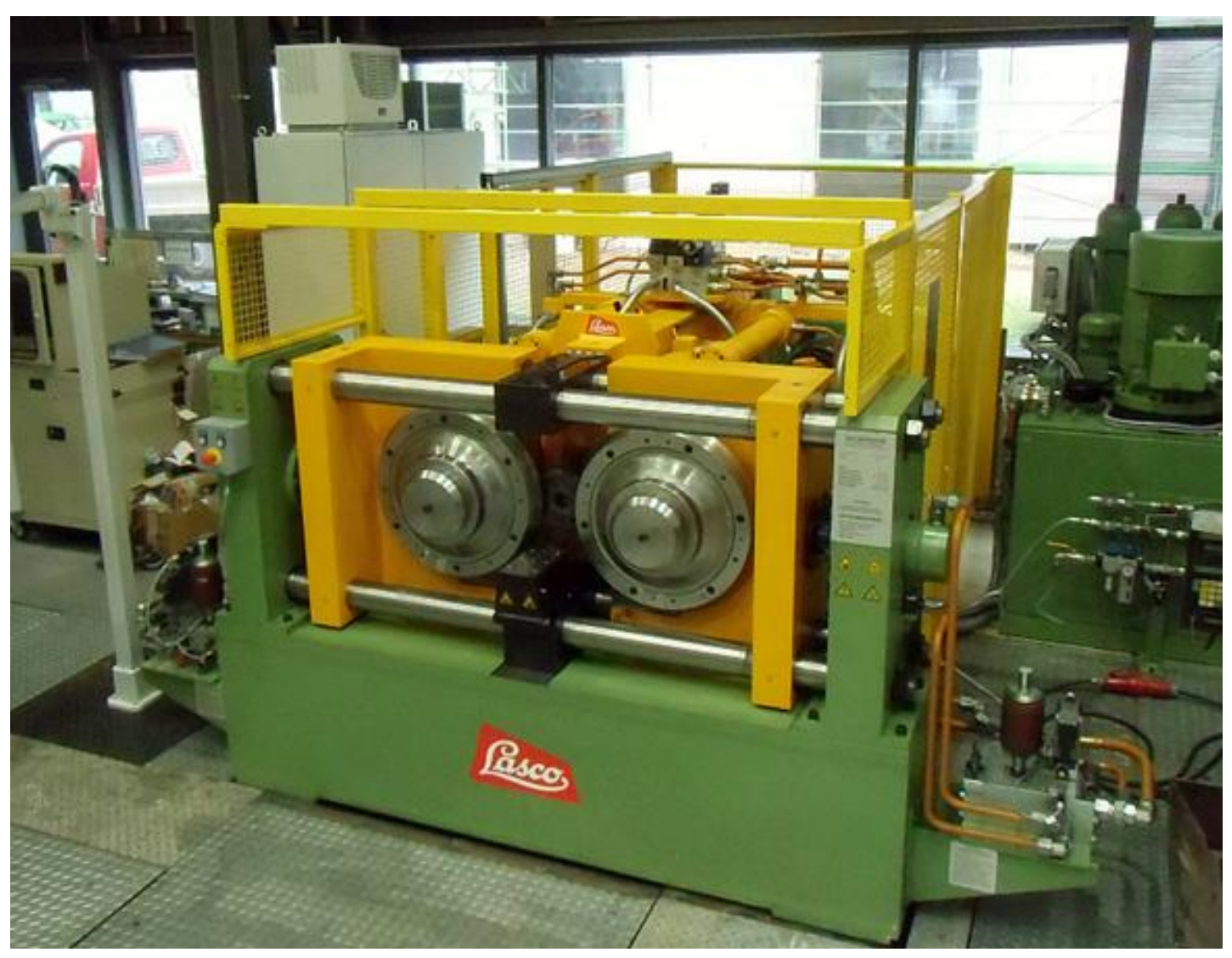

Fig. 31. Prototype machine for axial feed cross rolling [190] 

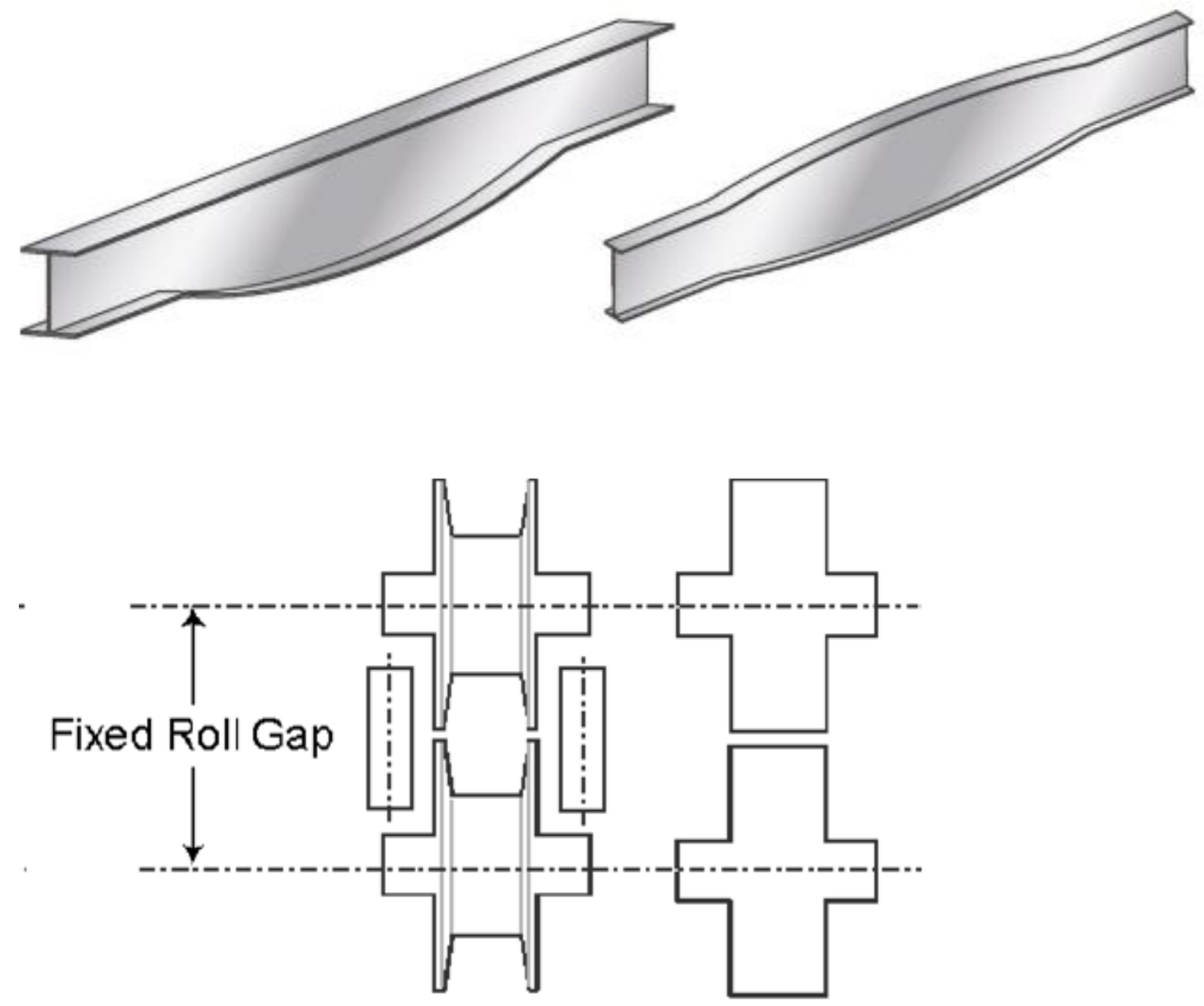

Stage 4

Stage 5

Fig. 32. Hot rolling for variable cross-section [27] 


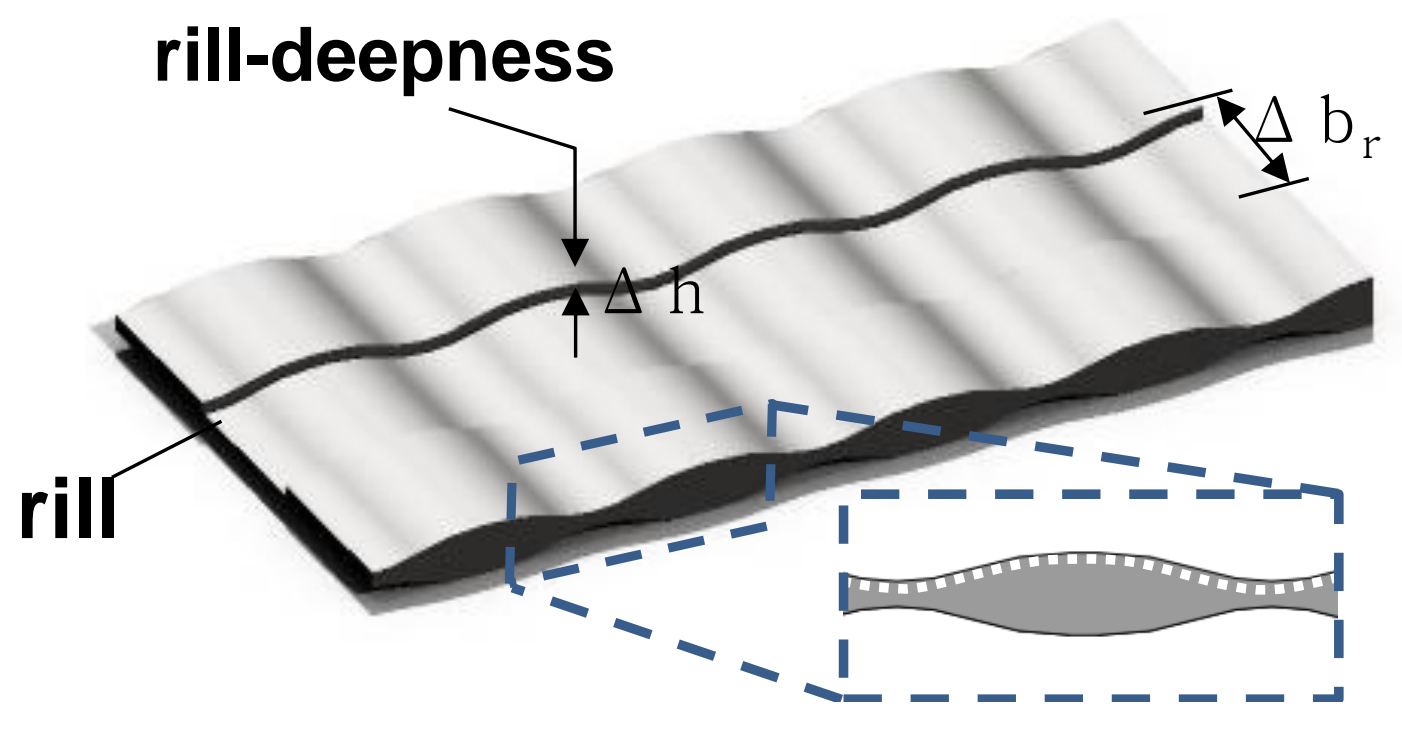

Fig. 33. 3D-profiled blank [166] 


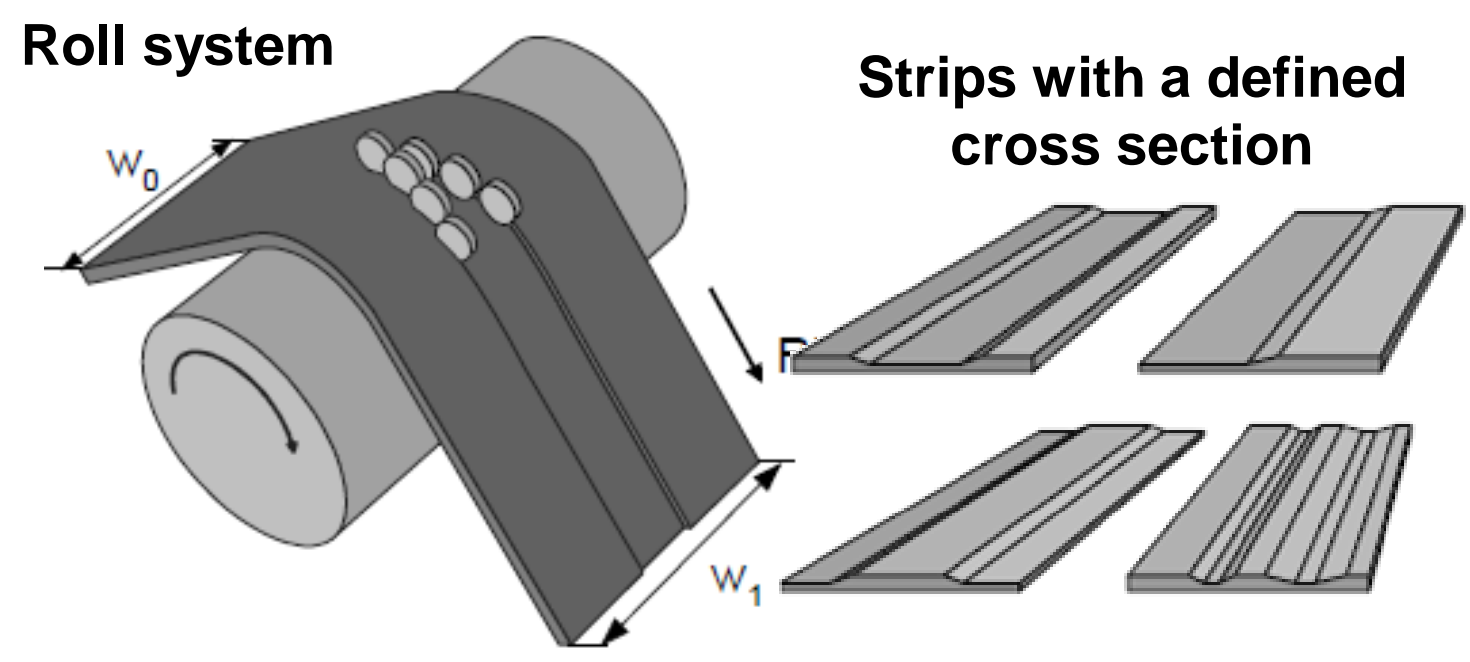

Fig. 34. Flexible rolling for defined cross section [88] 


\section{Plate forging}

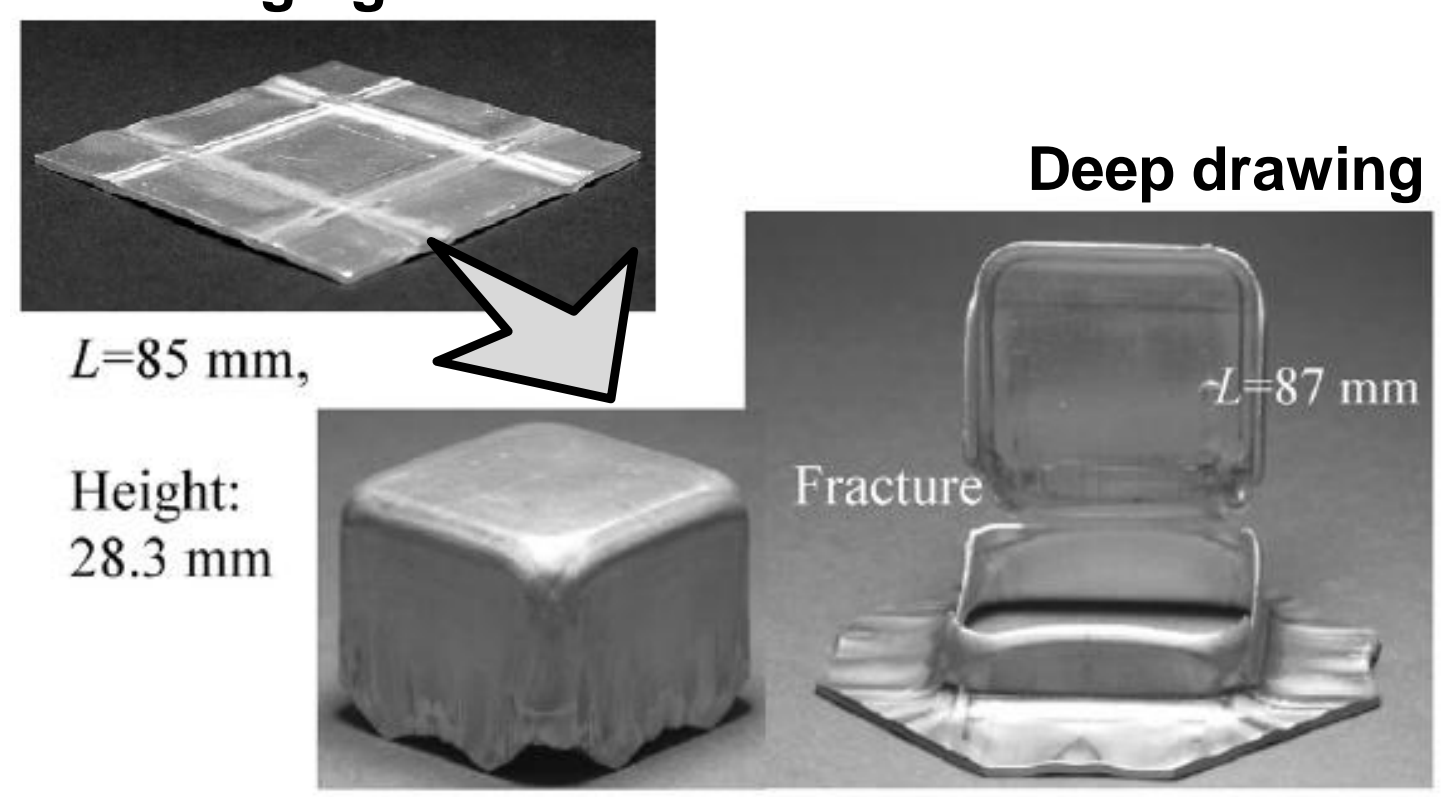

Fig. 35. Plate forming of tailored blanks [141] 


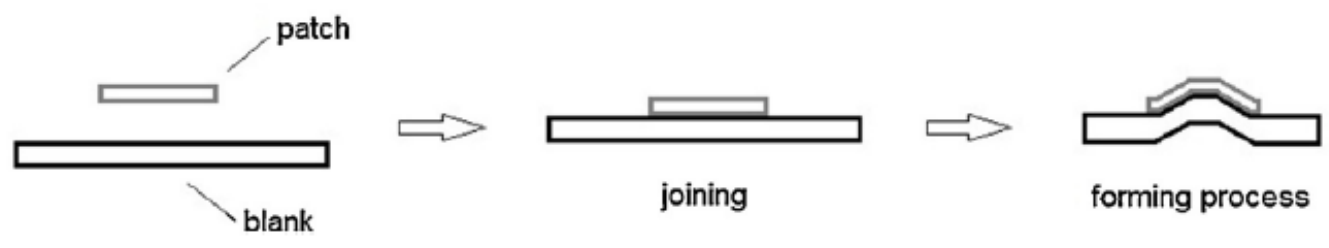

\section{Automotive components with patches}
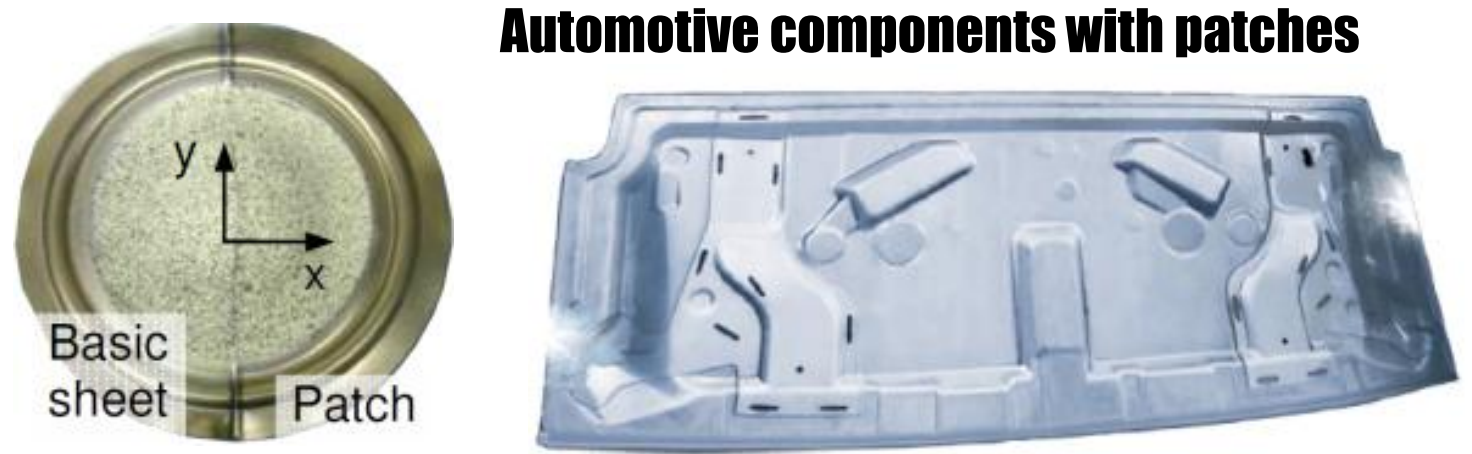

Fig. 36. Automotive components with patches [99] 


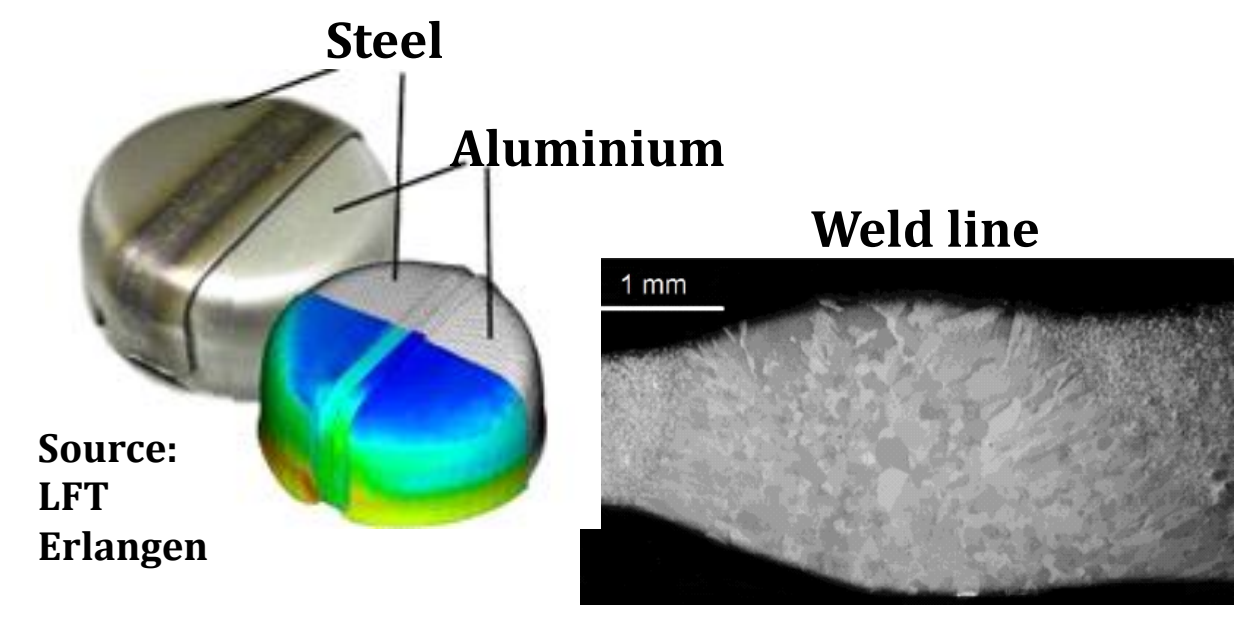

Five-piece body side (TWB)

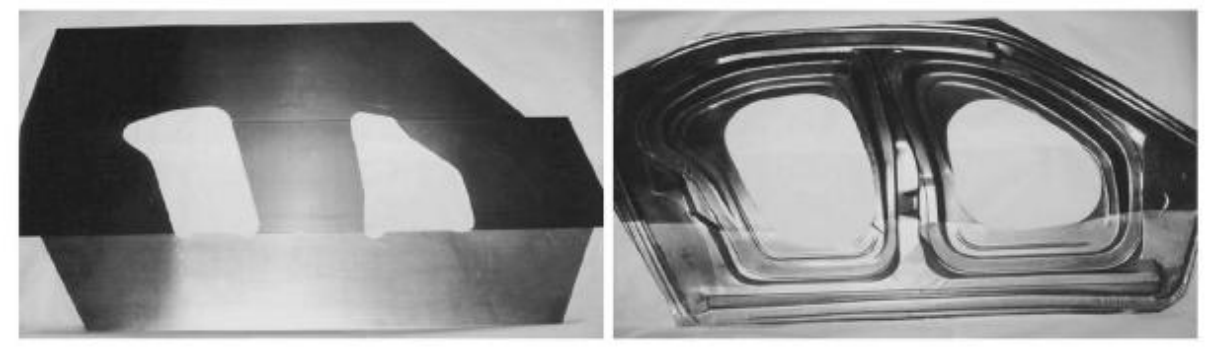

Fig. 37. Examples of the tailor welded blanks [132] 


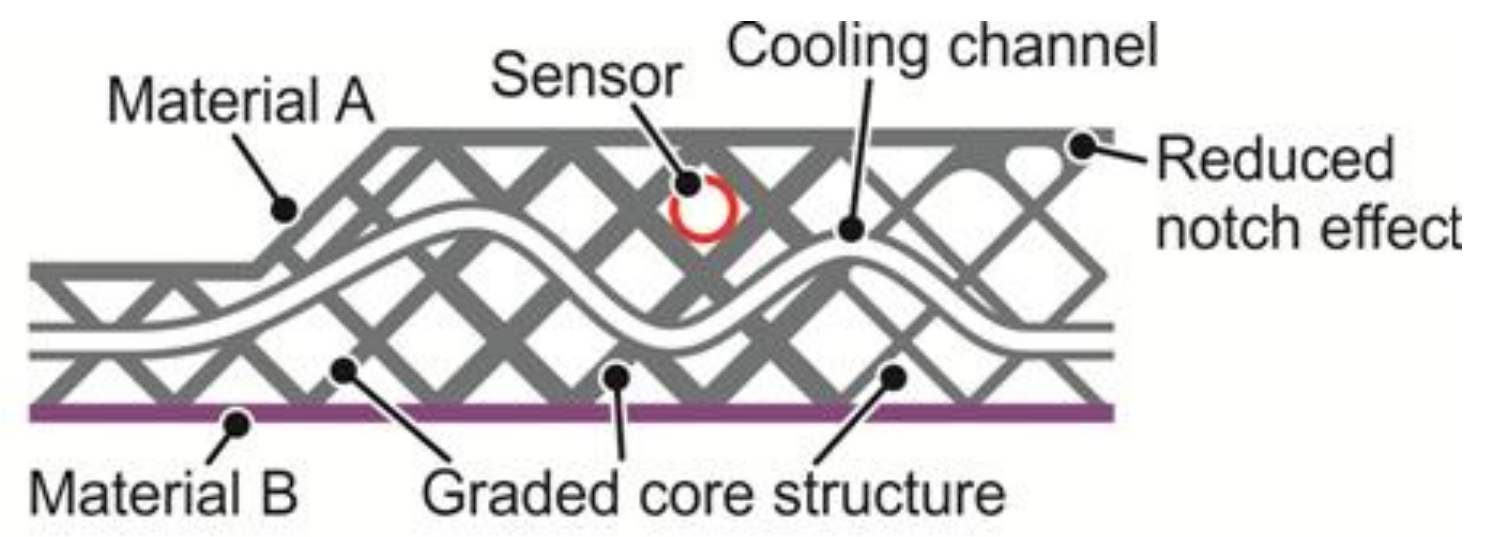

Fig. 38. Schematic composition of multi-material additively manufactured sandwich sheets with integrated functions 


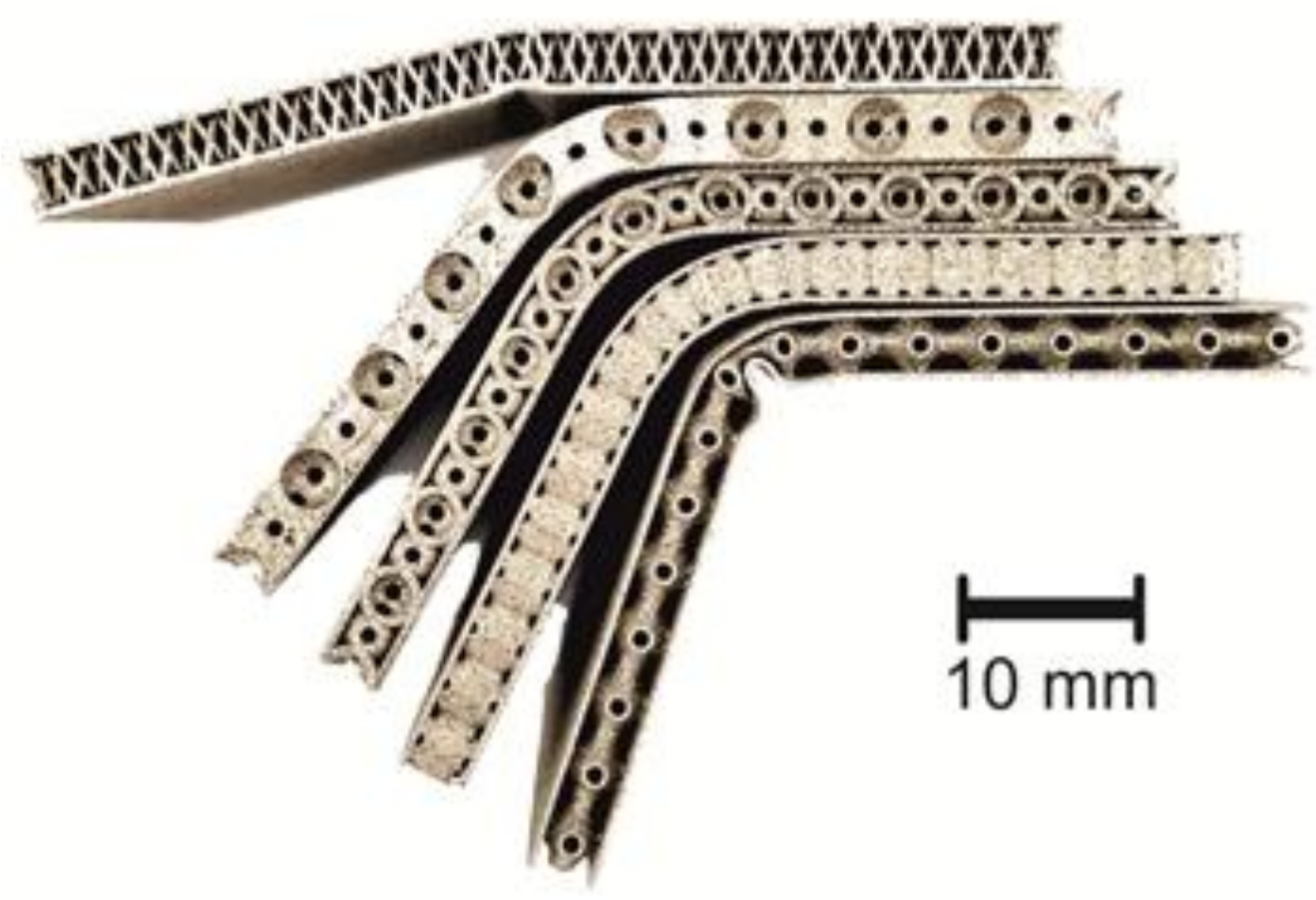

Fig. 39. Metallic sandwich sheets manufactured by selective laser melting with different core structures after bending to the same bending angle showing different spring-back. 


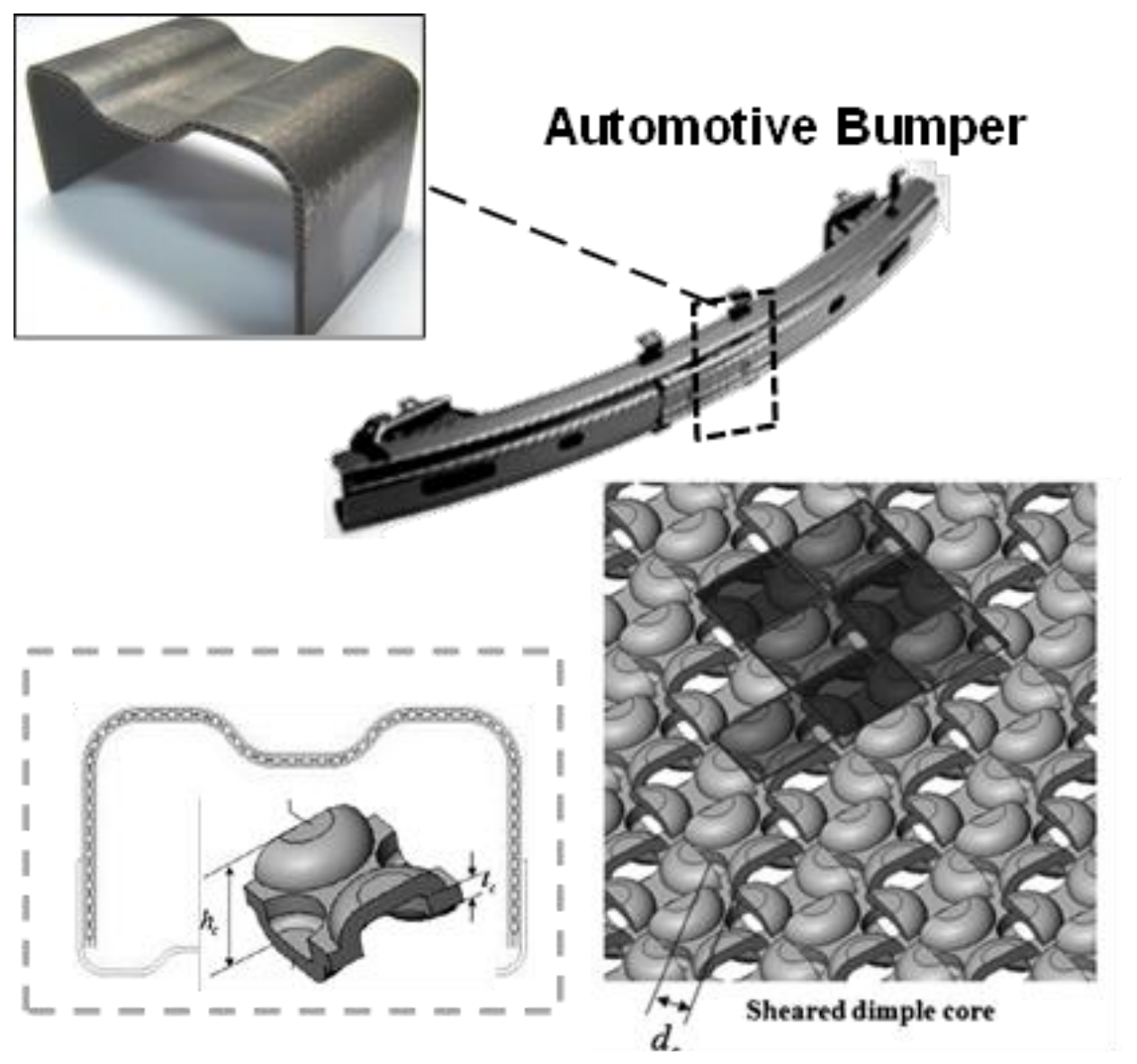

Fig. 40. Application of the bendable metallic sandwich plate $[171,172]$ 


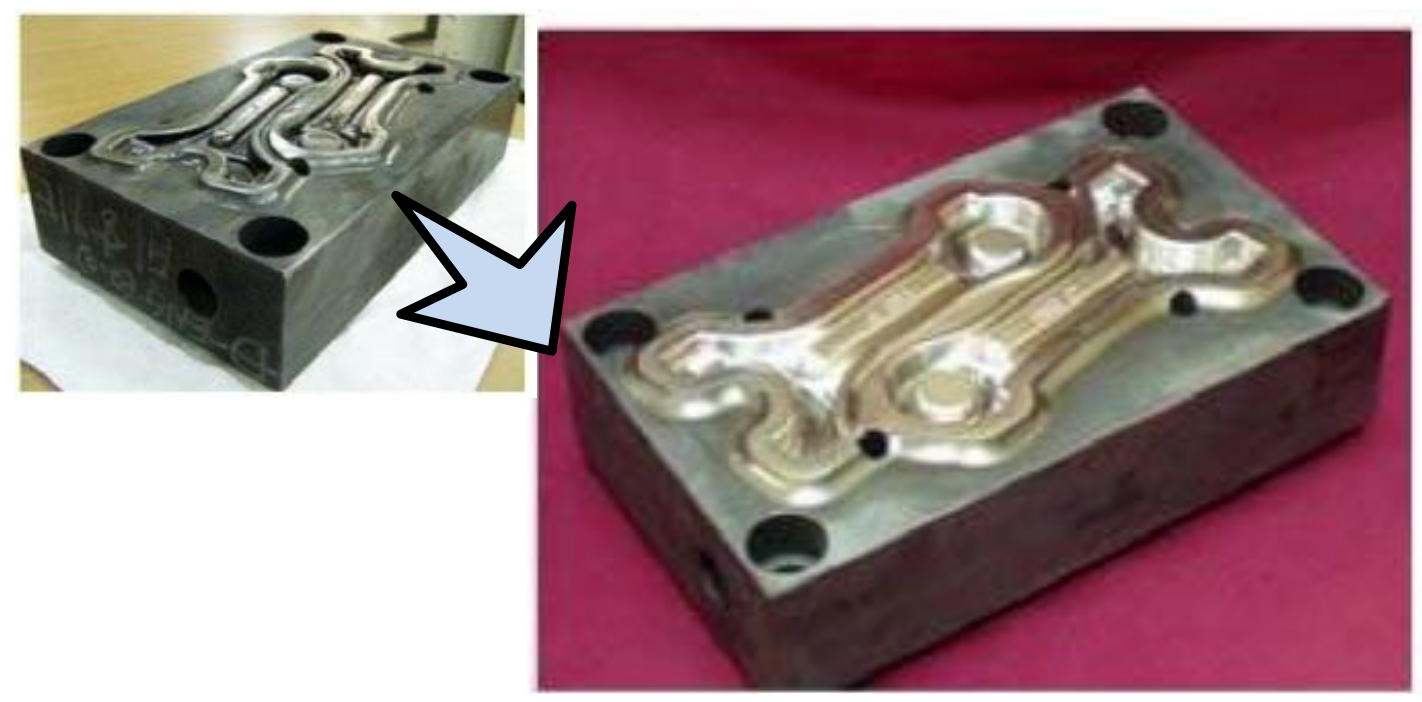

Fig. 41. Restoration of hot forging tools using laser assisted material deposition [3] 


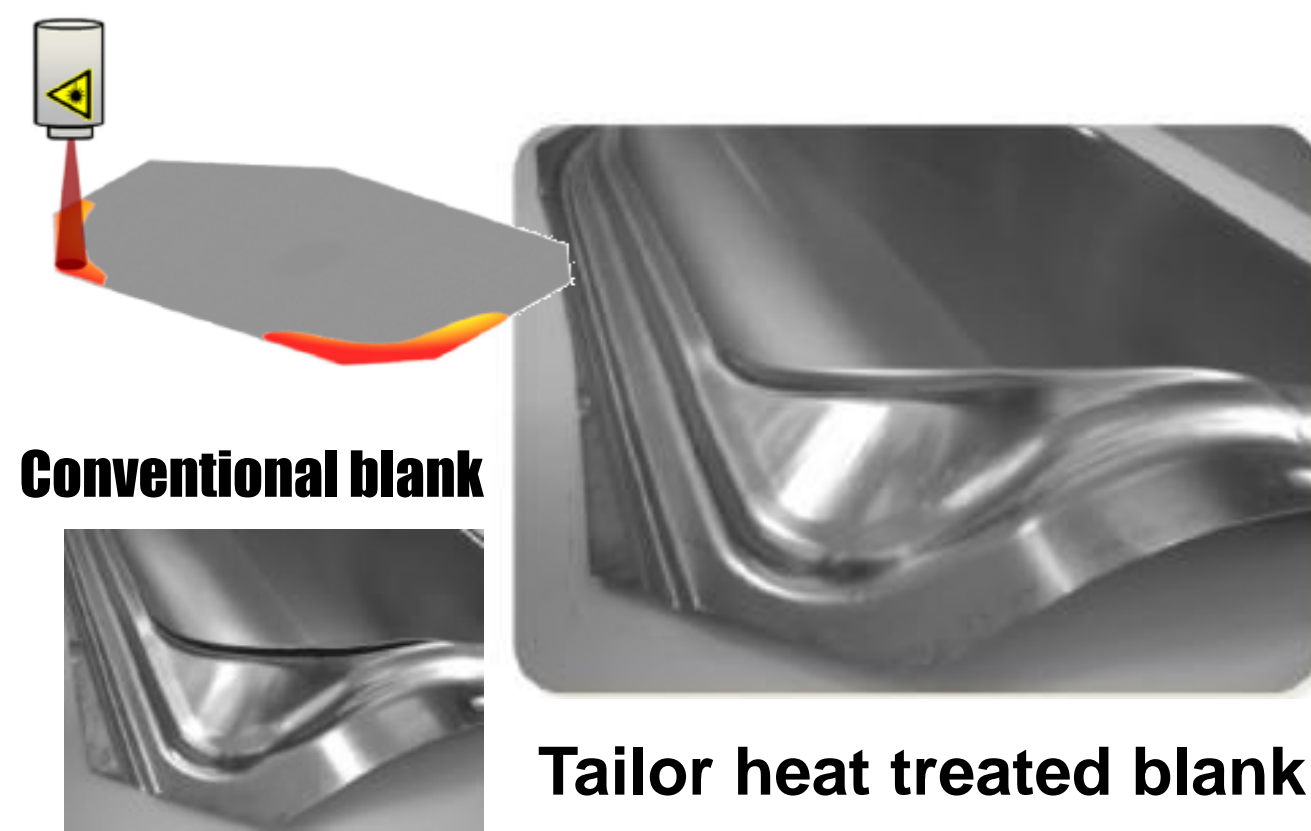

Fig. 42. Tailored heat treated blank (THTB) [132] 


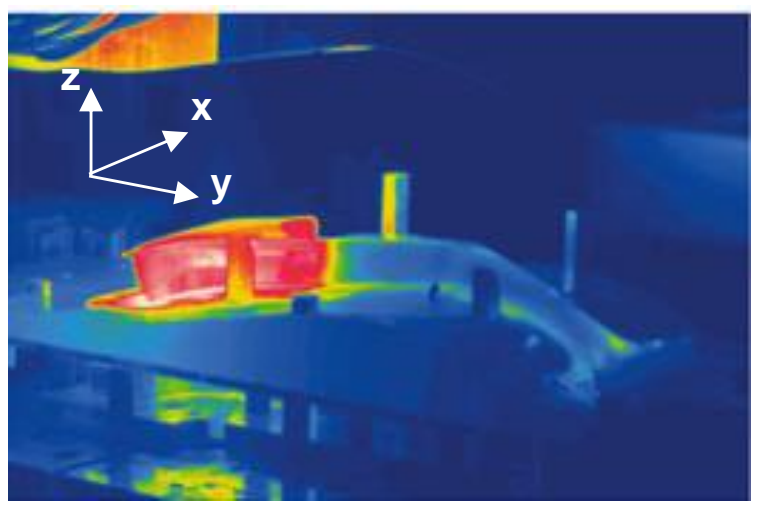

Temperature $\left[{ }^{\circ} \mathrm{C}\right]$

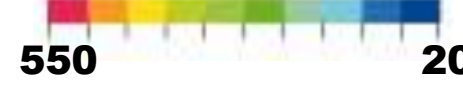

Low temp.

(High Strength)

\section{y}

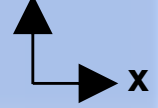

High temp.

(Shock Absorbing)

Fig. 43. Tailored tempering [76] 


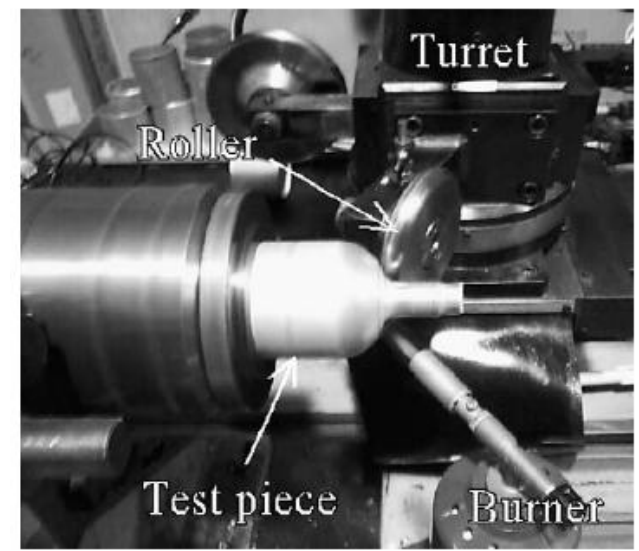

(a)

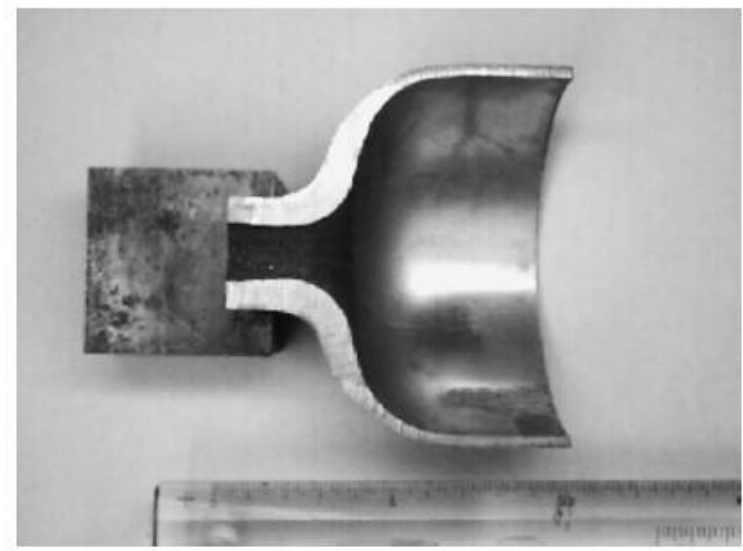

(b)

Fig. 44. Spinning process using gas burners (a) Photograph of experimental equipment in spinning (b) Geometry of the cross-section in formed magnesium alloy pipe 


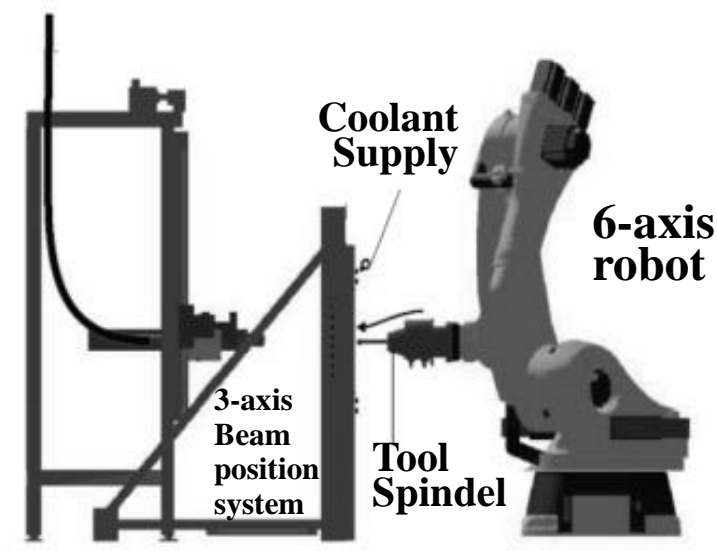

(a)

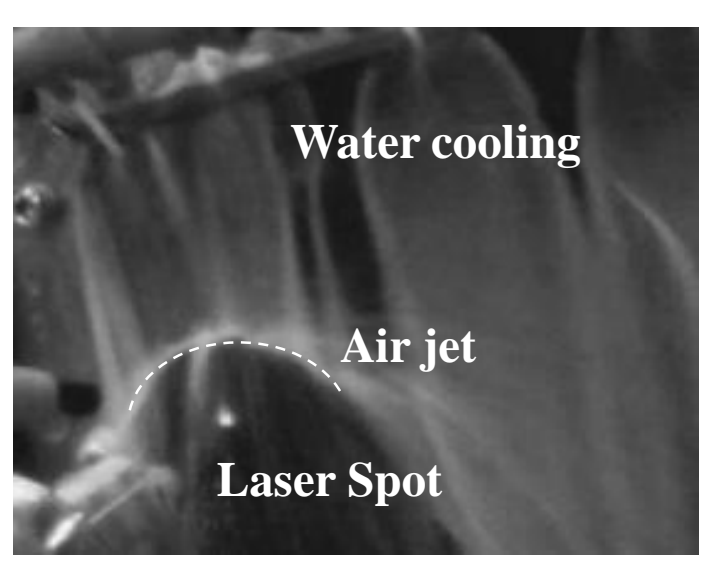

(b)

Fig. 45. Sheet incremental forming process using dynamic local heating (a) Experimental setup (b) Clamped workpiece and tool stylus with cooling flow locally re-moved by means of an air jet, and visible, dynamically moving heated spot [34] 


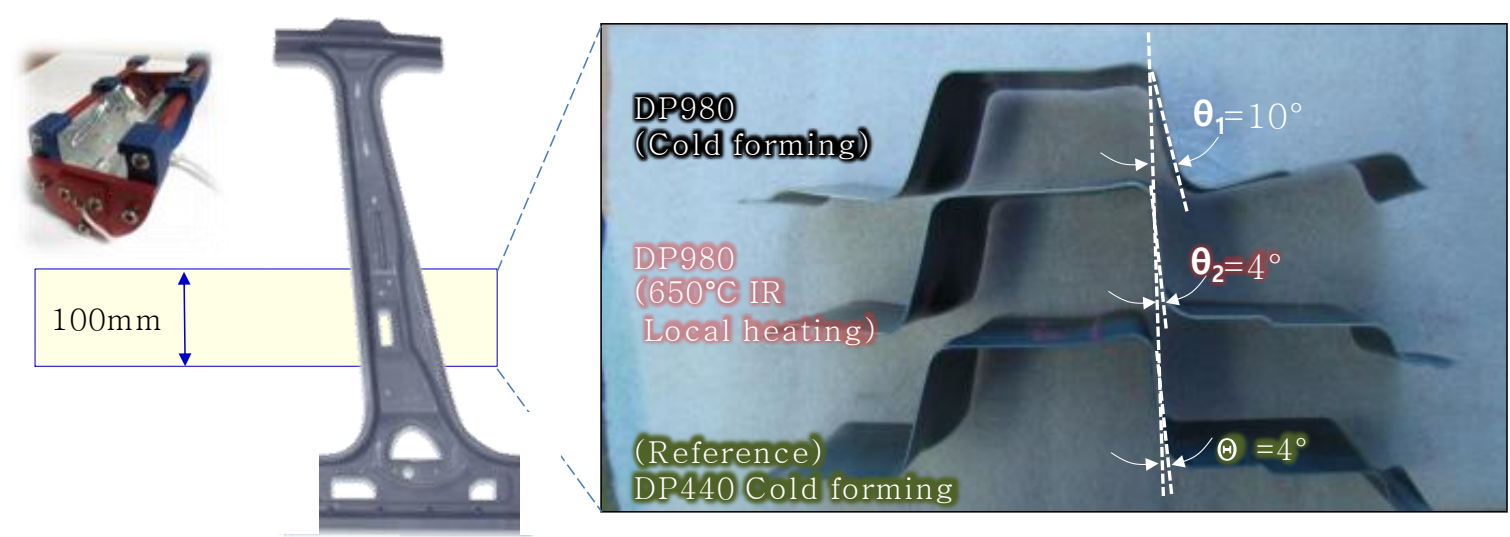

Fig. 46. B-pillar forming test using near infrared sources [107] 


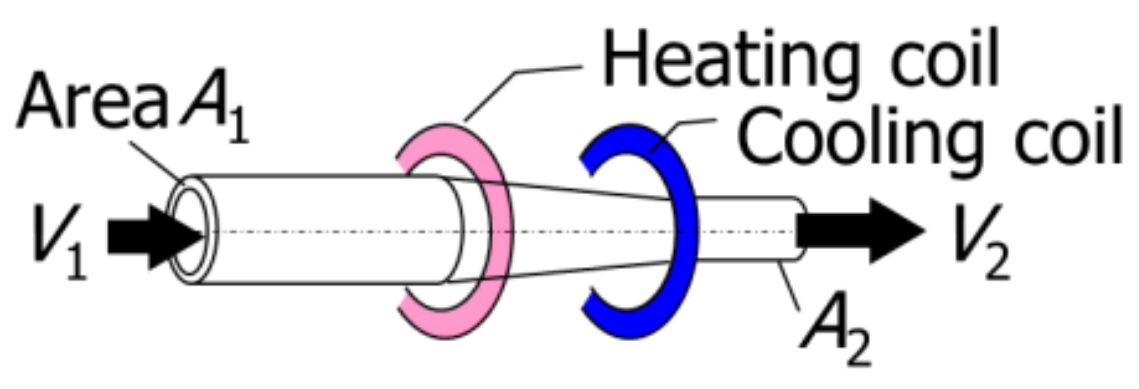

$V_{1}>V_{2}->$ axial compression

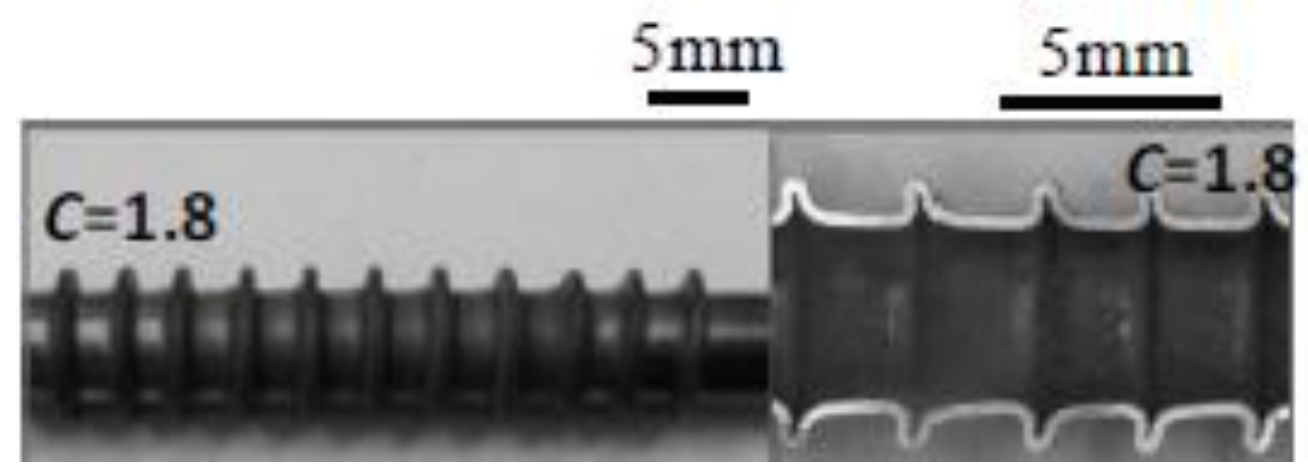

Fig. 47. Bellows forming and diametral expansion by local heating [216] 


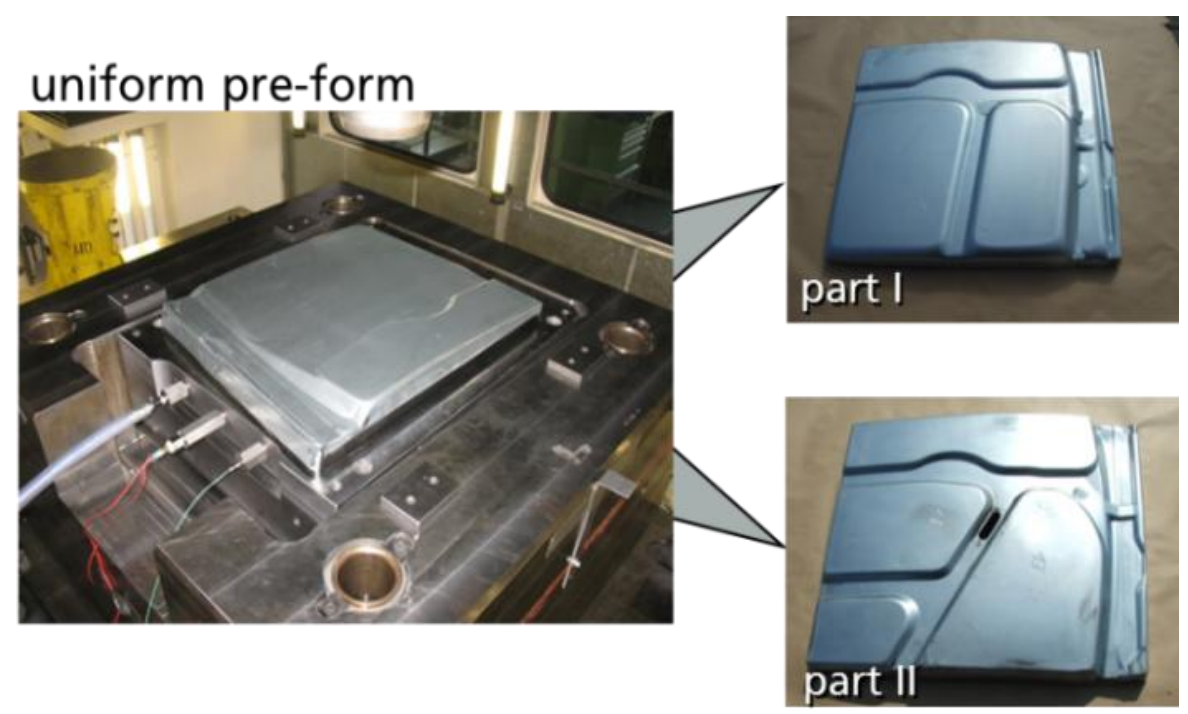

Fig. 48. Process combination of deep drawing and explosive forming 

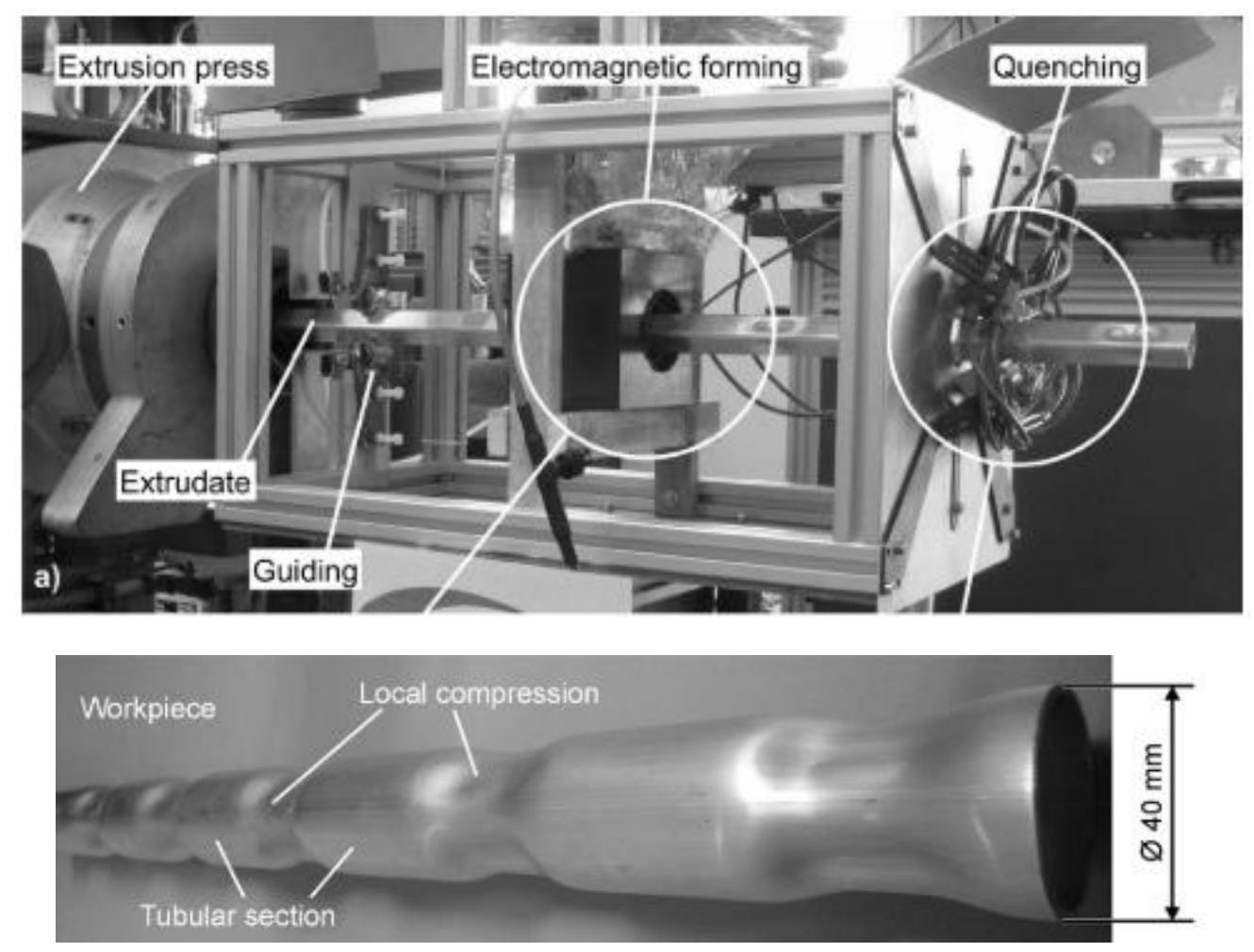

Fig. 49. Integrated electromagnetic forming and extrusion process [72] 


\section{Concept}
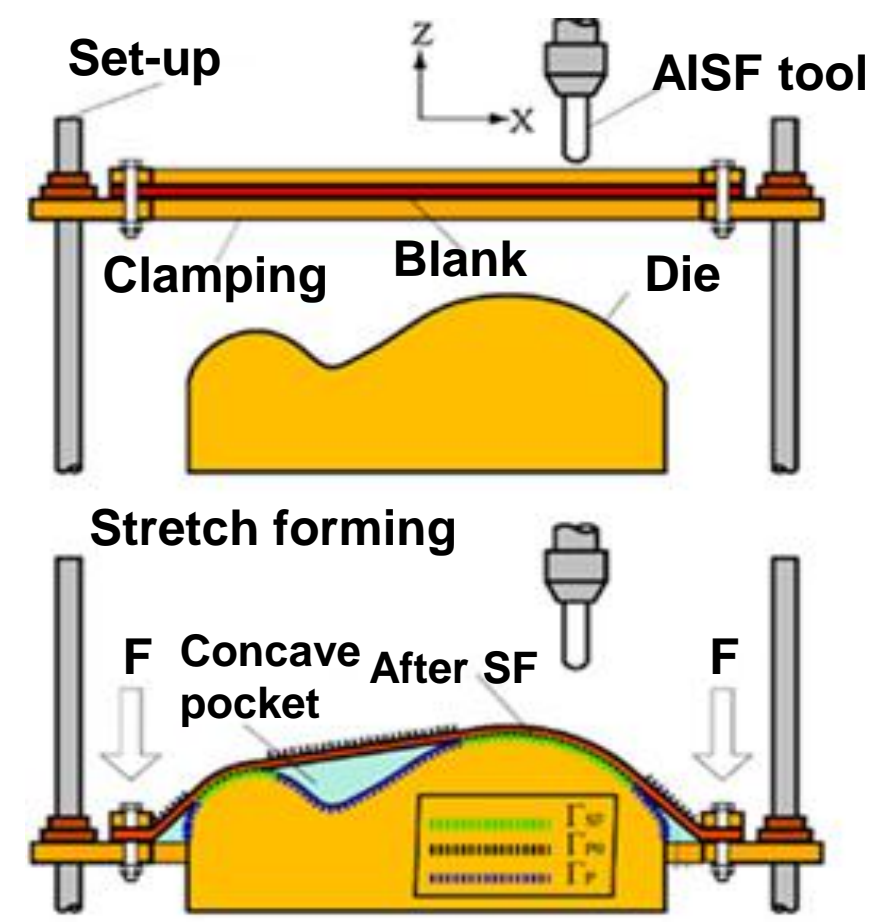

\section{AISF forming}

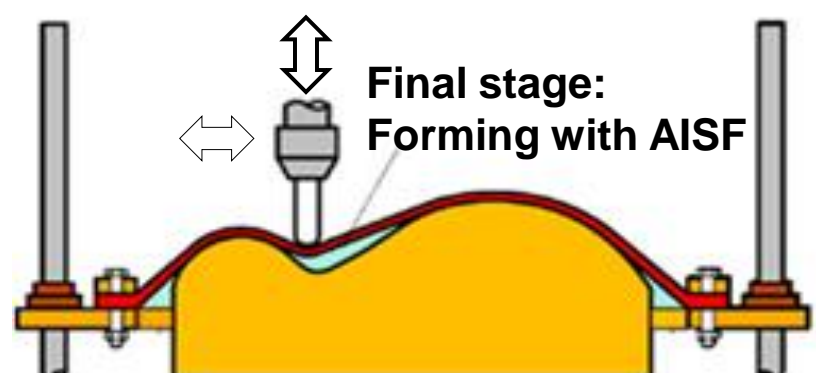

Fig. 50. Procedure of the process combination of stretch forming and incremental sheet forming [14] 


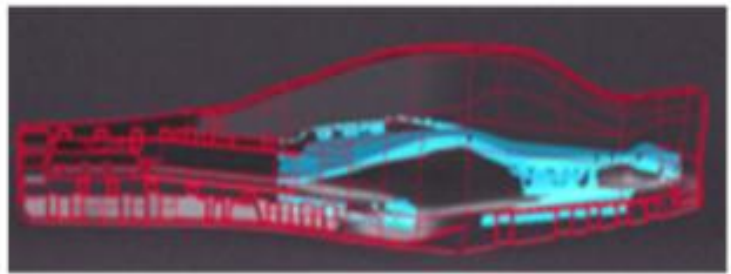

Part areas to be post-formed

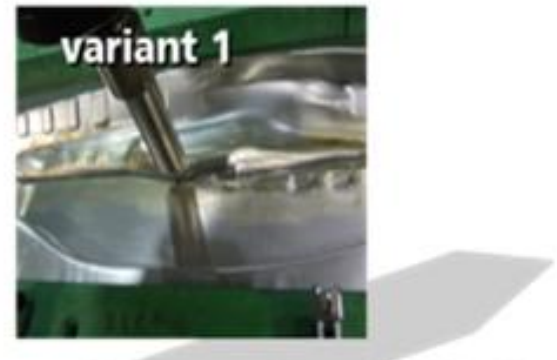

Incremental post-forming

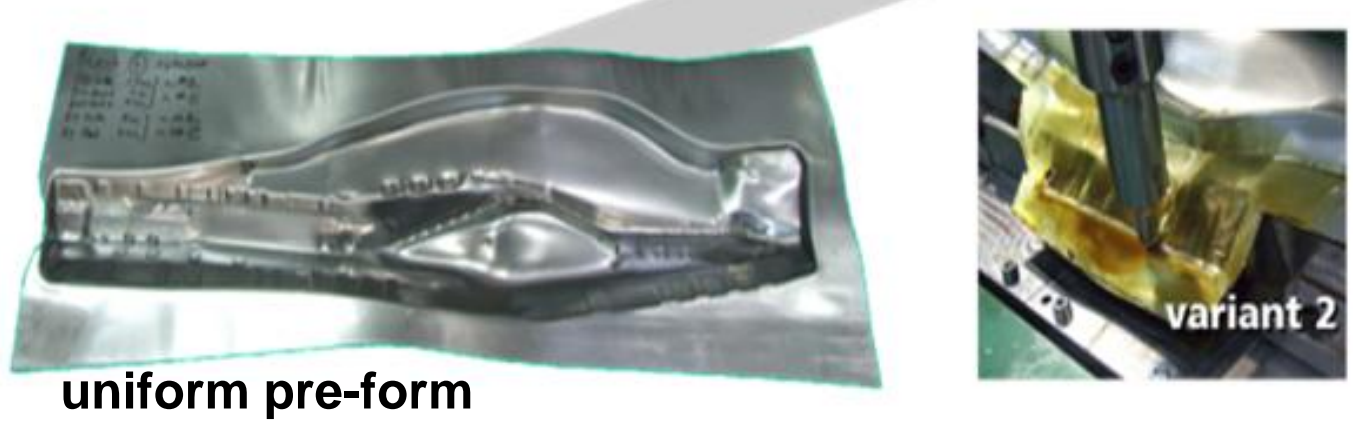

Fig. 51. Process combination "deep drawing - incremental sheet metal forming" [151, 152, 204] 


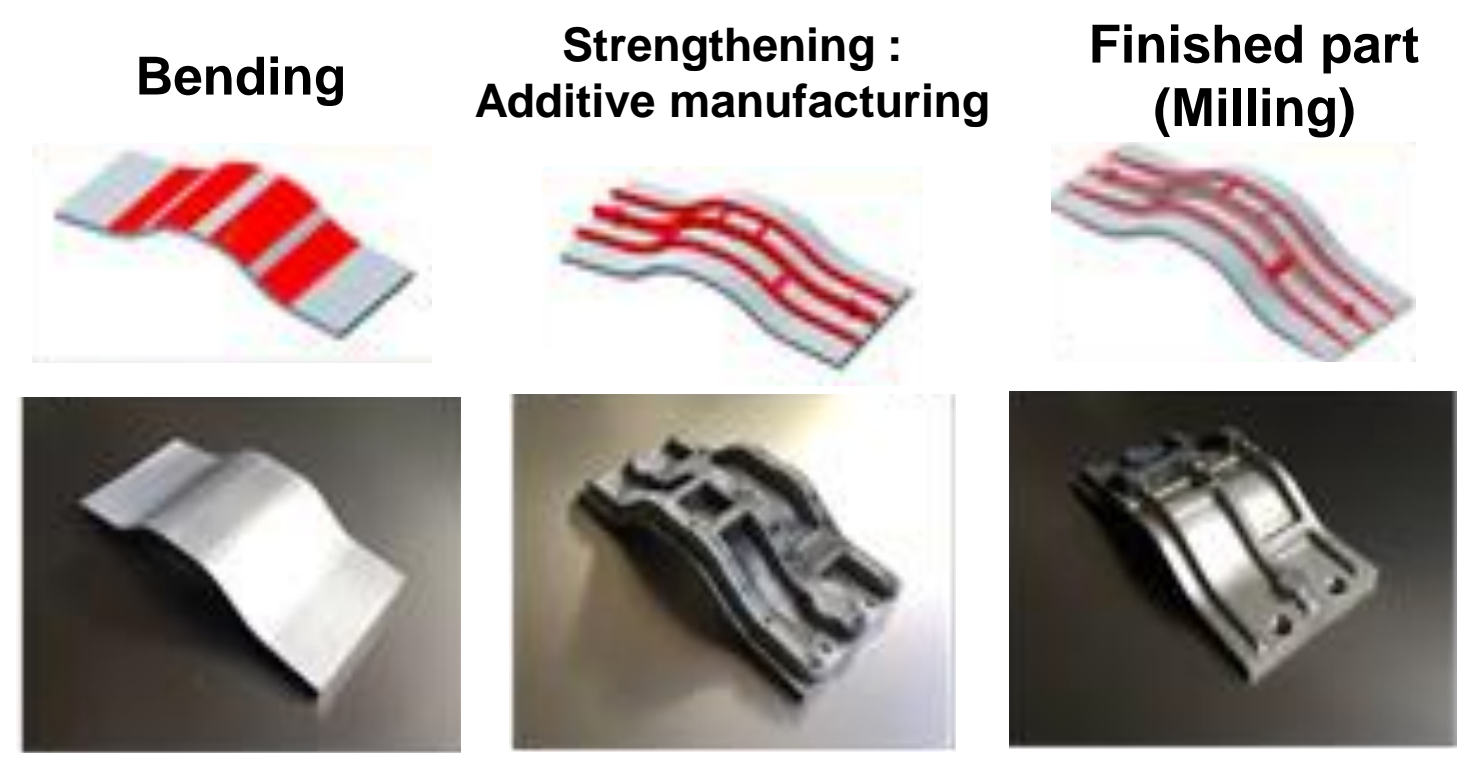

Fig. 52. Pre-form manufacturing and laser powder decomposition [18] 


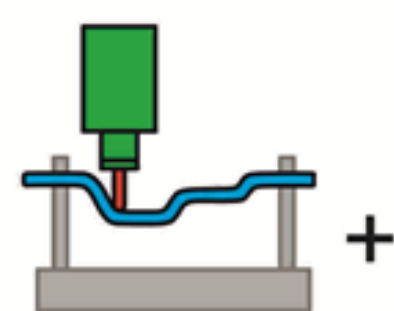

Incremental sheet metal forming

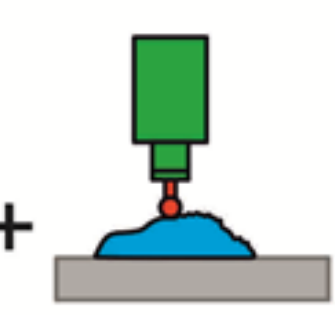

Roller burnishing/ deep rolling

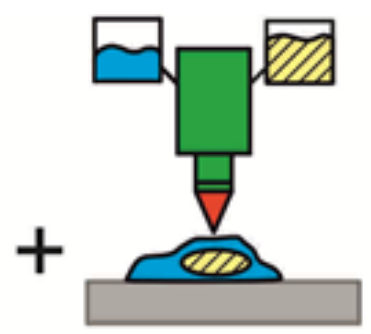

Laser powder deposition (also 2 metals)

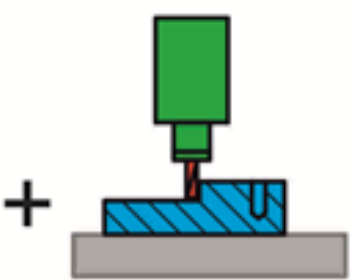

Drilling/milling

Fig. 53. Four manufacturing methods integrated in one machine [60] 


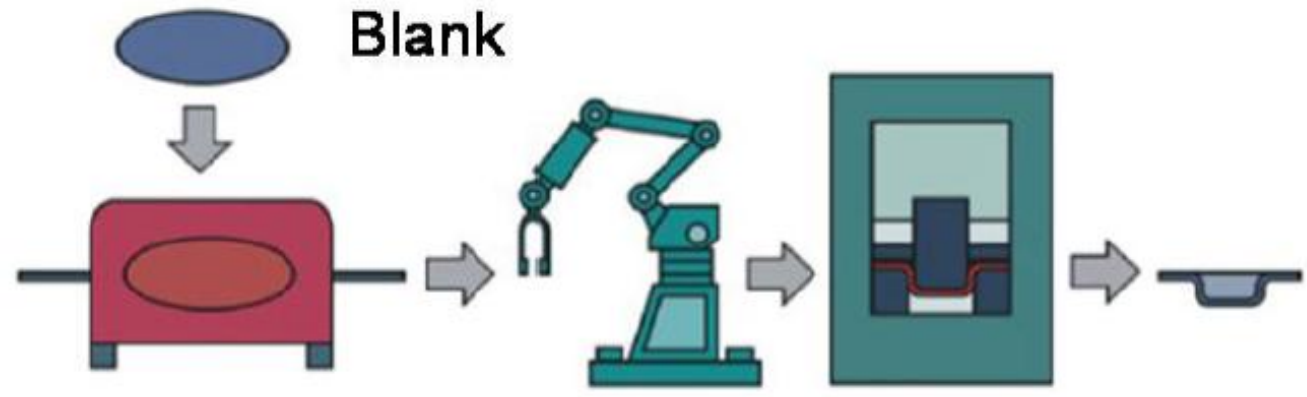

Austenitization

Forming and Part quenching
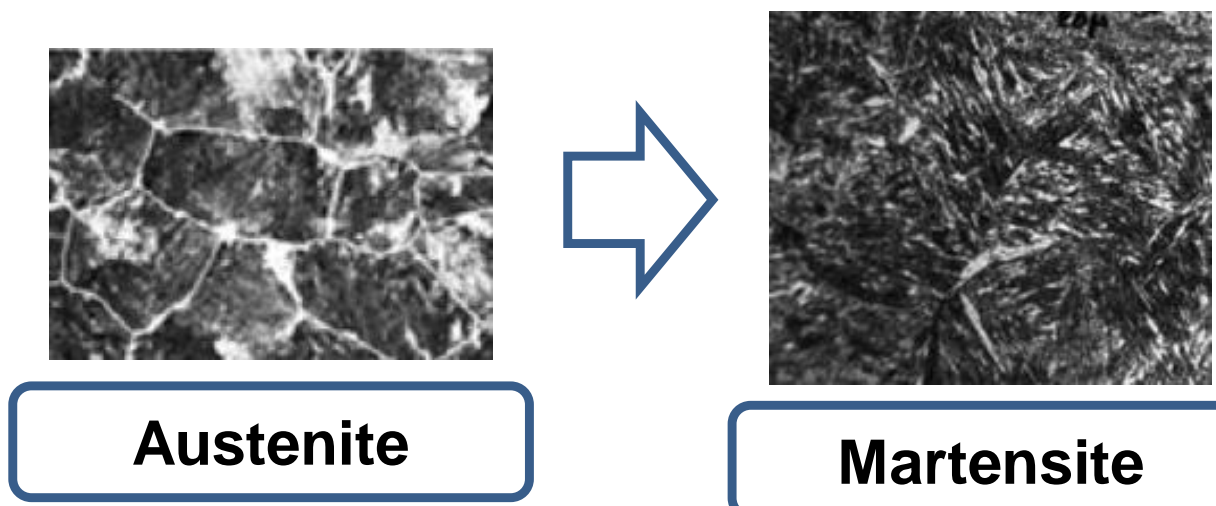

Martensite

UTS $=1,500 \mathrm{MPa}$

Fig. 54. Schematic figure of the hot stamping process $[76,143]$ 


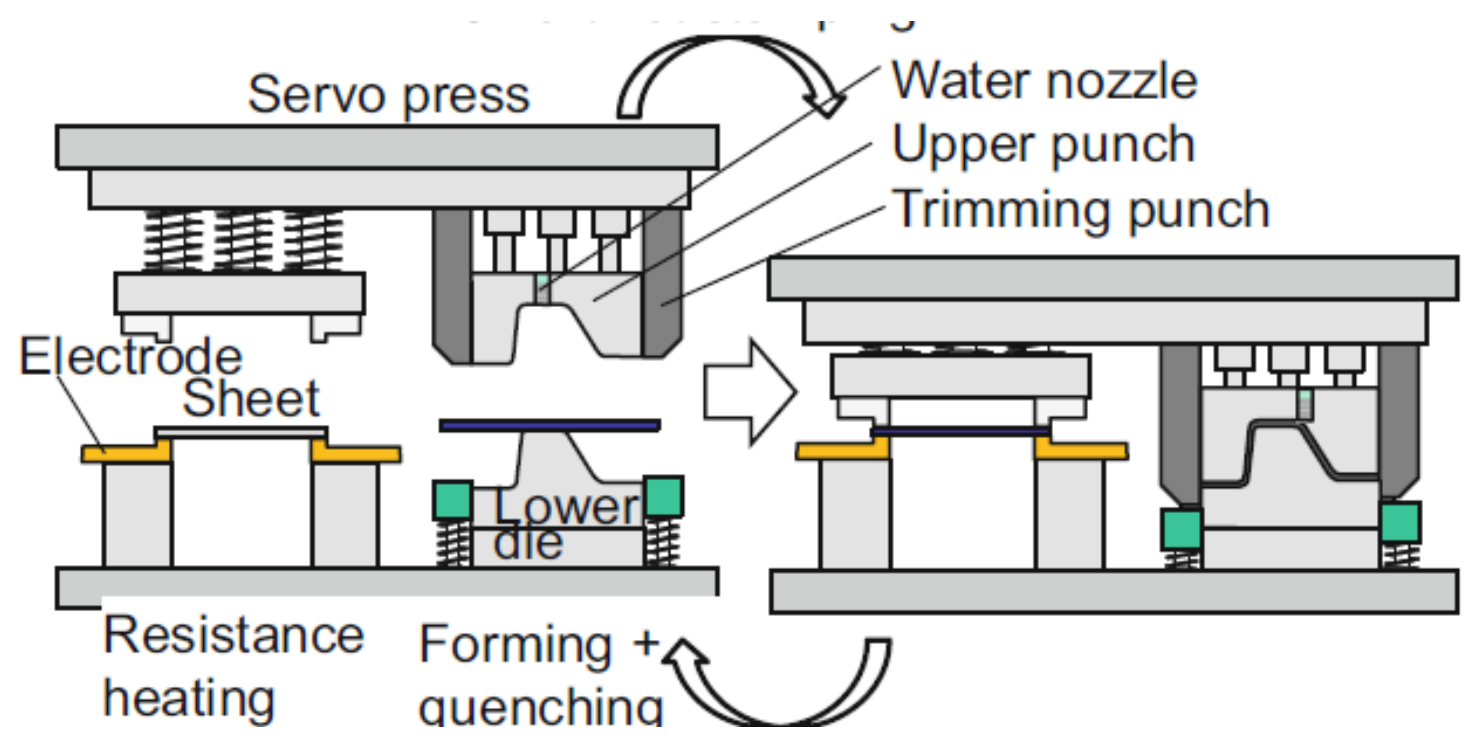

Fig. 55. Smart hot stamping having resistance heating, quenching, servo press and hot trimming [140] 


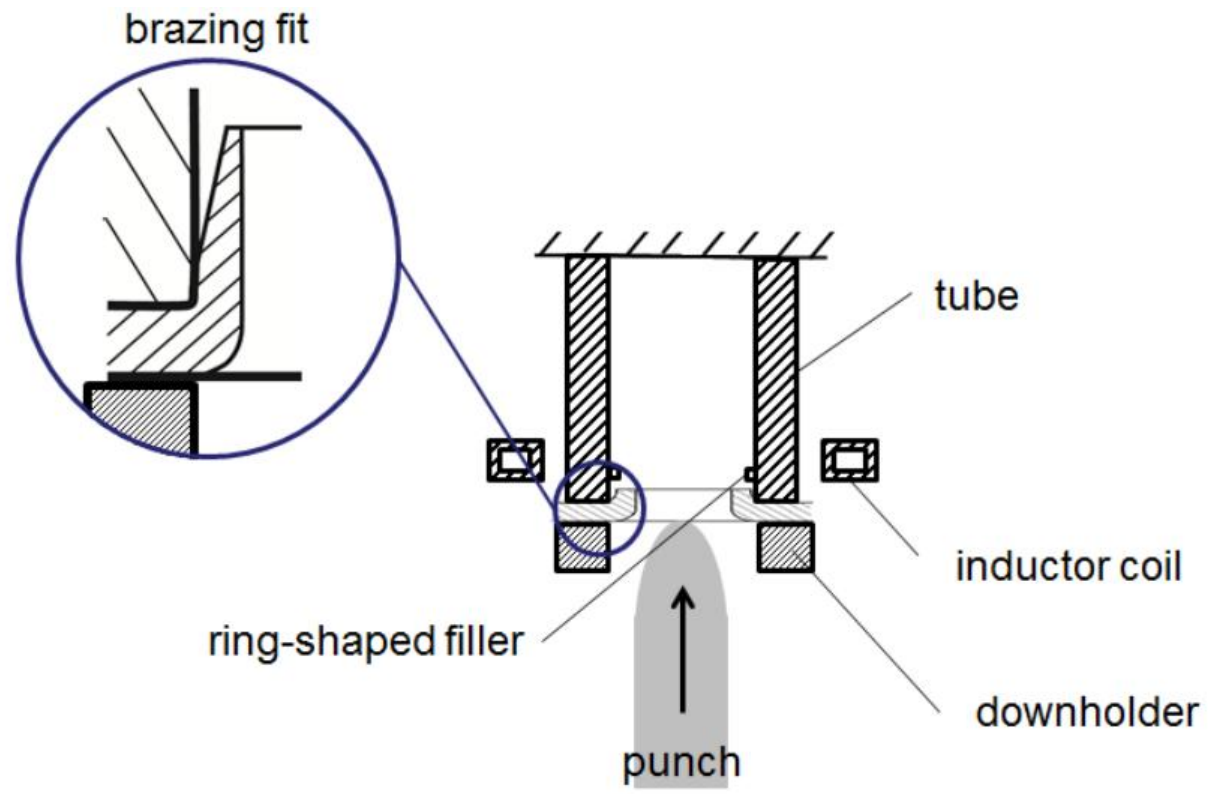

Fig. 56. Design of a combined forming and brazing process [15] 


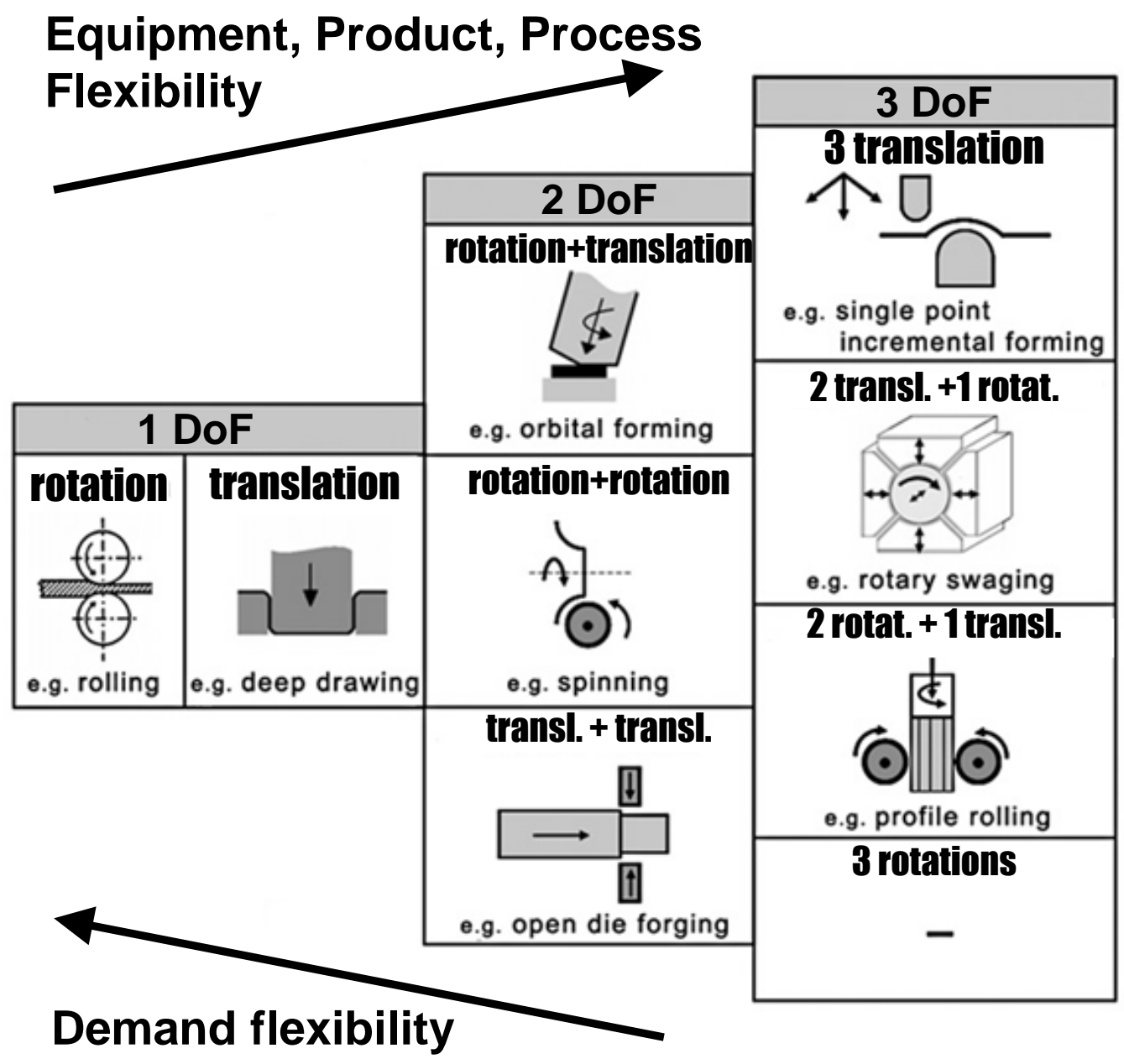

Fig. 57. Classification of forming processes [54] 


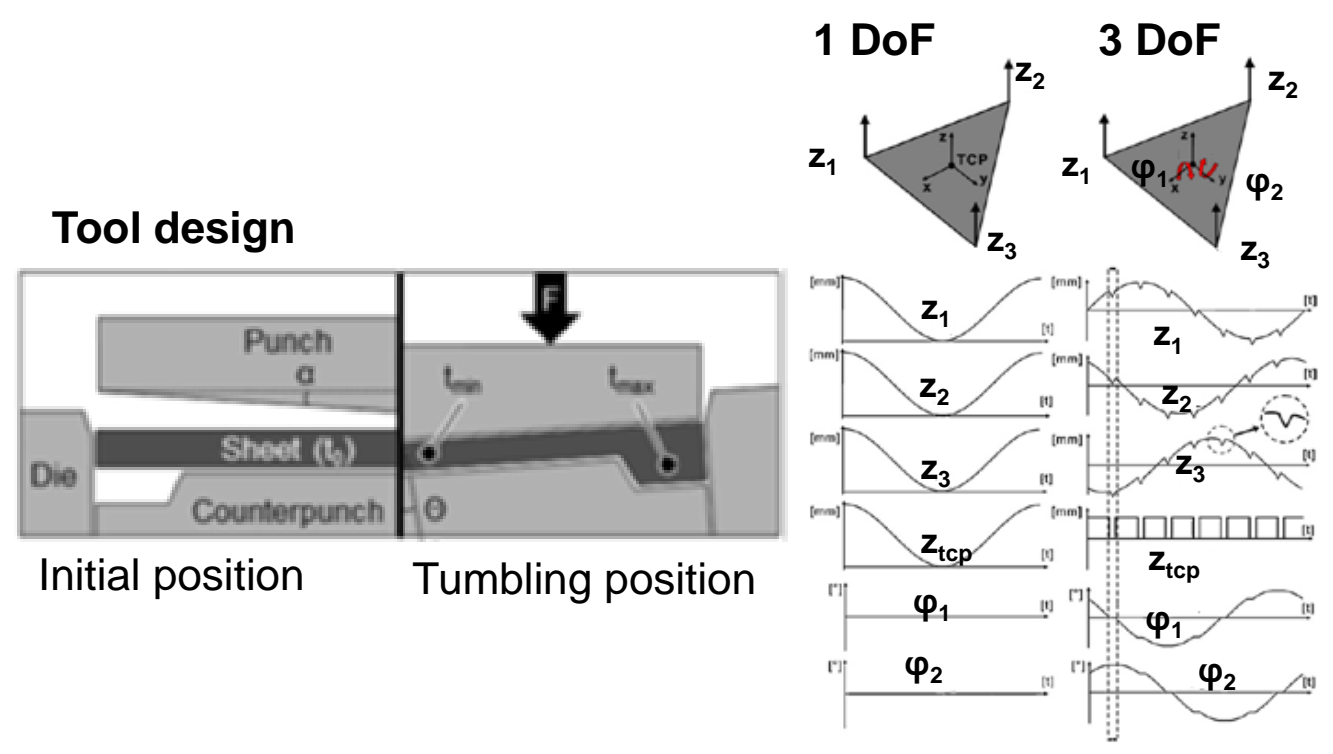

Fig. 58. Increased number of DoF by additional drives: left: additional device [50], right: split drive system [54] 


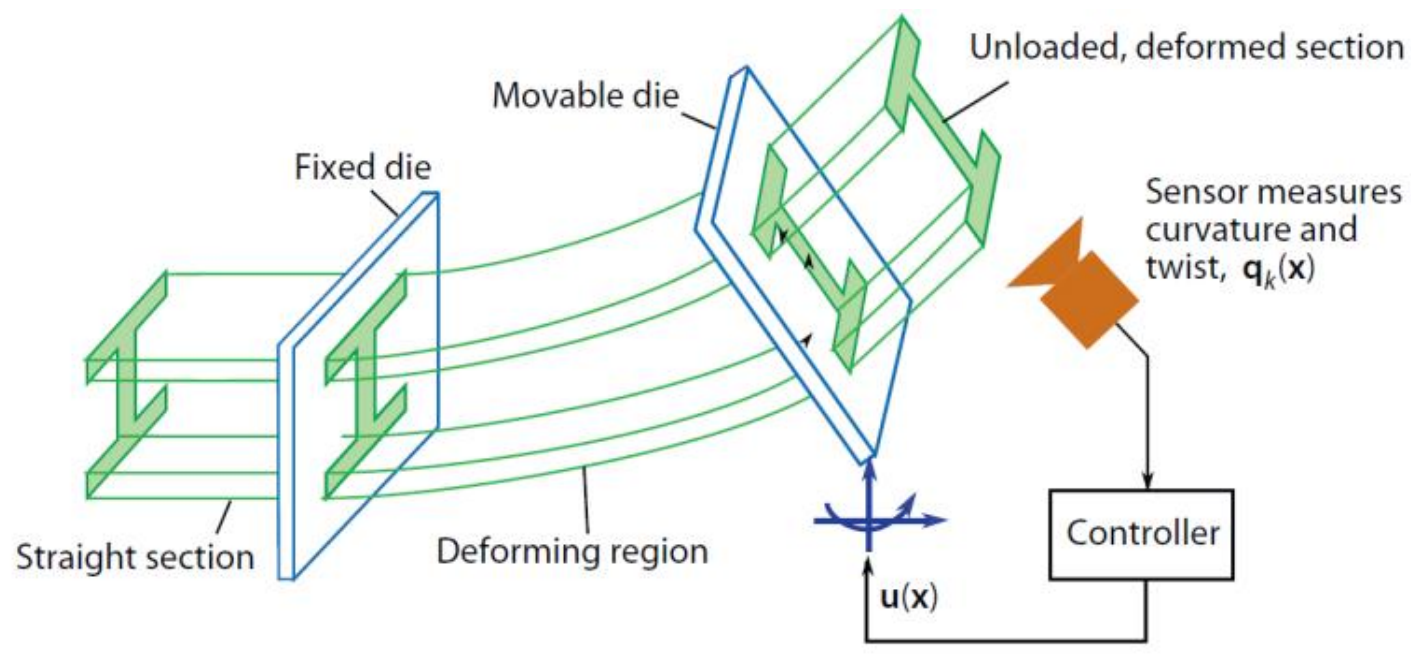

Fig. 59. Multi-axis bending and twisting [192] 


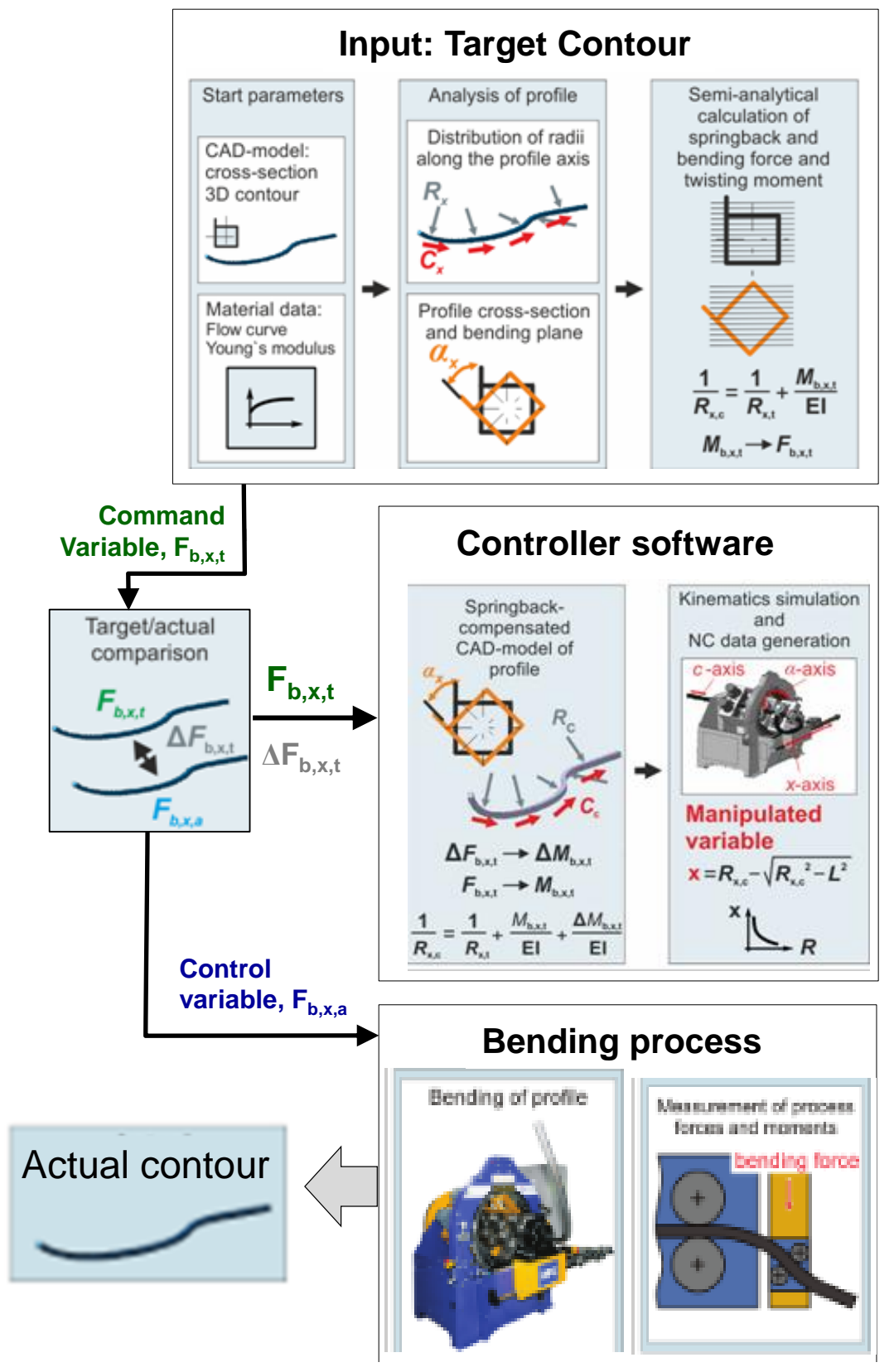

Fig. 60. Closed loop control of 3D profile bending [189] 


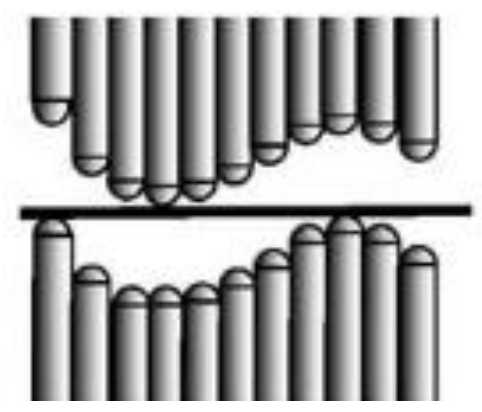

Initial state

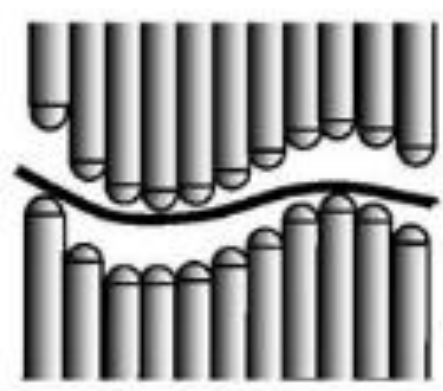

Intermediate state

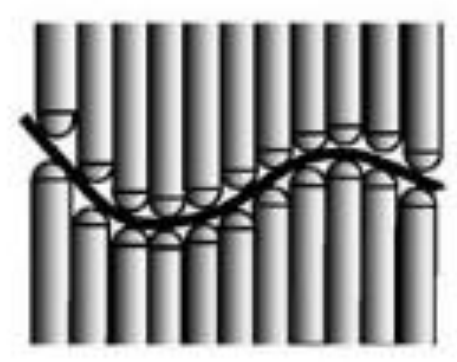

Final state

Fig. 61. Flexible forming with digitized die [112] 


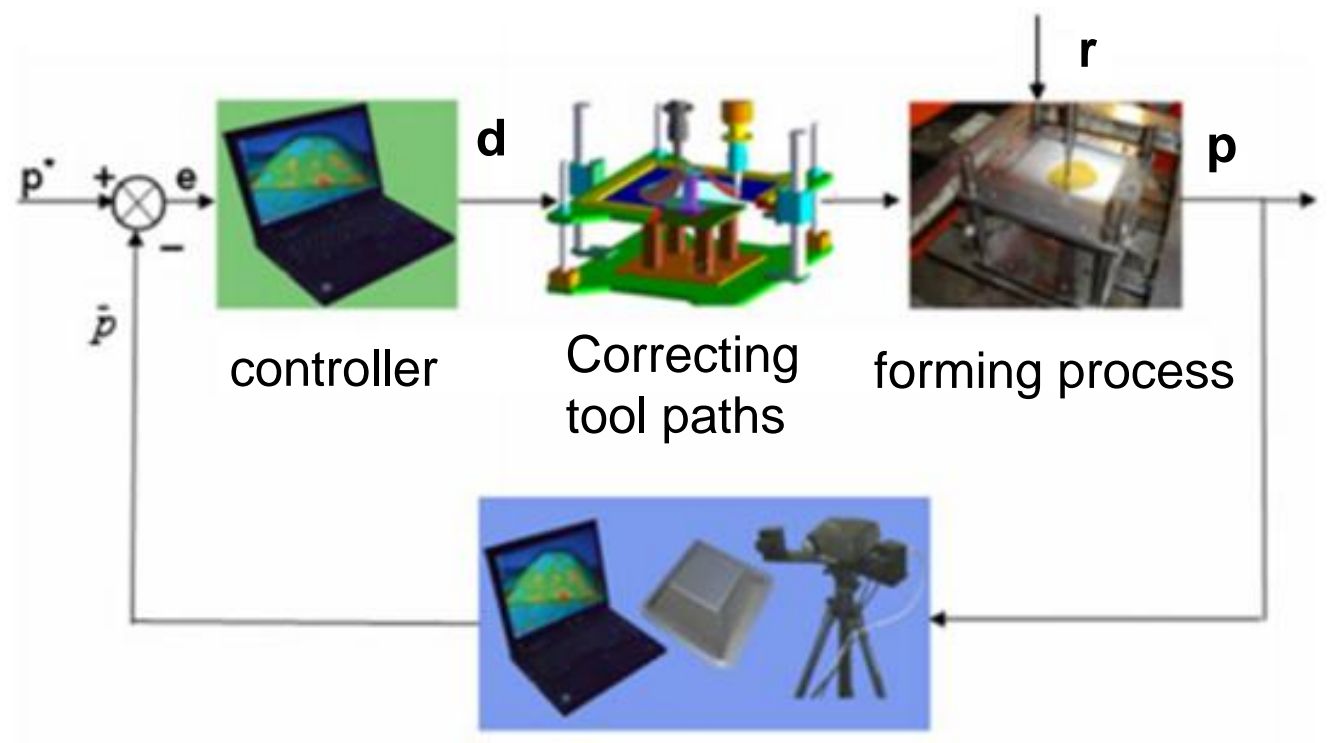

Measuring springback

Fig. 62. Tool path design of incremental forming [43] 


\begin{tabular}{|c|c|c|c|c|}
\hline & $\begin{array}{l}\text { Lot size } \\
\text { (Product- } \\
\text { ivity) }\end{array}$ & Complexity & $\begin{array}{c}\text { DOF } \\
\text { (Tool, M/C, } \\
\text { Motion) }\end{array}$ & $\begin{array}{l}\text { Physical } \\
\text { parameter }\end{array}$ \\
\hline $\begin{array}{c}\text { DOF increase } \\
\text {-Incr. Sheet Forming } \\
\text {-Incr. Bulk Forming }\end{array}$ & $\begin{array}{c}\mathrm{L}, \mathrm{M} \\
\mathbf{L}\end{array}$ & $\begin{array}{l}\text { M, H } \\
\text { L, M }\end{array}$ & $\begin{array}{c}\mathbf{M}, \mathbf{H} \\
\mathbf{M}\end{array}$ & - \\
\hline $\begin{array}{l}\text { Physical variation } \\
\text {-Geometric variation } \\
\text {-Material disposition } \\
\text {-Local(Incr.) heating }\end{array}$ & $\begin{array}{c}\mathbf{H} \\
\mathbf{L} \\
\mathrm{L}, \mathrm{M}, \mathrm{H}\end{array}$ & $\stackrel{\mathrm{L}}{\mathrm{H}}$ & $\begin{array}{l}\mathrm{L} \\
\mathrm{H} \\
\mathrm{L}\end{array}$ & $\begin{array}{l}\sqrt{ } \\
\sqrt{ } \\
\sqrt{ }\end{array}$ \\
\hline $\begin{array}{l}\text { Process combination } \\
\text {-Convent. + Convent. } \\
\text {-Flexible + Convent. } \\
\text {-Forming + Non-form. }\end{array}$ & $\underset{\mathrm{H}}{\mathrm{H}}$ & $\begin{array}{l}M, H \\
M, H \\
M, H\end{array}$ & $\underset{L}{L}, \mathbf{M}$ & $\begin{array}{l}- \\
-\end{array}$ \\
\hline $\begin{array}{c}\text { Flexibilzation of } \\
\text { M/C, System, Software } \\
\text { operation }\end{array}$ & $\mathbf{H}$ & $\mathbf{M}, \mathbf{H}$ & $\mathbf{H}$ & - \\
\hline
\end{tabular}

Table 1. Means of flexibility level increase in relation to four major influencing factors ( $\mathrm{H}=$ High, $\mathrm{M}=$ Medium, $\mathrm{L}=$ Low) 
